\author{
UNIVERSIDADE DE SÃO PAULO \\ INSTITUTO DE ENERGIA E AMBIENTE \\ PROGRAMA DE PÓS-GRADUAÇÃO EM ENERGIA - PPGE
}

NATHÁLIA WEBER NEIVA MASULINO

\begin{abstract}
ARMAZENAMENTO GEOLÓGICO DE CARBONO EM RESERVATÓRIOS NÃO CONVENCIONAIS NA FORMAÇÃO

IRATI DA BACIA DO PARANÁ: ESTIMATIVAS DE CAPACIDADE DE INJEÇÃO DE $\mathrm{CO}_{2}$ E CUSTOS ASSOCIADOS
\end{abstract}




\title{
ARMAZENAMENTO GEOLÓGICO DE CARBONO EM RESERVATÓRIOS NÃO CONVENCIONAIS NA FORMAÇÃO IRATI DA BACIA DO PARANÁ: ESTIMATIVAS DE CAPACIDADE DE INJEÇÃO DE CO 2 E CUSTOS ASSOCIADOS
}

\author{
Dissertação apresentada ao Programa de Pós-Graduação em \\ Energia do Instituto de Energia e Ambiente da \\ Universidade de São Paulo, para obtenção do título de \\ Mestre em Ciências. \\ Orientador: Prof. Dr. Colombo Celso Gaeta Tassinari \\ Coorientador: Prof. Dr. Marcio Augusto Sampaio Pinto
}

\section{Versão Corrigida}

(Versão original disponível na Biblioteca do Instituto de Energia e Ambiente e na Biblioteca Digital de Teses e Dissertações da USP)

\section{SÃO PAULO}


AUTORIZO A REPRODUÇÃO E DIVULGAÇÃO TOTAL OU PARCIAL DESTE

TRABALHO, POR QUALQUER MEIO CONVENCIONAL OU ELETRÔNICO, PARA FINS DE ESTUDO E PESQUISA, DESDE QUE CITADA A FONTE.

FICHA CATALOGRÁFICA

Masulino, Nathália Weber Neiva.

Armazenamento geológico de carbono em reservatórios não convencionais na Formação Irati da Bacia do Paraná: estimativas de capacidade de injeção de $\mathrm{CO}_{2}$ e custos associados. / Nathália Weber Neiva Masulino; orientador: Colombo Celso Gaeta Tassinari; coorientador: Marcio Augusto Sampaio Pinto - São Paulo, 2020.

105 f.: il.: $30 \mathrm{~cm}$.

Dissertação (Mestrado em Ciências) - Programa de Pós-Graduação em Energia - Instituto de Energia e Ambiente da Universidade de São Paulo.

1. Armazenamento geológico de carbono. 2. Reservatórios não convencionais. 3. Simulação numérica de reservatórios. I. Título. 
Nome: MASULINO, Nathália Weber Neiva

Título: Armazenamento geológico de carbono em reservatórios não convencionais na Formação Irati da Bacia do Paraná: estimativas de capacidade de injeção de $\mathrm{CO}_{2}$ e custos associados.

Dissertação apresentada ao Programa de PósGraduação em Energia, Instituto de Energia e Ambiente da Universidade de São Paulo para obtenção do título de Mestre em Ciências.

Data da aprovação: 30/04/2020

Banca examinadora

Prof. Dr. Colombo Celso Gaeta Tassinari Instituição: Instituto de Energia e Presidente Ambiente (IEE), Universidade de São Paulo (USP)

Prof. Dr. Fabio Taioli Instituição: Instituto de Energia e Julgamento: Aprovado Ambiente (IEE), Universidade de São Paulo (USP)

Prof. Dr. Rafael dos Santos Gioria Julgamento: Aprovado

Instituição: Escola Politécnica (EP), Universidade de São Paulo (USP)

Prof. Dr. Estanislau Luczynski Julgamento: Aprovado

Instituição: Instituto de Geociências (IG), Universidade Federal do Pará (UFPA) 
À Renata e ao Vinícius, por tudo. 


\section{AGRADECIMENTOS}

Ao meu orientador, Prof. Dr. Colombo Celso Gaeta Tassinari, e ao meu coorientador, Prof. Dr. Marcio Augusto Sampaio Pinto, pelos ensinamentos e atenção durante todas as fases desse trabalho.

Aos professores e funcionários do Instituto de Energia e Ambiente (IEE), em especial, ao Prof. Dr. Edmilson Moutinho dos Santos, Prof ${ }^{a}$. Dr ${ }^{\mathrm{a}}$. Hirdan Katarina de Medeiros, Prof ${ }^{\mathrm{a}}$. Dr $^{\mathrm{a}}$. Drielli Peyerl e Prof ${ }^{\mathrm{a}}$. Dr ${ }^{\mathrm{a}}$. Dominique Mouette, pelas oportunidades e amizade.

À equipe do Laboratório de Simulação e Gerenciamento de Reservatórios de Petróleo (LASG) da Escola Politécnica (EP), por abrir as portas para a minha pesquisa.

À equipe do Research Centre for Gas Innovation (RCGI), que, além de financiar parte da pesquisa, abraçou e incentivou novas ideias. Registro agradecimentos especiais a Karen Mascarenhas, Oscar Serrate, Prof. Dr. Julio Romano Meneghini, Prof. Dr. Gustavo Assi, Gabriel Penna (in memoriam) e a todos os funcionários.

À Coordenação de Aperfeiçoamento de Pessoal de Nível Superior (CAPES), pelo financiamento.

Aos amigos, professores e funcionários do IFP School, pela experiência excepcional do intercâmbio.

Aos demais amigos queridos que me acompanharam nesse período do Mestrado: Stephanie, Haline, Dorival, Vitor, Richardson, Bruna e Ébio.

À minha família, por todo o apoio: Catharina, Ady, Julio, Fernanda, Murilo, Alice, Edson, Victória, Maria, Tales, Clara e Vitoria.

Por fim, agradecimentos mais que especiais à minha mãe Renata, por todo o comprometimento com a minha formação e amor incondicional, e ao Vinícius, por todo o carinho e cuidado comigo, por ser minha inspiração. 


\section{RESUMO}

Masulino, Nathália Weber Neiva. Armazenamento geológico de carbono em reservatórios não convencionais na Formação Irati da Bacia do Paraná: estimativas de capacidade de injeção de $\mathrm{CO}_{2}$ e custos associados. 2020. 105 p. Dissertação (Mestrado em Ciências) - Instituto de Energia e Ambiente, Universidade de São Paulo, São Paulo, 2020.

Diante da necessidade de redução das emissões de gases de efeito estufa, os processos de Captura e Armazenamento de Carbono (CCS) são apontados como ferramenta promissora para o cumprimento das metas de temperatura. Dentre as diversas opções de contextos geológicos para armazenamento de $\mathrm{CO}_{2}$, os reservatórios de gás de folhelho constituem uma nova fronteira de estudos, incentivados pela ampla distribuição de reservas no mundo e pelo crescimento significativo da produção de gás natural não convencional nos últimos anos. No Brasil, os folhelhos negros da Formação Irati da Bacia do Paraná, além de estarem localizados próximos às regiões com maior concentração de fontes estacionárias emissoras, apresentam grande potencial de geração de gás natural. Dessa forma, o presente trabalho propôs o levantamento de estimativas de potencial de armazenamento de $\mathrm{CO}_{2}$ na Formação Irati, por meio de simulações numéricas de reservatório. Os resultados demonstraram uma capacidade próxima de 800 mil toneladas de $\mathrm{CO}_{2}$ por poço, abrangendo um reservatório com área de $1.200 \mathrm{~m}$ por $600 \mathrm{~m}$ e com espessura de $40 \mathrm{~m}$. A análise de sensibilidade em função da maximização da injeção de $\mathrm{CO}_{2}$ apontou para maior influência da pressão, espessura e saturação de gás do reservatório para essa avaliação. Também foram calculados os custos associados ao projeto de poço injetor para períodos de até 50 anos de injeção de $\mathrm{CO}_{2}$, cujos resultados trouxeram valores totais próximos a 60 milhões de dólares, com viabilidade econômica possível para preços da tonelada de $\mathrm{CO}_{2}$ acima de 72 dólares.

Palavras-chave: Armazenamento Geológico de Carbono; Reservatórios Não Convencionais; Simulação Numérica de Reservatórios. 


\begin{abstract}
Masulino, Nathália Weber Neiva. Geological carbon storage in unconventional reservoirs in the Irati Formation, Paraná Basin: estimates of $\mathrm{CO}_{2}$ injection capacity and associated costs. 2020. 105 p. Dissertation (Master's in Science) - Institute of Energy and Environment, University of São Paulo, São Paulo, 2020.
\end{abstract}

Given the need to reduce greenhouse gas emissions, Carbon Capture and Storage (CCS) processes are seen as a promising tool for meeting temperature targets. Among the various options of geological contexts for $\mathrm{CO}_{2}$ storage, shale gas reservoirs constitute a new frontier of studies, encouraged by the wide distribution of reserves in the world and by the significant growth in the production of unconventional natural gas in recent years. In Brazil, Irati Formation's black shales in Paraná Basin are located close to the regions with the highest concentration of stationary emitting sources and have great potential for generating natural gas. Thus, this work proposed the research of estimates of $\mathrm{CO}_{2}$ storage potential in Irati Formation, through numerical reservoir simulations. The results showed a capacity around 800 thousand tonnes of $\mathrm{CO}_{2}$ per well in a reservoir with an area of $1,200 \mathrm{~m} \times 600 \mathrm{~m}$, with a thickness of $40 \mathrm{~m}$. The sensitivity analysis related to the maximization of $\mathrm{CO}_{2}$ injection pointed out a greater influence of pressure, thickness and gas saturation of the reservoir for this evaluation. Associated costs of injection well project were also calculated for periods up to 50 years of $\mathrm{CO}_{2}$ injection, resulting in total costs around US\$ 60 million with possible economic feasibility for $\mathrm{CO}_{2}$ tonne prices above US\$ 72 .

Keywords: Geological Carbon Storage; Unconventional Reservoirs; Numerical Reservoir Simulation. 


\section{LISTA DE FIGURAS}

Figura 1. Mapa de bacias com recursos avaliados de gás e óleo de folhelho (EIA, 2013).

Figura 2. Fontes estacionárias emissoras de $\mathrm{CO}_{2}$ no Brasil, com destaque à localização da Bacia do Paraná (Rockett, 2010). 22

Figura 3. Preços de carbono em dólares por tonelada de $\mathrm{CO}_{2}$ equivalente nas iniciativas existentes no mundo, considerando a parcela de emissões de gases de efeito estufa cobertas nas jurisdições. Os tamanhos dos círculos são proporcionais ao total arrecadado pelos governos, com exceção de iniciativas cujas arrecadações governamentais ficaram abaixo de 100 milhões de dólares em 2018 (Banco Mundial, 2019).

Figura 4. Opções para armazenamento geológico de $\mathrm{CO}_{2}$ (adaptado de IPCC, 2005). . 29

Figura 5. Ilustração esquemática da geologia de recursos de gás natural. (Adaptado de EIA, 2011)

Figura 6. Triângulo de recursos de gás natural convencionais e não convencionais, com indicação das variações de volumes, permeabilidades e custos de extração e necessidade tecnológica. Recursos mais próximos da base da pirâmide requerem maiores gastos para extração e tecnologias mais avançadas (adaptado de Holditch, 2006). 32

Figura 7. Elementos chave necessários a uma produção comercial de gás de folhelho (adaptado de Kundert e Mullen, 2009). 33

Figura 8. Idealização das heterogeneidades do meio poroso (Warren e Root, 1963).... 37

Figura 9. Diagrama esquemático do transporte de gás em reservatórios de gás de folhelho em nanoescala (Zhao et al., 2018). 38

Figura 10. Mecanismos de transporte e armazenamento de gás em reservatórios de gás de folhelho em diferentes escalas (Javadpour et al., 2007). 39

Figura 11. Dinâmica esquemática do fluxo de $\mathrm{CO}_{2}$ e $\mathrm{CH}_{4}$ em folhelhos ricos em matéria orgânica (Godec et al., 2014)...... 
Figura 12. Segurança do armazenamento quanto aos mecanismos de trapa ao longo do tempo (IPCC, 2005).

Figura 13. Mecanismos de armazenamento de $\mathrm{CO}_{2}$ e fases do $\mathrm{CO}_{2}$ em um reservatório de folhelho. As fases ilustradas representam o $\mathrm{CO}_{2}$ armazenado: em adsorção; livre gasoso ou em estado supercrítico; em dissolução na fase aquosa; e na fase mineral, devido a reações geoquímicas. Os números indicam os elementos de trapa, sendo: (1) trapa por sorção competitiva, ou preferência de adsorção pelo $\mathrm{CO}_{2}$ em relação ao $\mathrm{CH}_{4}$; (2) trapa residual; (3) trapa por solubilidade; (4) trapa mineral (adaptado de Liu et al., 2016).... 43

Figura 14. Aplicações de simuladores numéricos de reservatório na engenharia de

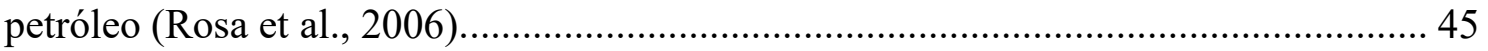

Figura 15. Localização da Bacia do Paraná (ANP, 2017) ............................................ 49

Figura 16. Carta estratigráfica da Bacia do Paraná (Milani et al., 2007). 51

Figura 17. Mapa geológico simplificado da Bacia do Paraná (adaptado de Milani et al., 2006) 52

Figura 18. Seção geológica esquemática da Bacia do Paraná (Milani e Zalán, 1998)... 53

Figura 19. Relação entre excesso máximo de sorção e COT para amostras de folhelhos da Fm. Irati e Fm. Ponta Grossa, com base em testes realizados a $45{ }^{\circ} \mathrm{C}$, entre 8 a $12 \mathrm{MPa}$ (De Souza, 2018, adaptado de Weniger et al., 2010). 54

Figura 20. Imagens de microscopia eletrônica de varredura (MEV) de amostras da Fm. Irati, com presença de microvazios entre as placas de argilominerais, poros interpartículas (De Souza, 2018). 56

Figura 21. Diagrama de fases do $\mathrm{CO}_{2}$, com indicação do ponto crítico da fase supercrítica (Constant, 2015, adaptado de van der Meer, 2005).

Figura 22. Imagem do modelo M0 no Builder, referente ao reservatório hipotético na Fm. Irati. 67

Figura 23. Vista bidimensional da camada com o poço injetor, no Builder. 67

Figura 24. Total de $\mathrm{CO}_{2}$ injetado no modelo base $\mathrm{M} 0$, em 1.000 anos. 73 
Figura 25. Injeção de $\mathrm{CO}_{2}$ anual, no modelo base (M0).

Figura 26. Declínio da injeção de $\mathrm{CO}_{2}$ a cada dez anos, no modelo base (M0)............ 75

Figura 27. Vazão de injeção de $\mathrm{CO}_{2}$, em 1000 anos. 75

Figura 28. Detalhe da vazão de injeção de $\mathrm{CO}_{2}$ nos primeiros 20 anos. 76

Figura 29. Vista em planta das quatro camadas do reservatório, identificando a evolução da fração de $\mathrm{CO}_{2}$ na fase gasosa do reservatório, até o fim do período de injeção de $\mathrm{CO}_{2}$, em anos selecionados. As frações são identificadas por cores de acordo com a legenda ao lado, de 0 em azul a 1,0 (equivalente a 100\%) em vermelho. 77

Figura 30. Vista em planta das quatro camadas do reservatório ao fim do período de injeção, identificando as proporções do armazenamento de $\mathrm{CO}_{2}$ na fase em adsorção em relação ao total de $\mathrm{CO}_{2}$ armazenado 78

Figura 31. Vista em planta da camada 2, na qual está localizado o poço injetor, identificando as concentrações de $\mathrm{CO}_{2}$ por volume, em gmole $/ \mathrm{m}^{3}$, em anos selecionados, até o $136^{\circ}$ ano. 78

Figura 32. Evolução da fase em adsorção do $\mathrm{CO}_{2}$ em relação do total injetado, em M0.

Figura 33. Evolução da fase em adsorção do $\mathrm{CO}_{2}$ em relação ao $\mathrm{CH}_{4}$ em adsorção no reservatório, em M0

Figura 34. Análise de sensibilidade das propriedades do reservatório em relação à injeção de $\mathrm{CO}_{2}$. Foram considerados os seguintes parâmetros: pressão, espessura, saturação de gás, densidade, porosidade, permeabilidade, temperatura, compressibilidade e coeficiente de difusão do $\mathrm{CO}_{2}$ 80

Figura 35. Evolução da pressão ao logo do tempo de injeção, com valor máximo de $21.507 \mathrm{kPa}$ atingido no ano 760, em M0.

Figura 36. Vistas em planta da camada com poço injetor de $\mathrm{CO}_{2}$, mostrando a evolução da pressão (em $\mathrm{kPa})$ em anos selecionados. 
Figura 37. Comparativo do $\mathrm{CO}_{2}$ armazenado nos modelos limites (M- e $\mathrm{M}+$ ) e base (M0), em 1000 anos.

Figura 38. Comparativo da efetividade do armazenamento de $\mathrm{CO}_{2}$ na fase adsorvida em relação ao total injetado, nos modelos limites (M- e M+) e base (M0), em 1000 anos. 83

Figura 39. Total de $\mathrm{CO}_{2}$ injetado por tempo de projeto, em $\mathrm{M} 0$ 85

Figura 40. Custos totais por poço por tempo de injeção de $\mathrm{CO}_{2}$, em M0. 85

Figura 41. Relação entre custos de injeção por quantidade de $\mathrm{CO}_{2}$ injetado, em M0... 86

Figura 42. Custos por tonelada de $\mathrm{CO}_{2}$ injetado, em $\mathrm{M} 0$.

Figura 43. Relação da variação do incremento da injeção de $\mathrm{CO}_{2}$ e o aumento ou redução do custo por tonelada de $\mathrm{CO}_{2}$ injetado, a cada 10 anos

Figura 44. Evolução do $\mathrm{CO}_{2}$ injetado em 50 anos, nos modelos $\mathrm{M}-, \mathrm{M} 0$ e $\mathrm{M}+$. 88

Figura 45. Comparativo de custos totais por tempo de projeto em M-, M0 e M+. 88

Figura 46. Comparação das variações de custos por tonelada de $\mathrm{CO}_{2}$ injetado por tempo de projeto em $\mathrm{M}-, \mathrm{M} 0$ e $\mathrm{M}+$. 


\section{LISTA DE TABELAS}

Tabela 1. Resultados de experimentos de adsorção de metano e dióxido de carbono a alta pressão em amostras da Fm. Irati (Weniger et al., 2010), medidos a $45^{\circ} \mathrm{C}$.

Tabela 2. Valores utilizados para o reservatório do modelo de base M0.

Tabela 3. Valores utilizados para o poço injetor com fraturamento hidráulico do modelo base M0. 66

Tabela 4. Parâmetros assumidos para análise de sensibilidade das características geológicas do reservatório não convencional (M0), em função da injeção de $\mathrm{CO}_{2} \ldots \ldots . . .68$

Tabela 5. Definição dos valores mínimos e máximos das características geológicas para composição dos cenários limites $\mathrm{M}$ - e M+. 70

Tabela 6. Custos atribuídos ao projeto de poço injetor (adaptado de Bielicki et al., 2018). 


\section{LISTA DE SIGLAS}

ANP Agência Nacional do Petróleo, Gás Natural e Biocombustíveis

BECCUS Bio-Energy with Carbon, Capture, Utilization and Storage

CAPES Coordenação de Aperfeiçoamento de Pessoal de Nível Superior

CCS Carbon, Capture and Storage

CCUS Carbon, Capture, Utilization and Storage

CDS Cenário de Desenvolvimento Sustentável

CMG Computer Modelling Group

COT Carbono Orgânico Total

EGR Enhanced Gas Recovery

EIA Energy Information Administration

EOR Enhanced Oil Recovery

EP Escola Politécnica

Fm. Formação

GCCSI Global CCS Institute

GEE Gases de Efeito Estufa

IEA International Energy Agency

IEAGHG International Energy Agency Greenhouse Gas R\&D Programme

IEE Instituto de Energia e Ambiente

IPCC Intergovernmental Panel on Climate Change

LASG Laboratório de Simulação e Gerenciamento de Reservatórios de

Petróleo

MEV Microscopia Eletrônica de Varredura 
ONU Organização das Nações Unidas

PVT Pressão, Volume e Temperatura

RCGI Research Centre for Gas Innovation

SPE Society of Petroleum Engineers

USP Universidade de São Paulo 


\section{LISTA DE SÍMBOLOS}

\begin{tabular}{|c|c|}
\hline $\mathrm{CH}_{4}$ & Metano \\
\hline $\mathrm{CO}_{2}$ & Dióxido de carbono \\
\hline${ }^{\circ} \mathrm{C}$ & Graus Celsius \\
\hline $\mathrm{cm}^{2} / \mathrm{s}$ & Centímetro ao quadrado por segundo \\
\hline $\mathrm{ft}$ & Pé \\
\hline gmol & Grama-mol \\
\hline $\mathrm{gmol} / \mathrm{kg}$ & Grama-mol por quilograma \\
\hline Gt & Gigatonelada \\
\hline $\mathrm{kg} / \mathrm{m}^{3}$ & Quilograma por metro cúbico \\
\hline $\mathrm{km}$ & Quilômetro \\
\hline $\mathrm{kPa}$ & QuiloPascal \\
\hline $\mathrm{kPa} / \mathrm{m}$ & QuiloPascal por metro \\
\hline $\mathrm{m}$ & Metro \\
\hline $\mathrm{mD}$ & MiliDarcy \\
\hline mmol & Milimol \\
\hline $\mathrm{MPa}$ & MegaPascal \\
\hline Mscf/d & Milhares de pés cúbicos por dia \\
\hline $\mathrm{m}^{3} / \mathrm{d}$ & Metros cúbicos por dia \\
\hline $\mathrm{nD}$ & NanoDarcy \\
\hline $\mathrm{nm}$ & Nanometro \\
\hline Psi & Libra-força por polegada quadrada \\
\hline $\mathrm{Psi} / \mathrm{ft}$ & Libra-força por polegada quadrada por pé \\
\hline $\mathrm{t}$ & Tonelada \\
\hline $\mathrm{tCO}_{2}$ & Tonelada de dióxido de carbono \\
\hline
\end{tabular}




\section{SUMÁRIO}

1. INTRODUÇÃO

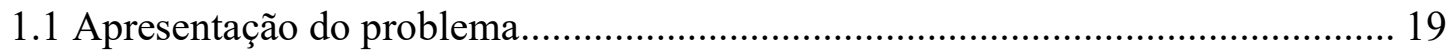

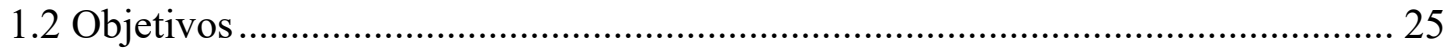

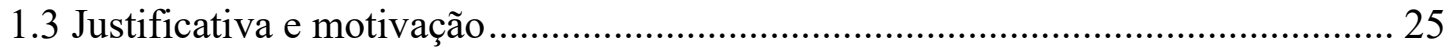

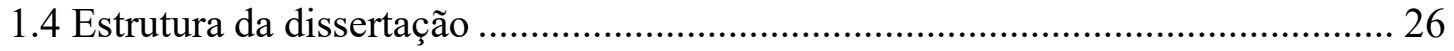

2. ARMAZENAMENTO GEOLÓGICO DE CARBONO EM RESERVATÓRIOS DE GÁS DE FOLHELHO

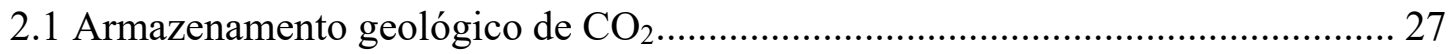

2.2 Recursos não convencionais: reservatórios de gás de folhelho ........................... 29

2.3 Aspectos relevantes para modelagem de reservatórios de gás de folhelho .......... 34

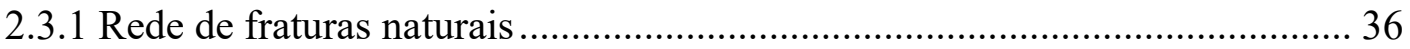

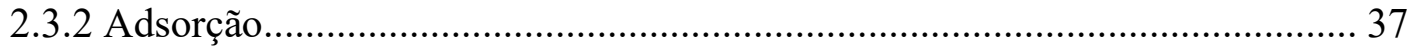

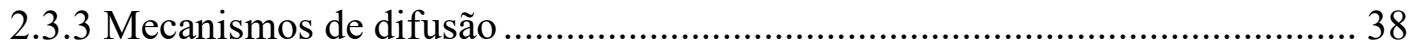

2.4 Injeção de $\mathrm{CO}_{2}$ em reservatórios de gás de folhelho .......................................... 40

2.4.1 Mecanismos de trapa e armazenamento de $\mathrm{CO}_{2}$........................................ 40

2.4.2 Estudos de simulação numérica de reservatórios para injeção de $\mathrm{CO}_{2} \mathrm{em}$

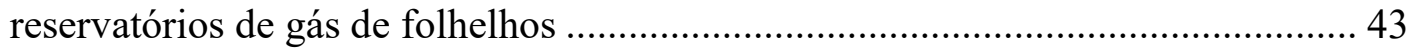

3. A FORMAÇÃO IRATI 49

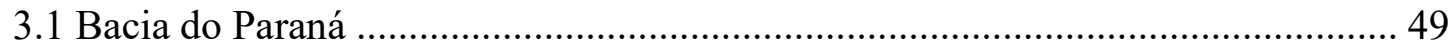

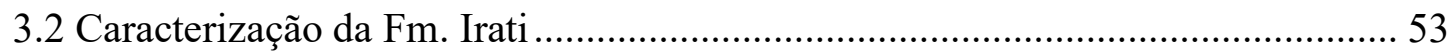




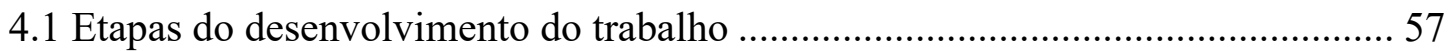

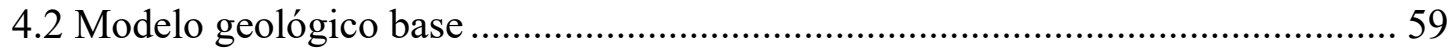

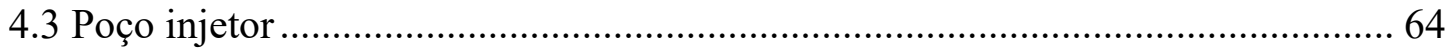

4.4 Parâmetros para análise de sensibilidade ............................................................ 67

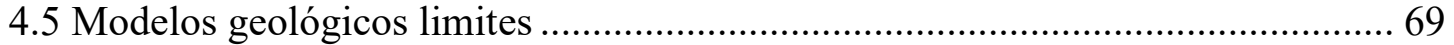

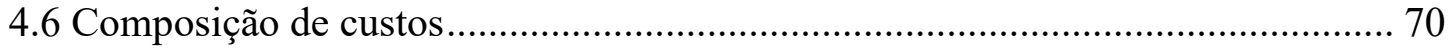

5. RESULTADOS E DISCUSSÃO 73

5.1 Estimativa da capacidade de injeção de $\mathrm{CO}_{2}$ por poço....................................... 73

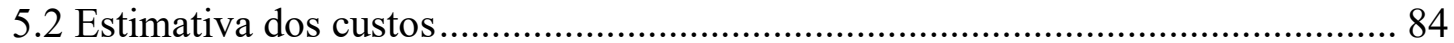

6. CONCLUSÕES E CONSIDERAÇÕES FINAIS 91

$\begin{array}{ll}\text { Referências bibliográficas } & 94\end{array}$ 


\section{INTRODUÇÃO}

\subsection{Apresentação do problema}

A crescente atenção quanto à concentração de Gases do Efeito Estufa (GEE) na atmosfera impõe um grande desafio ao setor de energia global: a necessidade de redução das emissões de dióxido de carbono $\left(\mathrm{CO}_{2}\right)$. O setor de energia é responsável por cerca de $70 \%$ do total de emissões de GEE no mundo, sendo a maior parte do $\mathrm{CO}_{2}$ liberado proveniente de combustão (IEA, 2019). O processo de captura e armazenamento de carbono, conhecido pela sigla em inglês CCS (Carbon Capture and Storage) - e, por vezes, CCUS (Carbon Capture Utilization and Storage), desponta como uma promissora opção mitigadora (IPCC, 2005), com relevantes benefícios potenciais econômicos, ambientais e no que concerne à segurança de suprimento energético. Segundo a Agência Internacional de Energia (IEA, do inglês International Energy Agency), o processo de CCS foi considerado a única tecnologia estudada atualmente capaz de reduzir significativamente as emissões relacionadas ao uso de combustíveis fósseis. A adoção em larga escala de CCS pode entregar cerca de 13\% do acumulado da redução de emissões totais necessária para limitar a $2^{\circ} \mathrm{C}$ o aumento da temperatura global até $2050^{1}$ (IEA, 2015). O cenário de desenvolvimento sustentável (CDS) do relatório World Energy Outlook 2017 aponta para a necessidade de atingir o equivalente à emissão líquida zero de $\mathrm{CO}_{2}$ antes do final do século ou mesmo emissões "negativas", com sequestro atmosférico de $\mathrm{CO}_{2}$, para que esse aumento da temperatura não ultrapasse $1,8^{\circ} \mathrm{C}$. Para essa perspectiva, não há tecnologia capaz de atingir a meta como solução única e, portanto, faz-se necessária uma combinação de tecnologias, incluindo energias renováveis e usinas nucleares, com aplicação ajustada às diferentes restrições geográficas, econômicas e sociais nos países (IEA, 2017a).

O processo de CCS desempenha papel relevante nesse cenário, especialmente no tocante às emissões negativas, que podem ser alcançadas por meio da combinação do armazenamento de carbono à geração de bioenergia ou à captura direta de ar. No setor industrial, também é considerado fundamental para redução das emissões na produção de

\footnotetext{
${ }_{1}^{1}$ Acordo de Paris, firmado na Conferência do Clima da ONU COP21, estabelece que os países signatários adotem medidas para minimizar a mudança climática, determinando como teto o aumento da temperatura média global em $2^{\circ} \mathrm{C}$ acima dos níveis pré-industriais, com empenho para limitar a $1,5^{\circ} \mathrm{C}(\mathrm{ONU}, 2015)$.
} 
aço, cimento e produtos químicos, que exige um grande aumento nos níveis de $\mathrm{CO}_{2}$ capturado (IEA, 2017b; Banco Mundial, 2017).

O conjunto de técnicas que compõem o CCS envolve processos de separação de $\mathrm{CO}_{2}$ de fontes emissoras (industriais e relacionadas ao setor energético, como plantas de geração de energia e unidades de produção de petróleo), transporte para os locais designados para isolamento da atmosfera e injeção para armazenamento de longo prazo, notadamente em formações geológicas profundas, como reservatórios de petróleo e gás natural depletados. A injeção de $\mathrm{CO}_{2}$ já é utilizada pela indústria petrolífera desde o início da década de 1970 para recuperação avançada, incrementando a produção por favorecimento do deslocamento miscível e aumento da pressão (Nordbotten e Celia, 2012), o que contribuiu para a atual extensão do conhecimento sobre armazenamento de carbono em reservatórios convencionais.

Apesar de receber menor atenção, reservatórios não convencionais de hidrocarbonetos, em especial os reservatórios de gás de folhelho (equivalente a shale gas, em inglês), por vezes chamado coloquialmente de "gás de xisto", apresentam grande potencial para armazenamento geológico de $\mathrm{CO}_{2}$, devido à ampla distribuição geográfica das reservas, apresentada na Figura 1, e ao recente crescimento da produção mundial, principalmente da América do Norte. Os folhelhos são geralmente caracterizados pela baixa permeabilidade e, portanto, apresentam consideráveis barreiras à explotação. Entretanto, os recentes avanços na perfuração horizontal e no fraturamento hidráulico, além do aumento dos preços do gás natural, impulsionaram a produção de gás de folhelho em volumes tão elevados e com tamanho impacto na geopolítica do petróleo que foi cunhado o termo "Revolução do Shale" (Yergin, 2011). 


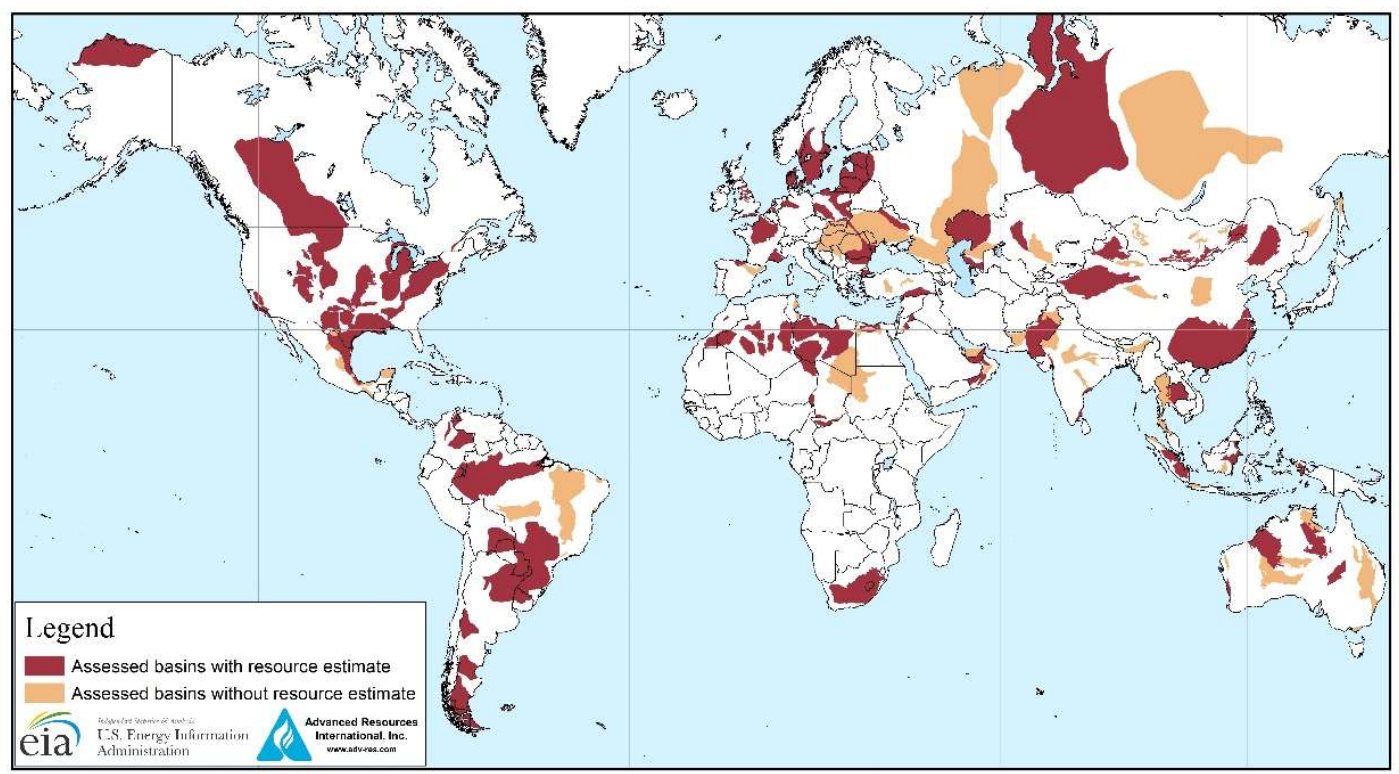

Figura 1. Mapa de bacias com recursos avaliados de gás e óleo de folhelho (EIA, 2013).

No Brasil, a despeito das lacunas de regulação para atividades de CCS e para recursos não convencionais, algumas formações de folhelhos negros, como são chamados os folhelhos ricos em matéria orgânica, apresentam bom potencial para geração de gás e para armazenamento de $\mathrm{CO}_{2}$. Os folhelhos da Formação (Fm.) Irati apresentam altos teores de matéria orgânica, com possibilidade de valores elevados de maturação e potencial gerador de gás. A injeção de $\mathrm{CO}_{2}$ nessa formação geológica, objeto de estudo deste trabalho, também é favorecida pela sua localização estratégica, já que a Fm. Irati pertence à Bacia do Paraná, que coincide com as regiões com maior concentração de emissões de carbono por fontes estacionárias do Brasil. A Figura 2 expõe a localização da Bacia do Paraná e as massas de $\mathrm{CO}_{2}$ emitidas por fontes estacionárias no país. 


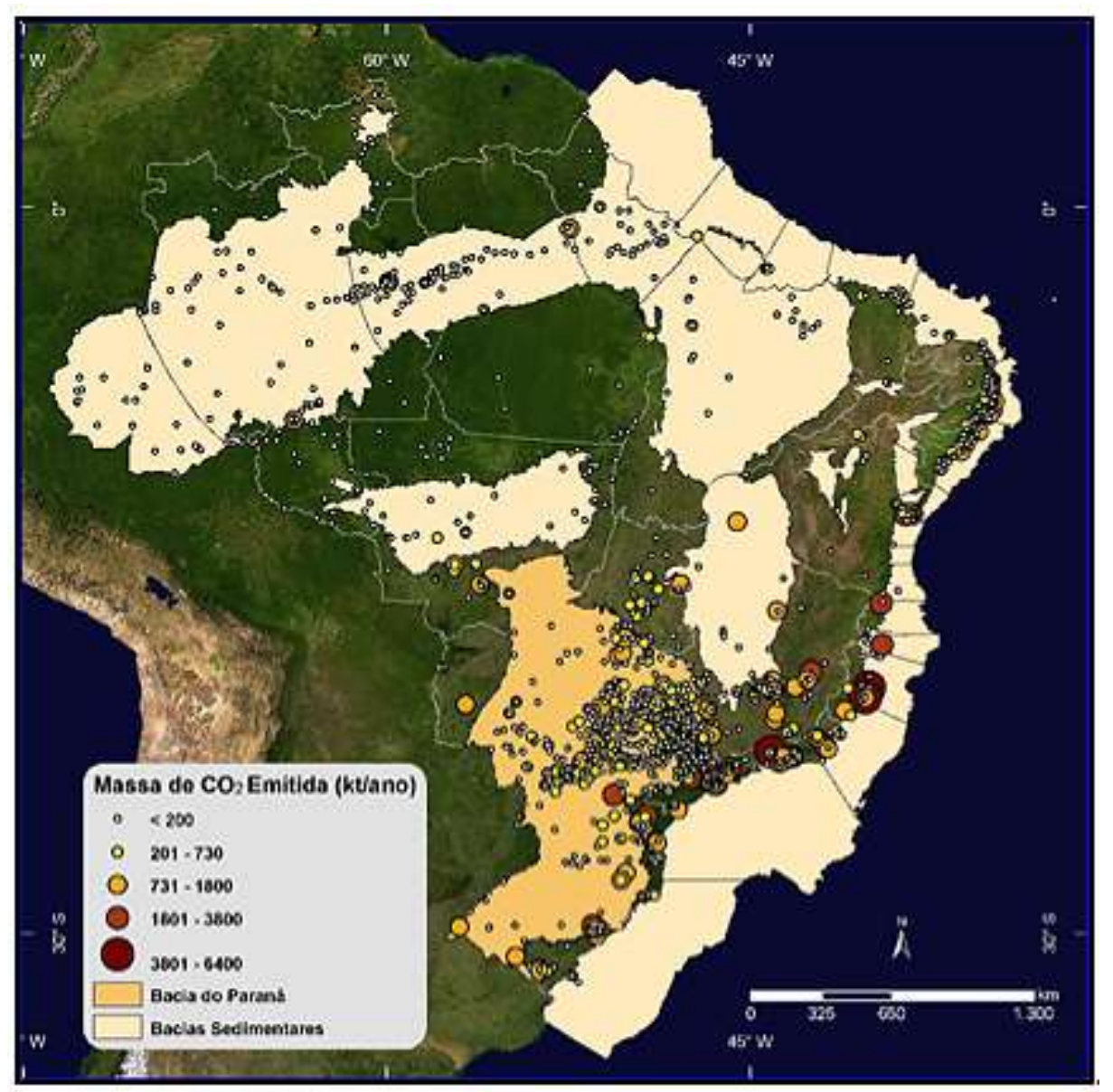

Figura 2. Fontes estacionárias emissoras de $\mathrm{CO}_{2}$ no Brasil, com destaque à localização da Bacia do Paraná (Rockett, 2010).

A localização da Fm. Irati, no subsolo das regiões sul e sudeste, permite não só a injeção de $\mathrm{CO}_{2}$ proveniente da combustão e processos industriais que envolvem óleo, gás e carvão, mas também de usinas de bioenergia, provenientes da cana-de-açúcar. Os processos de bioenergia com captura e armazenamento de carbono, conhecidos como BECCS (da sigla em inglês para Bio-Energy with Carbon Capture and Storage), apresentam benefício ainda maior para mitigação das mudanças climáticas, por serem considerados tecnologias de emissões líquidas negativas, já que moléculas de $\mathrm{CO}_{2}$ presentes na atmosfera são absorvidas durante o crescimento da cana-de-açúcar.

Entretanto, apesar do domínio e segurança da tecnologia de injeção de $\mathrm{CO}_{2}$, os custos do processo são considerados grandes entraves à difusão de CCS no mundo, ao lado de outros fatores como percepção pública, falta de regulação e questões políticas. A viabilização do ponto de vista econômico de projetos comerciais de CCS pode estar 
sujeita à criação de mecanismos de precificação de carbono, entre outras possibilidades menos estudadas. Os mecanismos de precificação de carbono são basicamente divididos entre a criação de taxas para emissões de $\mathrm{CO}_{2}$ ou a criação de sistemas de comercialização de licenças para emissão. Atualmente, existem no mundo 57 iniciativas em execução ou planejadas, em jurisdições nacionais e subnacionais, que ao todo cobrem apenas $20 \%$ do total de emissões de gases de efeito estufa. Apesar da aderência ainda incipiente, muitos países buscam fortalecer esses mecanismos por meio de políticas públicas internas e acordos de comércio internacional (Banco Mundial, 2019). As iniciativas existentes e planejadas de precificação de carbono no mundo são exibidas na Figura 3, com seus respectivos preços e abrangências de jurisdição. 


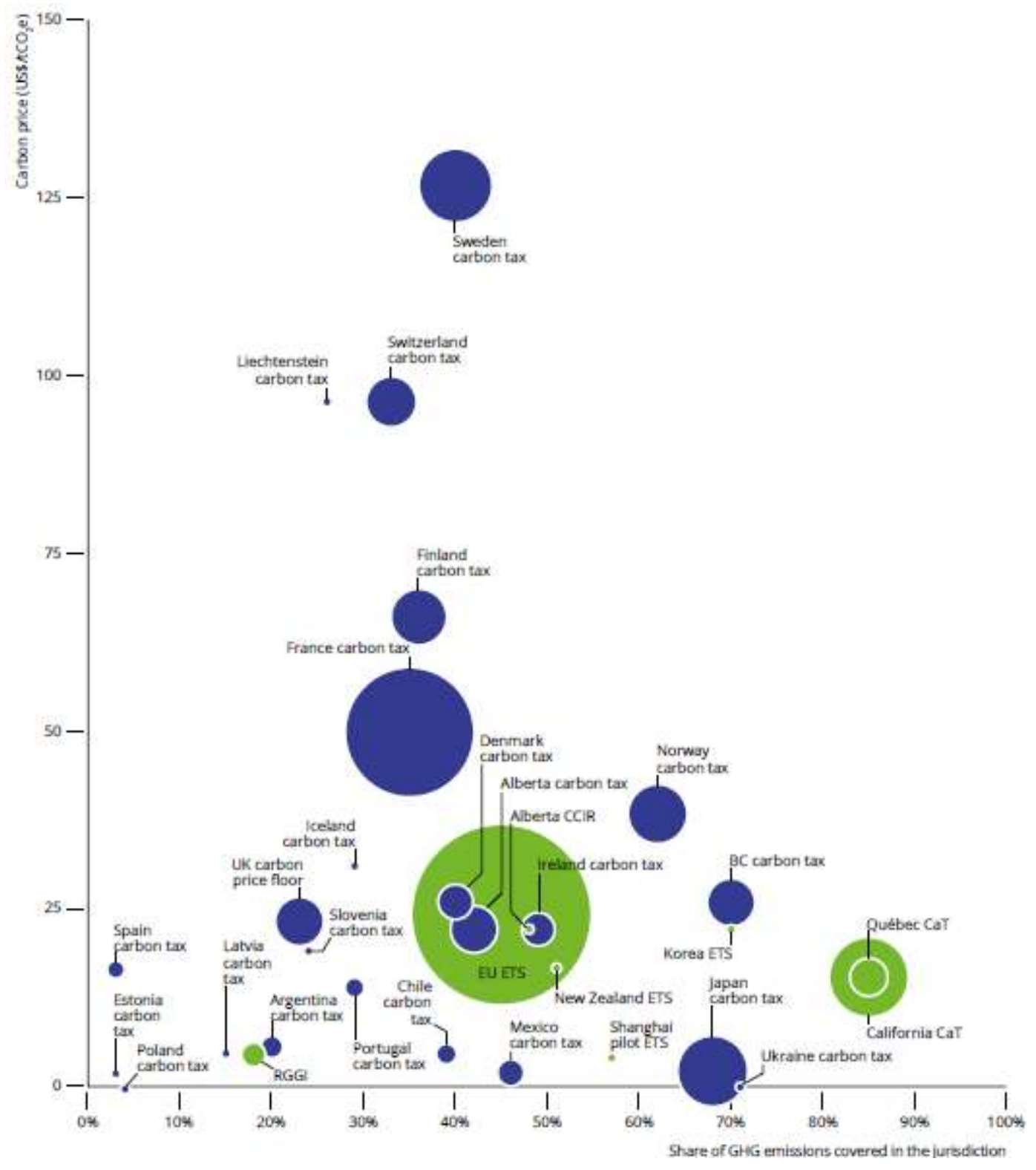

Figura 3. Preços de carbono em dólares por tonelada de $\mathrm{CO}_{2}$ equivalente nas iniciativas existentes no mundo, considerando a parcela de emissões de gases de efeito estufa cobertas nas jurisdições. Os tamanhos dos círculos são proporcionais ao total arrecadado pelos governos, com exceção de iniciativas cujas arrecadações governamentais ficaram abaixo de 100 milhões de dólares em 2018 (Banco Mundial, 2019).

Diante dessa conjuntura, para avaliação da aplicação de armazenamento de carbono nos reservatórios de folhelhos no Brasil, são necessárias análises do potencial de injeção de $\mathrm{CO}_{2}$ e seus custos. 


\subsection{Objetivos}

O presente trabalho tem como objetivo analisar o potencial teórico de armazenamento de $\mathrm{CO}_{2}$ na Fm. Irati da Bacia do Paraná, com avaliação da influência das características geológicas na capacidade total. O estudo compreende uma unidade de volume determinada a partir do raio de influência de um poço injetor, o que permite posterior avaliação de potencial de injeção de $\mathrm{CO}_{2}$ a partir da determinação de área de superfície aplicável. A análise inclui cenários que abrangem as incertezas geológicas devidas à dificuldade de obtenção de dados da Fm. Irati, além de estimativas do intervalo de custos de um projeto de poço injetor considerando esses cenários.

Os objetivos específicos do trabalho consistem em prover os seguintes itens para um projeto de poço de injeção de $\mathrm{CO}_{2}$ em uma unidade de volume da Fm. Irati:

- Análise da influência das características geológicas no potencial de armazenamento de $\mathrm{CO}_{2}$;

- Estimativa do potencial de injeção de $\mathrm{CO}_{2}$;

- Estimativa de custos; e

- Estimativa do preço da tonelada de $\mathrm{CO}_{2}$ para viabilidade econômica do projeto.

Espera-se contribuir para o conhecimento acerca do comportamento de reservatórios de gás de folhelho como opção para armazenamento geológico de $\mathrm{CO}_{2}$, além de fornecer valores iniciais que sirvam como referência para discussão da capacidade de injeção de $\mathrm{CO}_{2}$ total na Fm. Irati e ordem de grandeza dos investimentos. Também se espera que a estimativa de custo de injeção por tonelada de $\mathrm{CO}_{2}$ proveja uma base para discussão de mecanismos de precificação de carbono no Brasil e políticas públicas de estímulo à redução da emissão de gases de efeito estufa.

\subsection{Justificativa e motivação}

Com o potencial geológico da Fm. Irati para acumulações de gás de folhelho, temse uma oportunidade estratégica para implementação de empreendimentos de CCS na Bacia do Paraná, pela possibilidade de desenvolvimento de BECCS na região, atendendo aos esforços voltados à transição para uma economia de baixo carbono e aos Objetivos 
do Desenvolvimento Sustentável (ODS) da Organização das Nações Unidas (ONU), contemplando os objetivos 7 e $13^{2}$.

Também a insuficiência de estudos sobre o comportamento de reservatórios de gás de folhelho quanto à dinâmica da interação entre o $\mathrm{CO}_{2}$ injetado, os fluidos e as rochas que compõem o reservatório configuram relevante desafio para estabelecer o potencial dos folhelhos negros como alternativa para armazenamento geológico de carbono. Devese considerar também que o foco de grande parte dos estudos existentes é voltado à recuperação avançada do gás pela utilização do $\mathrm{CO}_{2}$, que não tem como prioridade a avaliação do impacto na capacidade total do armazenamento.

Como motivação pessoal, além das oportunidades de estudos expostas, as técnicas que envolvem a injeção de $\mathrm{CO}_{2}$ são uma possibilidade de aplicação de competências da Engenharia de Petróleo, que pode contribuir desde a avaliação exploratória de locais adequados até a construção de poços, planejamento e análise do comportamento do reservatório para injeção de $\mathrm{CO}_{2}$.

\subsection{Estrutura da dissertação}

Como fundamentação teórica, a dissertação apresenta dois capítulos, voltados (i) ao levantamento do estado da arte do armazenamento geológico de $\mathrm{CO}_{2}$ em reservatórios de gás de folhelho, com estudo dos aspectos relevantes para simulação numérica de reservatório nesse contexto; e (ii) à pesquisa de dados e características da Fm. Irati relevantes à construção de modelo geológico representativo.

Na sequência, é descrito o método de trabalho estabelecido para determinação do potencial de injeção e avaliação de custos, considerando as incertezas inerentes à coleta de dados.

Por fim, os resultados das simulações e cálculos são apresentados e analisados quanto ao potencial de injeção e possível intervalo de variações, que abrange cenários pessimista e otimista, e quanto aos custos, aplicados a todos os cenários.

\footnotetext{
${ }^{2}$ Os Objetivos do Desenvolvimento Sustentável 7 e 13 têm como objetivo assegurar o acesso confiável, sustentável, moderno e a preço acessível à energia para todos e tomar medidas urgentes para combater a mudança climática e seus impactos, respectivamente.
} 


\section{ARMAZENAMENTO GEOLÓGICO DE CARBONO EM RESERVATÓRIOS DE GÁS DE FOLHELHO}

\subsection{Armazenamento geológico de $\mathrm{CO}_{2}$}

Considerado uma opção promissora para atingir as metas climáticas e de transição energética (IEA, 2019), o armazenamento geológico de carbono atua na mitigação das emissões de gases de efeito estufa sem exigir grandes transformações de processos industriais e geração de energia convencionais.

Para que o dióxido de carbono $\left(\mathrm{CO}_{2}\right)$ seja armazenado ou "sequestrado", é necessário que primeiro seja capturado em volumes adequados de fontes emissoras estacionárias, comprimido e transportado a um local designado, onde será injetado através de um poço até a profundidade na qual se encontre a formação geológica que servirá de reservatório, completando a cadeia básica do processo conhecido como Captura e Armazenamento de Carbono (CCS, em inglês).

O estudo de Kearns et al. (2017) aponta um potencial global de capacidade de armazenamento geológico de até 55.581 gigatoneladas $(\mathrm{Gt})$ de $\mathrm{CO}_{2}$, considerando regiões onshore e offshore praticamente acessíveis ${ }^{3}$, com base no potencial de armazenamento por volume de bacias sedimentares. Entretanto, outros critérios podem ser observados para determinação desses valores, como aspectos de segurança, logística e características geológicas.

De acordo com o Global CCS Institute (GCCSI, 2018), são necessários, de maneira geral, os seguintes elementos em um contexto geológico para um armazenamento efetivo:

- Formações rochosas com volume suficiente de espaços vazios, ou poros, que forneçam a capacidade para estocar o $\mathrm{CO}_{2}$;

- Permeabilidade para que o $\mathrm{CO}_{2}$ possa acessar os poros da formação que servirá de reservatório; e

- Rocha selante ou barreira que impeça o escape de $\mathrm{CO}_{2}$.

\footnotetext{
${ }^{3} \mathrm{O}$ potencial offshore praticamente acessível foi limitado com base nos seguintes critérios: profundidade da água a menos de 300 metros, a 300 quilômetros de uma grande massa de terra e fora das regiões ártica ou antártica (Kearns et al., 2017).
} 
Essas características geológicas que propiciam o armazenamento de carbono são análogas às que permitem naturalmente as acumulações de óleo e gás, aprisionadas por milhões de anos. Essa semelhança torna atrativo o aproveitamento de reservatórios depletados, que já foram alvo de produção de hidrocarbonetos, para injeção de $\mathrm{CO}_{2}$.

A injeção de $\mathrm{CO}_{2}$ em reservatórios de hidrocarbonetos é um processo amplamente utilizado pela indústria petrolífera com a finalidade de incrementar a produção, por meio da técnica de recuperação avançada. Na década de 1970, foi proposto o armazenamento geológico de $\mathrm{CO}_{2}$ antropogênico como uma forma de mitigação das emissões dos gases de efeito estufa, mas somente anos depois, no início da década de 1990, a ideia progrediu em pesquisas (IPCC, 2005). Muitos estudos nesse sentido focaram nos aquíferos salinos como um grande potencial para injeção de $\mathrm{CO}_{2}$, desconectando a atividade de sequestro de carbono da produção petrolífera. Mais recentemente, são estudadas outras opções que despontam como alternativa para armazenamento, que incluem os reservatórios não convencionais de óleo e gás, camadas de carvão, basaltos e cavidades naturais ou artificiais.

A Figura 4 ilustra de forma esquemática os diversos contextos geológicos que são utilizados ou estudados para armazenamento de $\mathrm{CO}_{2}$. 


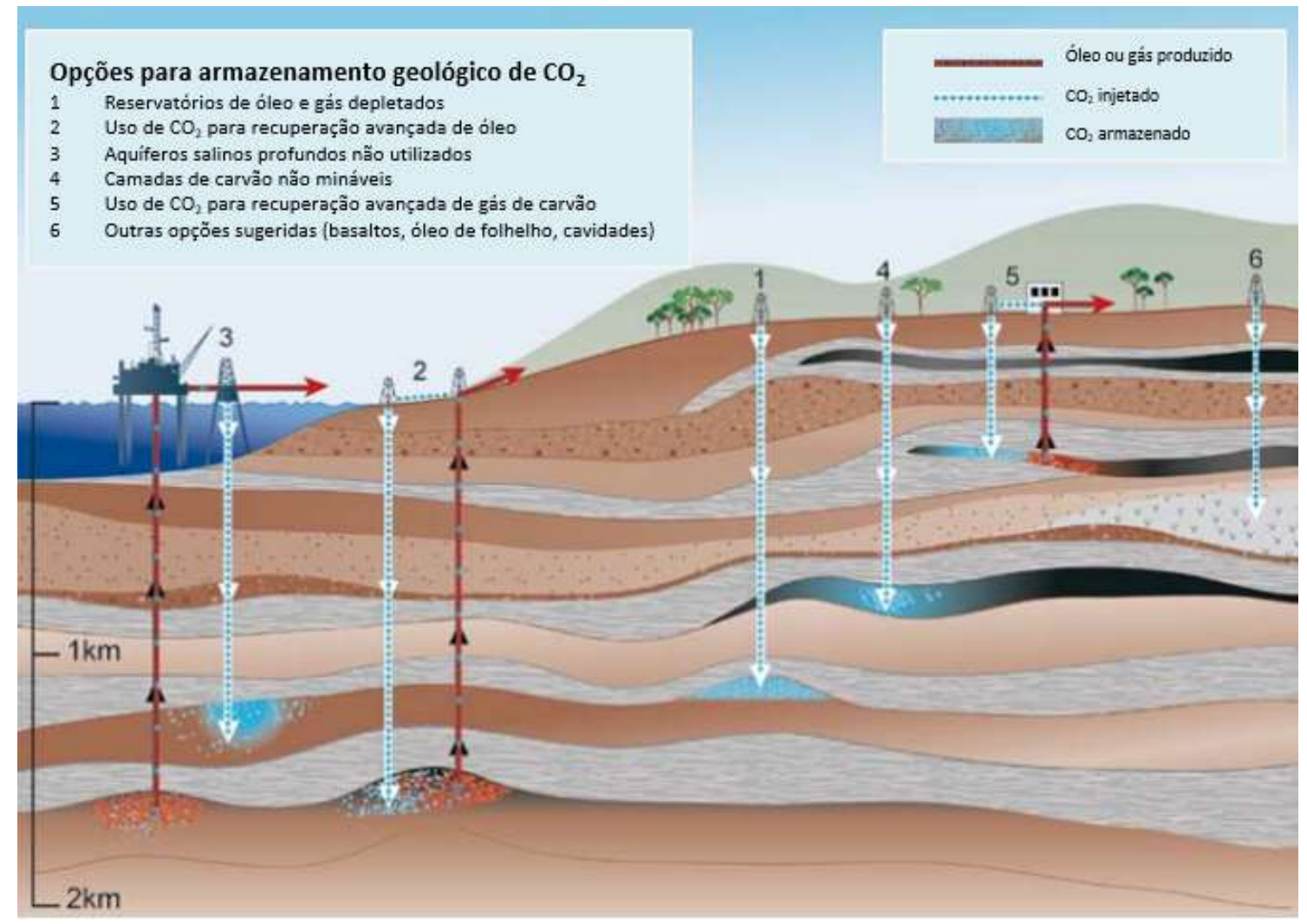

Figura 4. Opções para armazenamento geológico de $\mathrm{CO}_{2}$ (adaptado de IPCC, 2005).

\subsection{Recursos não convencionais: reservatórios de gás de folhelho}

Dentre as opções aventadas para sequestro de $\mathrm{CO}_{2}$, os reservatórios de gás de folhelho - classificados como reservatórios não convencionais - apresentam importante perspectiva do ponto de vista técnico. Além de possuir características específicas que podem ser vantajosas para o armazenamento de carbono, que serão tratadas mais a frente, há uma distribuição muito abrangente desses recursos no mundo, que tiveram na década passada um aumento expressivo de produção com a "Revolução do Shale" nos Estados Unidos.

O gás de folhelho é o gás natural que se encontra retido em formações de folhelhos, que são as rochas geradoras de hidrocarbonetos. É composto principalmente por metano $\left(\mathrm{CH}_{4}\right)$, podendo apresentar pequenas quantidades de etano, propano e butano, além de traços de $\mathrm{CO}_{2}$ e $\mathrm{N}_{2}$ (Kalkreuth et al., 2018). Seus reservatórios são classificados como não convencionais, categoria na qual também são frequentemente enquadrados hidrocarbonetos como o chamado tight gas, hidratos de metano, gás de camadas de carvão, areias betuminosas, entre outros. 
A definição de reservatório não convencional de hidrocarbonetos não é precisa e é apresentada na literatura a partir de variações de características do reservatório e da tecnologia existente, possibilitando reclassificações de um mesmo contexto geológico de acordo com o desenvolvimento de novas técnicas. Essas variações não dizem respeito às propriedades dos hidrocarbonetos contidos no reservatório, mas à comparação com o conceito de "convencional" quanto a fatores tecnológicos, geológicos e econômicos. De maneira geral, reservatórios não convencionais são aqueles que apresentam alguma característica diferenciada, cujos recursos não são desenvolvidos pelos métodos convencionais (Ma et al., 2016).

A criação de acumulações de óleo e gás é condicionada à combinação de elementos geológicos e processos em um ajuste de tempo e espaço correto. Os sistemas petrolíferos envolvem rocha geradora, rocha reservatório, rocha selante e rocha(s) de sobrecarga, com processos de geração, migração e acumulação de hidrocarbonetos e de formação de trapa (Magoon e Beaumont, 1999). Em um sistema petrolífero convencional, o hidrocarboneto gerado migra até encontrar uma trapa, permanecendo armazenado em rochas sedimentares com altos níveis de porosidade e permeabilidade. No caso dos reservatórios de gás de folhelho, o hidrocarboneto não sofre o processo de migração e, portanto, a rocha geradora também é a rocha reservatório e a trapa. As variações de ocorrência de recursos de gás natural estão representadas de forma esquemática na Figura 5. 


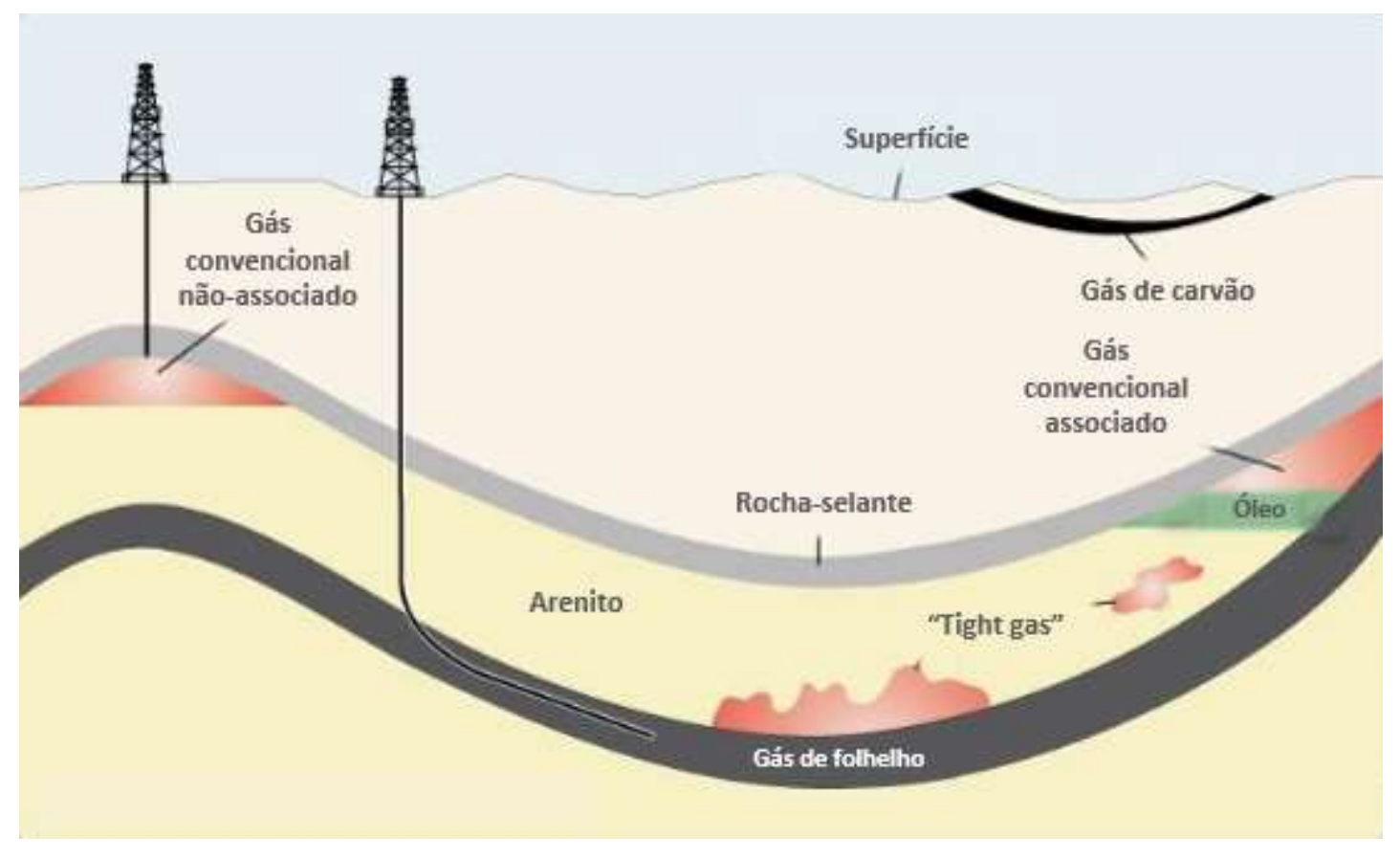

Figura 5. Ilustração esquemática da geologia de recursos de gás natural. (Adaptado de EIA, 2011)

A Figura 6 ilustra o triângulo de recursos de hidrocarbonetos, identificando as transições entre convencionais e não convencionais. Do topo da pirâmide - constituído por reservatórios convencionais - em direção à base, há o aumento do volume dos recursos existentes. Entretanto, o acesso a esses recursos com maiores volumes é dificultado pela diminuição da permeabilidade, o que implica em maiores custos de produção, com tecnologias diferenciadas das utilizadas para os recursos convencionais. 


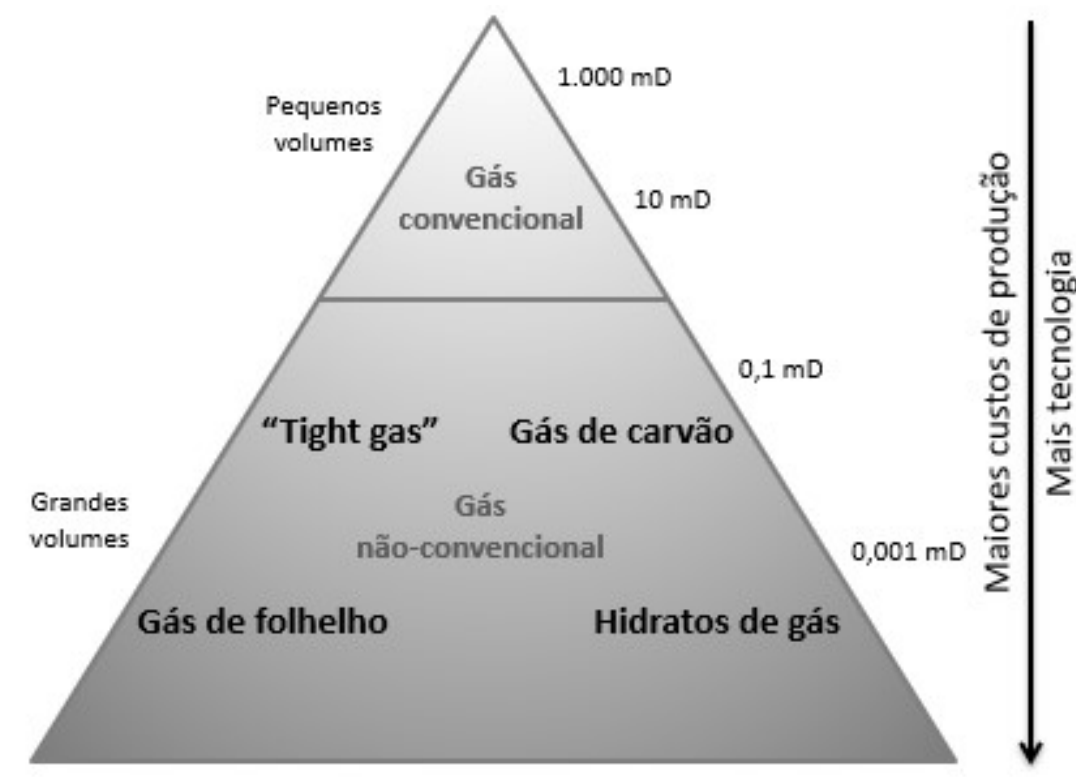

Figura 6. Triângulo de recursos de gás natural convencionais e não convencionais, com indicação das variações de volumes, permeabilidades e custos de extração e necessidade tecnológica. Recursos mais próximos da base da pirâmide requerem maiores gastos para extração e tecnologias mais avançadas (adaptado de Holditch, 2006).

Os folhelhos são rochas sedimentares clásticas formadas pela consolidação de partículas argilosas e síltico-argilosas em lâminas finas com baixa permeabilidade. São as rochas sedimentares mais abundantes no mundo e possuem bom potencial para rocha geradora, quando apresenta conteúdo de matéria orgânica acima de 1\%, e para rocha selante, pela sua baixa permeabilidade ${ }^{4}$. Formações de folhelhos que contêm gás natural são ricos em matéria orgânica (Javadpour et al., 2007) e são formadas por sedimentos de rochas que sofreram intemperismo e foram transportados e depositados como grãos finos em lagos, lagoas, deltas de rios e no assoalho oceânico junto a grandes quantidades de plâncton mortos ou plantas do mar. A capacidade dos folhelhos de produzir gás guarda relação com características físicas e químicas, e tem origem em processos térmicos ou biológicos, aos quais a matéria orgânica (querogênio) confinada é submetida (Martini et al., 1998; Schoell, 1983). As características físicas são ligadas à porosidade e à permeabilidade, enquanto as características químicas envolvem a quantidade e a qualidade do gás gerado (Selley, 2012), avaliadas pela análise de parâmetros de geoquímica orgânica, notadamente pirólise de Rock-Eval, teor de carbono orgânico total (COT), e parâmetros de petrografia orgânica, como reflectância da vitrinita, fluorescência

\footnotetext{
${ }^{4}$ Oilfield Glossary, Schlumberger. Disponível em:

$<\{$ “https://www.glossary.oilfield.slb.com/Terms/s/shale.aspx" $\}>$. Acesso em: 15/12/2019.
} 
da liptinita, índice de alteração e coloração de esporos, acritarcas e microfósseis (da Silva, 2007).

Para que haja uma acumulação de gás de folhelho com potencial para produção comercial, é necessário que o reservatório apresente proporções adequadas de maturidade, gás livre e gás total (total gas in place, TGIP), espessura, fraturas naturais e pressão (Kundert e Mullen, 2009). Entretanto, outros elementos são desejáveis para que ocorra uma melhor produção, conforme identificado na Figura 7:

Produção de gás de folhelho $\left\{\begin{array}{l}\text { Fraturas naturais } \\ \text { Matéria orgânica } \\ \text { Maturidade } \\ \text { Total de gás no reservatório } \\ \text { Gás livre } \\ \text { Pressão } \\ \text { Resistência ao cisalhamento } \\ \text { Mineralogia } \\ \text { Espessura } \\ \text { Permeabilidade }\end{array}\right.$

Figura 7. Elementos chave necessários a uma produção comercial de gás de folhelho (adaptado de Kundert e Mullen, 2009).

A configuração laminada dos folhellhos formada por grãos finos, com diferentes composições e históricos de compactação acentua a característica anisotrópica dos reservatórios de folhelho, o que exige métodos de produção diferenciados em relação aos utilizados em reservatórios convencionais, com tecnologias de completação mais avançadas, com poços horizontais e fraturamento hidráulico (Huang et al., 2017). A técnica de fraturamento hidráulico se tornou bastante comum em reservatórios não convencionais, pois estimula a permeabilidade do reservatório de forma a viabilizar economicamente a recuperação de hidrocarbonetos. O método consiste no bombeamento de um fluido de fraturamento (água + areia + produtos químicos) no poço a altas vazões para aumentar a pressão de fundo e exceder a pressão de fratura da rocha (Gandossi, 2013). 
Em suma, Gholinezhad et al. (2018) identificam algumas das principais diferenças entre formações de gás de folhelho e formações convencionais, conforme relacionado abaixo:

- O tradicional método volumétrico para análise e avaliação de recursos de um potencial reservatório não é adequado para aplicação em reservatórios não convencionais (Haskett e Brown, 2005);

- As formações de folhelho atuam tanto como rocha selante quanto rocha reservatório e, como consequência, a exploração do gás de folhelho ocorre no centro de bacias extensas (Andrews, 2013);

- Reservatórios de gás de folhelho apresentam grandes redes de fraturas naturais;

- As permeabilidades dos reservatórios de gás de folhelho são consideradas significativamente baixas em relação aos reservatórios convencionais, com valores em escala de nano a microDarcy (William-Kovacs, 2012). Essa característica resulta na necessidade de fraturamento hidráulico para que a produção de gás seja economicamente viável, com fluxo não Darcyano;

- O gás de folhelho fica em grande parte armazenado devido à adsorção;

- A migração do gás da rocha geradora para uma camada mais permeável é bloqueada pela baixa permeabilidade dos folhelhos (enquanto rocha geradora); e

- Os diâmetros dos poros também são consideravelmente menores em formações de folhelhos em relação a formações convencionais, atingindo cerca de dois nanômetros no máximo, apenas.

\subsection{Aspectos relevantes para modelagem de reservatórios de gás de folhelho}

Dentre as diferenças entre reservatórios convencionais e reservatórios de gás de folhelho, a característica que representa possivelmente as maiores implicações para previsão de comportamento destes reservatórios é a ordem de grandeza da permeabilidade, cuja variação entre nano e microDarcy resulta em desafios adicionais para a modelagem do sistema, tanto por método analítico quanto numérico. Além disso, a pouca experiência acumulada até o momento com a produção desses recursos resulta na 
falta de conhecimento empírico do comportamento desses reservatórios sob produção no longo prazo (Houzé et al., 2018).

A equação de difusão tradicionalmente utilizada para reservatórios de óleo e gás combina, em um meio homogêneo, Equação da Continuidade, Equação de Estado e Equação Constitutiva. Entretanto, para o estudo de reservatório de gás de folhelhos, apenas a conservação de massa pode ser compreendida do mesmo modo que em reservatórios convencionais. Assim, para as demais equações que constituem a equação de difusividade, são postos os seguintes desafios, resumidos em Houzé et al. (2018):

- As equações de difusão são mais complexas e é aceitável que sejam consideradas, pelo menos, três diferentes escalas de difusão em uma equação;

- As propriedades das rochas são altamente dependentes da tensão;

- As tradicionais correlações PVT provenientes de experimentos laboratoriais são questionáveis, devido à convergência entre tamanhos dos poros e das moléculas;

- As condições iniciais de produção vêm após processos de fraturamento hidráulico e, portanto, as condições iniciais devem considerar gradientes de pressão e saturação no tempo zero da produção;

- Os modelos de poços também apresentam maiores complexidades, ainda que seja assumido conhecimento sobre a geometria exata das fraturas;

- O entendimento sobre a geometria do fluxo nos reservatórios de folhelho ainda possui muitas lacunas, como a necessidade (ou não) do uso de rede de fraturas discretas; e

- Falta de dados de qualidade sobre reservatórios de folhelho.

As complexas redes de fraturas naturais dos folhelhos, que implicam que o meio não pode ser considerado homogêneo, e propriedades geoquímicas (como mecanismo de armazenamento de gás por adsorção) resultam em diferentes combinações de mecanismos de transporte de gás, como fluxo não Darcyano, difusão de Knudsen e processos de adsorção/dessorção (Javadpour et al.,2007; Sun et al., 2013; Wu et al., 2014). A interação entre as fraturas naturais do reservatório com as fraturas hidráulicas aplicadas gera essa complexidade e não-planaridade (Cipolla et al., 2010). Essa geometria de fluxo intrincada somada à baixa permeabilidade, à combinação de processos de transporte e à forte interação entre rochas e fluidos tornam o estudo do fluxo em reservatórios não convencionais mais desafiadores quando comparado aos convencionais (Wu et al., 2014). 
Dessa forma, a construção de modelo geológico para simulação de reservatório, além de incluir poço com fraturamento hidráulico, deve considerar os seguintes aspectos: rede de fraturas naturais, adsorção de gás e mecanismos de difusão.

\subsubsection{Rede de fraturas naturais}

Diversos estudos publicados propõem modelos numéricos para produção de gás de folhelho em redes complexas de fraturas, buscando também combinar a descrição dessa complexidade com o tempo necessário para simulação computacional. Um dos métodos mais comuns aplicados para caracterização de reservatórios fraturados é o modelo de dupla porosidade/dupla permeabilidade (Yang et al., 2016), considerando que o modelo de rede de fraturas discretas (RFD) - outro modelo tradicional para reservatórios naturalmente fraturados - tem sua aplicação aos folhelhos questionada (Houzé, 2018).

O modelo de dupla-porosidade foi inicialmente tratado por Barenblatt et al. (1960), que assumiu a hipótese de modelo contínuo para a rede de fraturas naturais como equivalente a um meio poroso, de forma figurativa. A partir dessa proposta, são diferenciados dois meios de porosidade: a rede de fraturas e a matriz porosa. A relação entre esses meios se dá pela função de transferência, ou o modo em que a matriz se comunica com as fraturas. Em Warren e Root (1963), são simplificadas as heterogeneidades do meio poroso transformando de forma idealizada o reservatório em blocos, representando a matriz, cujas separações entre blocos seriam as fraturas naturais (Figura 8). O trabalho trouxe uma formulação para a função de transferência e solução aproximada para um modelo de dupla-porosidade. As equações de Warren e Root (1963) foram posteriormente trabalhadas por Kazemi et al. (1976), que incluiu fluxo bifásico e propôs fraturas assumidas em forma ortogonal nas três direções e atuam como limites para elementos da matriz. A formulação da dupla-permeabilidade se diferencia em relação à dupla-porosidade por assumir conexão entre os blocos da matriz, resultando em diferentes caminhos para fluxo de fluido. 

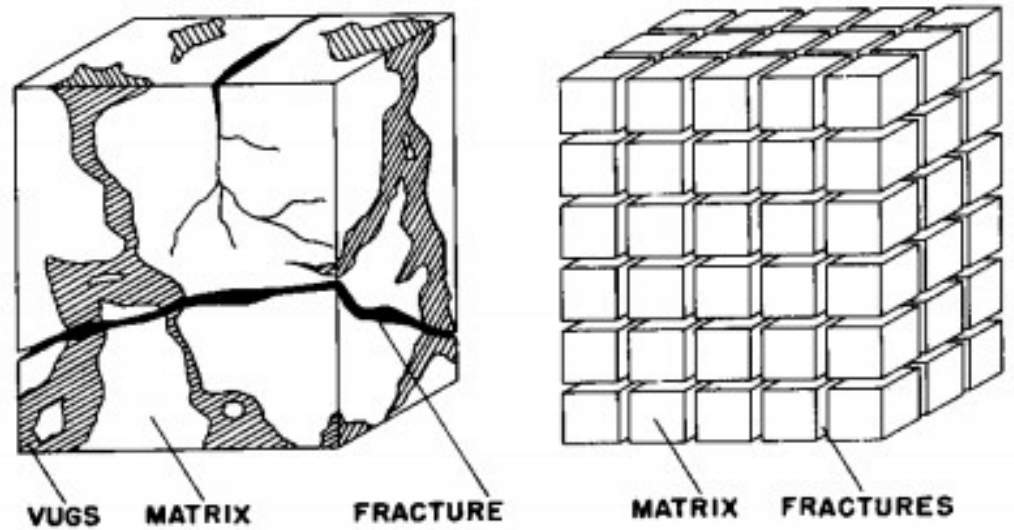

Figura 8. Idealização das heterogeneidades do meio poroso (Warren e Root, 1963).

\subsubsection{Adsorção}

Reservatórios de gás de folhelhos apresentam predominantemente poros em micro e nanoescala, em grande parte com raios inferiores a $10 \mathrm{~nm}$ (Akkutlu e Fathi, 2012). O gás natural fica contido, de maneira geral, como gás livre em poros da matriz e fraturas naturais e como gás adsorvido nas superfícies da matriz, principalmente em argilominerais, cujas proporções podem variar de $20 \%$ a $85 \%$ do total de gás armazenado (Curtis, 2002; Jenkins e Boyer, 2008; Martini et al., 2003; Sun et al., 2013; Wu et al., 2014). O processo de adsorção consiste na acumulação de moléculas de gás na superfície de um sólido e sua capacidade é determinada por métodos de isotermas de adsorção, como os modelos de Langmuir, BET (Brunauer-Emmett-Teller) e Dubinin-Polanyi (Rani et al., 2019). O comportamento do processo de adsorção em um reservatório de gás de folhelho é baseado no seu conteúdo de carbono orgânico total (COT) e na pressão e temperatura da formação. O método das isotermas de Langmuir é o modelo empírico mais utilizado e descreve um aumento progressivo da ocupação da superfície em função da pressão até atingir o limite da capacidade de adsorção, ou seja, quando toda a área da superfície estiver revestida com uma única camada de moléculas (Heller e Zoback, 2014). A isoterma de Langmuir para um gás puro pode ser expressa pela seguinte equação:

$$
V_{P}=\frac{V_{L} \times P}{P_{L}+P}
$$


na qual $\mathrm{V}_{\mathrm{P}}$ é o volume de adsorção à pressão $\mathrm{P}, \mathrm{V}_{\mathrm{L}}$ é o volume de Langmuir que representa a adsorção total à pressão infinita, e $\mathrm{P}_{\mathrm{L}}$ é a pressão de Langmuir, atingida quando metade do volume de Langmuir é adsorvida (Langmuir, 1916).

\subsubsection{Mecanismos de difusão}

Devido às redes de nanoporos dos reservatórios de gás de folhelho, o fluxo convencional da equação de Darcy não descreve com acuracidade o transporte de gás (Javadpour et al., 2007). Considerando as redes de fraturas naturais, a nanoescala dos poros e as formas de armazenamento de gás, o transporte de gás nesses reservatórios pode compreender uma combinação de diferentes mecanismos, como fluxo viscoso, difusão de Knudsen e difusão de superfície, bem como a adsorção/dessorção do gás (Zhao et al., 2018), ilustrados na Figura 9.

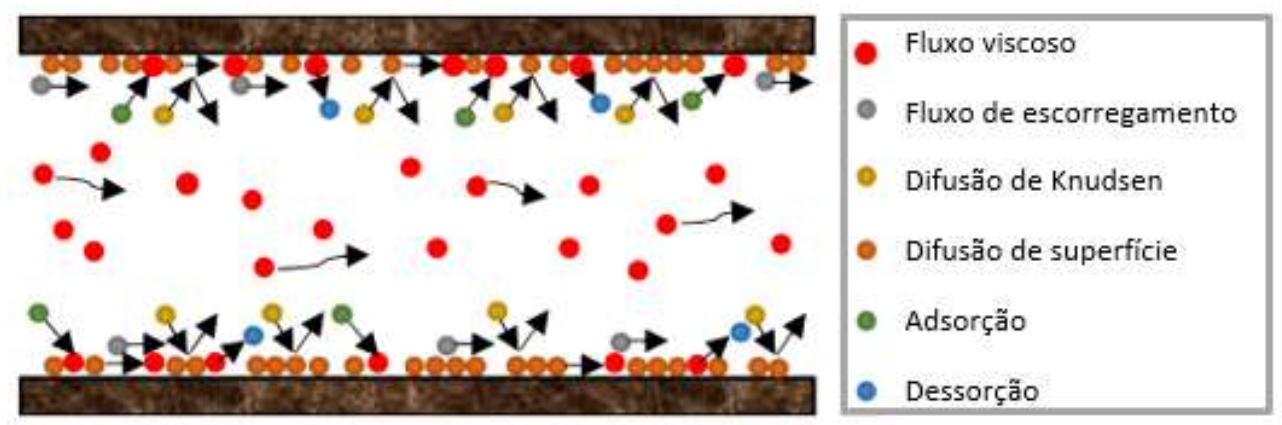

Figura 9. Diagrama esquemático do transporte de gás em reservatórios de gás de folhelho em nanoescala (Zhao et al., 2018).

Entretanto, a descrição precisa do fenômeno de transporte em reservatórios não convencionais ainda é uma área ativa de pesquisa, cuja literatura apresenta frequentemente diversas contradições (Houzé et al., 2018). Somada à variedade de mecanismos de transporte, as diferentes abordagens para escala, como exposto na Figura 10, ampliam os desafios de modelagem de reservatórios de gás de folhelho. Por exemplo, em microporos, o fluxo ocorre de forma semelhante a um reservatório convencional, o 
que permite o uso da Equação de Darcy, com fluxo laminar, porém, nos nanoporos, é necessário utilizar modelos diferenciados, combinando abordagens contínua e molecular.

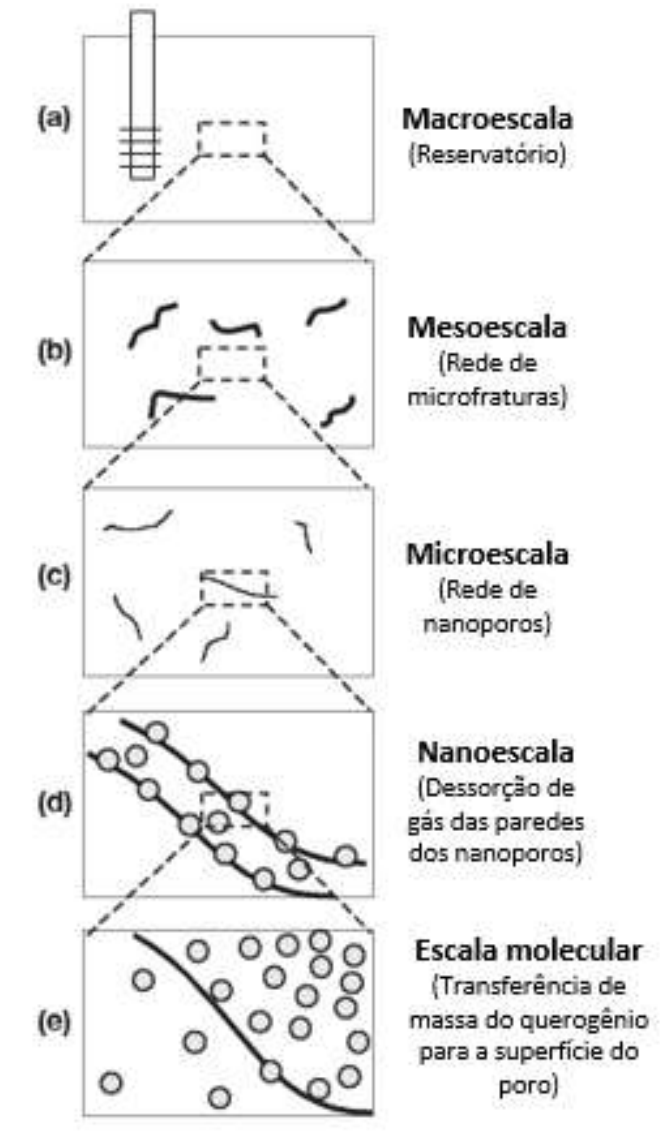

Figura 10. Mecanismos de transporte e armazenamento de gás em reservatórios de gás de folhelho em diferentes escalas (Javadpour et al., 2007).

Entretanto, para obtenção de um modelo prático, são necessárias simplificações, com agrupamentos de escalas (Houzé et al., 2018). Para simplificação dos mecanismos de transporte nos nanoporos, Javadpour et al. (2007) propõem como alternativa para descrição do fluxo a utilização de um coeficiente de difusão constante. 


\subsection{Injeção de $\mathrm{CO}_{2}$ em reservatórios de gás de folhelho}

A matéria orgânica contida nos reservatórios de gás de folhelho propicia processo de adsorção não apenas para o gás natural $\left(\mathrm{CH}_{4}\right)$, mas também para $\mathrm{CO}_{2}$. O grande potencial para armazenamento de $\mathrm{CO}_{2}$ em folhelhos é abordado por Nuttall et al. (2005), que observou que amostras de folhelhos demonstraram adsorção do tipo de Langmuir para $\mathrm{CH}_{4}$ e $\mathrm{CO}_{2}$, com grande preferência de adsorção para o $\mathrm{CO}_{2}$ em relação ao $\mathrm{CH}_{4}$.

Essa característica torna os reservatórios de folhelhos muito atrativos para armazenamento de $\mathrm{CO}_{2}$, considerando que a intensidade da produção de gás de folhelho nos Estados Unidos deixa grandes volumes disponíveis para injeção de fluidos. Ademais, a preferência de adsorção pode servir de mecanismo de recuperação avançada de $\mathrm{CH}_{4}$ (Godec et al., 2014), o que pode trazer uma vantagem econômica à atividade de injeção de $\mathrm{CO}_{2}$.

Como ilustrada na Figura 11, a adsorção preferencial nos reservatórios de gás de folhelho, similar ao que ocorre com o carvão mineral, constitui de forma conceitual devido à insuficiência de estudos em escala de campo - um mecanismo de trapa do reservatório pela adsorção do $\mathrm{CO}_{2}$ na matéria orgânica, além de possibilitar um processo mais eficiente de recuperação avançada de gás (IEAGHG, 2013; Godec et al., 2014).

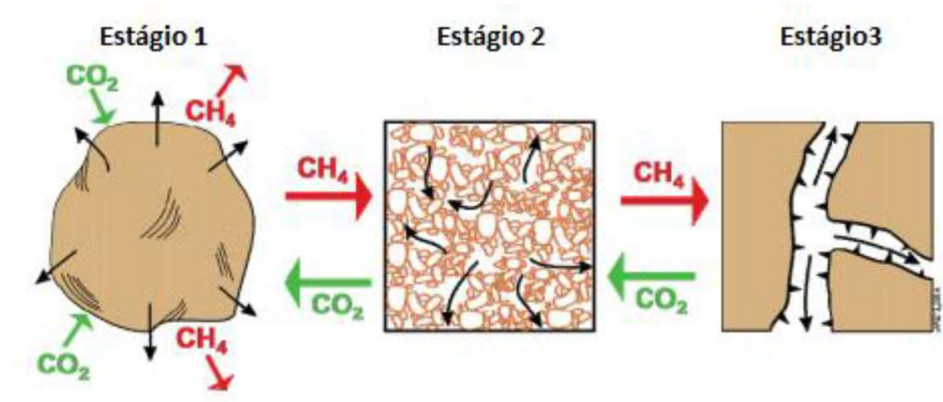

Figura 11. Dinâmica esquemática do fluxo de $\mathrm{CO}_{2}$ e $\mathrm{CH}_{4}$ em folhelhos ricos em matéria orgânica (Godec et al., 2014).

\subsubsection{Mecanismos de trapa e armazenamento de $\mathrm{CO}_{2}$}

Os diferentes contextos geológicos estudados para armazenamento de $\mathrm{CO}_{2}$ variam quanto à combinação dos mecanismos de trapa e, portanto, apresentam variações de 
efetividade. Para as diversas classificações de reservatórios de $\mathrm{CO}_{2}$, como reservatórios de hidrocarbonetos convencionais e aquíferos salinos, os principais mecanismos de trapa são (IPCC, 2005):

- Trapas físicas estruturais, que consistem em deformações na camada de rocha na qual o reservatório está contido, como anticlinais, domos salinos, dobras, falhas entre outros;

- Trapas físicas estratigráficas, formadas pelo contato com camadas de baixa permeabilidade ou por declínio da permeabilidade na própria camada do reservatório;

- Trapas físicas hidrodinâmicas, nas quais o $\mathrm{CO}_{2}$ injetado no fluxo de água da formação é restringido por camadas de baixa permeabilidade acima e abaixo; e

- Trapas geoquímicas, que ocorrem por reações geoquímicas entre o $\mathrm{CO}_{2}$ injetado, a água da formação e a rocha. Essas reações resultam na dissolução do $\mathrm{CO}_{2}$ na água (processo chamado de trapa de solubilidade) e na precipitação do $\mathrm{CO}_{2}$ como novos carbonatos minerais (chamado de trapa mineral).

Os reservatórios mais efetivos são aqueles nos quais o $\mathrm{CO}_{2}$ é aprisionado por camada selante de baixa permeabilidade ou é convertido em mineral sólido ou ainda é adsorvido nas superfícies e microporos de rochas (IPCC, 2005). A Figura 12 mostra a variação da contribuição dos mecanismos de trapa, em reservatórios de diversos contextos, em relação ao tempo posterior ao término da injeção de $\mathrm{CO}_{2}$. 


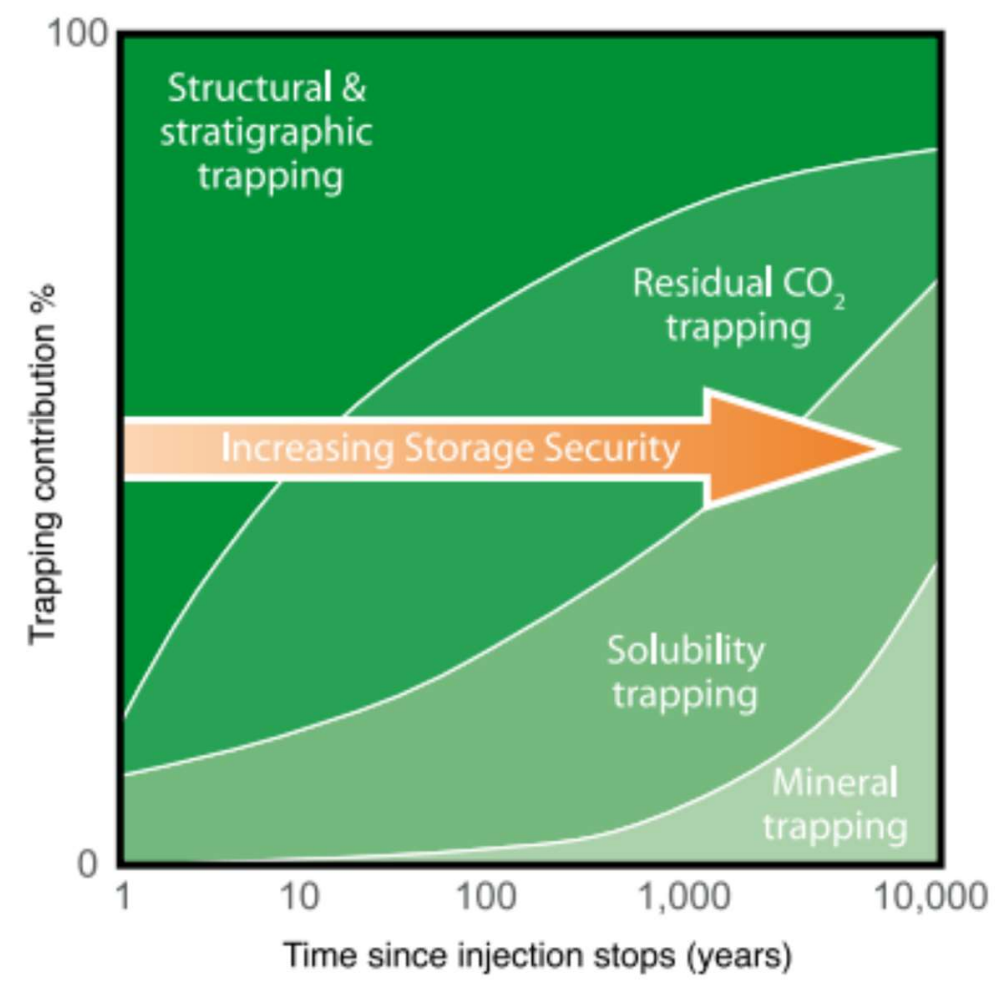

Figura 12. Segurança do armazenamento quanto aos mecanismos de trapa ao longo do tempo (IPCC, 2005).

Apesar desses mecanismos serem possíveis para reservatórios de gás de folhelho, a principal trapa de $\mathrm{CO}_{2}$ nestes tipos de formação seria por adsorção, que pode ser física, na qual os gases e a rocha são ligados por forças de van der Waals, e pode ser química, que envolve o compartilhamento e transferência de elétrons (IEAGHG, 2013). A habilidade dos folhelhos ricos em matéria orgânica de armazenar $\mathrm{CO}_{2}$ devido, notadamente, à capacidade de adsorção foi estudada em diversos trabalhos (Louks et al., 2009; Wang e Reed, 2009; Sondergeld et al., 2010, Ambrose et al., 2010; Kang et al., 2011). Entretanto, as reações $\mathrm{CO}_{2}$-água-rocha, podem desempenhar papel relevante no armazenamento de carbono em folhelhos negros, principalmente se considerados ao longo do tempo. Após sua injeção, o $\mathrm{CO}_{2}$ tende a se estabelecer, em um primeiro momento, por adsorção física e por trapa residual, na fase gasosa ou supercrítica. Mas, no longo termo, o $\mathrm{CO}_{2}$ pode se dissolver em quantidades significativas na água da formação e então passar por mais reações químicas e permanecer estocado, por exemplo, na fase mineral. 
O sistema de armazenamento e trapa de $\mathrm{CO}_{2}$ em reservatórios de gás de folhelho apresenta diferenças em relação à injeção de $\mathrm{CO}_{2}$ tradicionalmente estudada em aquíferos salinos (Liu et al., 2016). A Figura 13 mostra os principais mecanismos que atuam na capacidade e na segurança do processo de armazenamento de $\mathrm{CO}_{2}$ nos folhelhos.
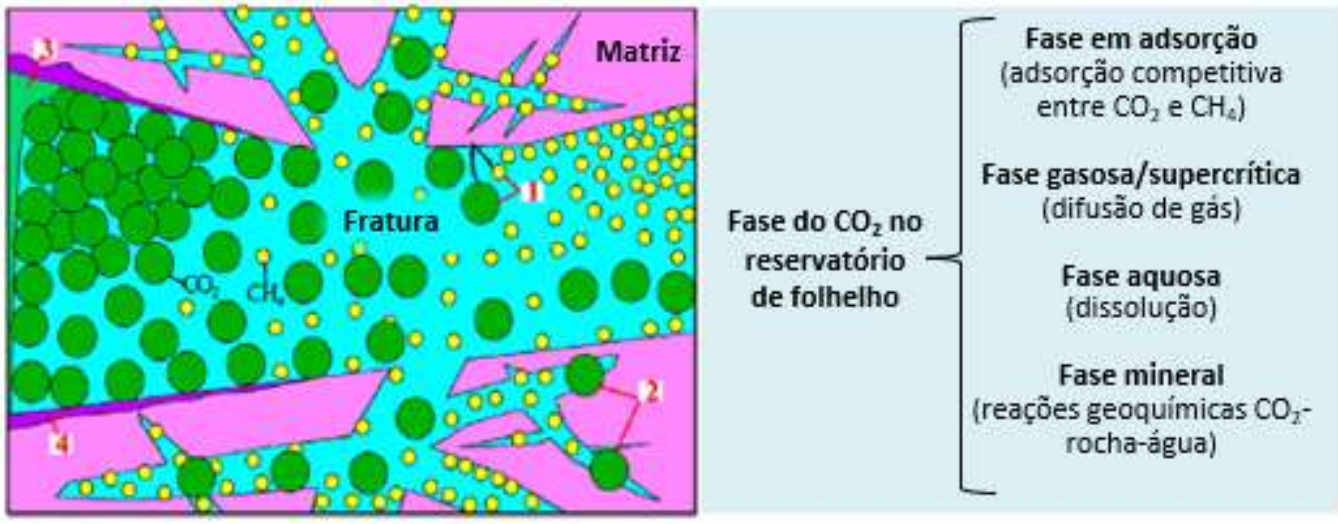

Figura 13. Mecanismos de armazenamento de $\mathrm{CO}_{2}$ e fases do $\mathrm{CO}_{2}$ em um reservatório de folhelho. As fases ilustradas representam o $\mathrm{CO}_{2}$ armazenado: em adsorção; livre gasoso ou em estado supercrítico; em dissolução na fase aquosa; e na fase mineral, devido a reações geoquímicas. Os números indicam os elementos de trapa, sendo: (1) trapa por sorção competitiva, ou preferência de adsorção pelo $\mathrm{CO}_{2}$ em relação ao $\mathrm{CH}_{4}$; (2) trapa residual; (3) trapa por solubilidade; (4) trapa mineral (adaptado de Liu et al., 2016).

\subsubsection{Estudos de simulação numérica de reservatórios para injeção de}

\section{$\mathrm{CO}_{2}$ em reservatórios de gás de folhelhos}

A aplicação de simulação numérica de reservatórios para os estudos de armazenamento geológico de $\mathrm{CO}_{2}$ é uma importante ferramenta para avaliação da viabilidade e capacidade do reservatório para receber o $\mathrm{CO}_{2}$ injetado. Esses estudos também servem como base para decisões operacionais do processo de injeção, fornecendo os parâmetros necessários ao planejamento da engenharia do projeto. Com a caracterização do potencial de armazenamento de $\mathrm{CO}_{2}$ de um determinado local, é possível avaliar o volume de $\mathrm{CO}_{2}$ que pode ser injetado e se o local pode ser acessado, a adequação das propriedades do reservatório à viabilidade econômica do processo de injeção, os riscos de migração e vazamento, entre outros, além de auxiliar na determinação de questões relacionadas a gestão e estratégias de otimização (Andersen, 2017; Saini, 2017). 
Na engenharia de petróleo, a simulação numérica é um dos métodos empregados para levantamento de previsões do comportamento de reservatórios de óleo e gás a partir de soluções numéricas, aplicada comumente por meio de simuladores numéricos de reservatórios, ou, como também são chamados, simuladores numéricos de fluxo. Os simuladores podem ser classificados como volumétricos, composicionais e térmicos, a depender do tratamento matemático utilizado. Em modelos volumétricos - também chamados de tipo Beta ou black oil -, o tratamento matemático está relacionado a funções da pressão e saturação do reservatório e assume que cada fase dos fluidos (água, óleo e/ou gás) é representada por um único componente, enquanto no método composicional, podem ser considerados diversos componentes. Já o modelo térmico é aplicado em situações em que há a necessidade da consideração de efeitos da variação de temperatura no reservatório. Outros métodos de classificação também são utilizados, como pelo número de dimensões (divididos entre unidimensionais, bidimensionais $\mathrm{e}$ tridimensionais) e pelo número de fases (monofásicos, bifásicos e trifásicos). Geralmente, os simuladores numéricos de fluxo utilizam a formulação e solução de equações matemáticas que descrevem processos físicos por meio: (i) da aplicação de um conjunto de leis básicas, como lei da conservação de massa, lei da conservação de energia e lei da conservação de quantidade de movimento; (ii) da descrição matemática de um fenômeno de transporte ligado à natureza do processo; e (iii) das equações de estado adequadas (Rosa et al., 2006). A partir da introdução de informações sobre dados geológicos, propriedades das rochas e fluidos e sobre a produção e método de completação, os simuladores numéricos de reservatórios são aplicados para análise do comportamento do reservatório, determinação do melhor esquema de desenvolvimento do campo, melhoria do conhecimento da geologia do reservatório, entre outras possibilidades também mostradas na Figura 14. 


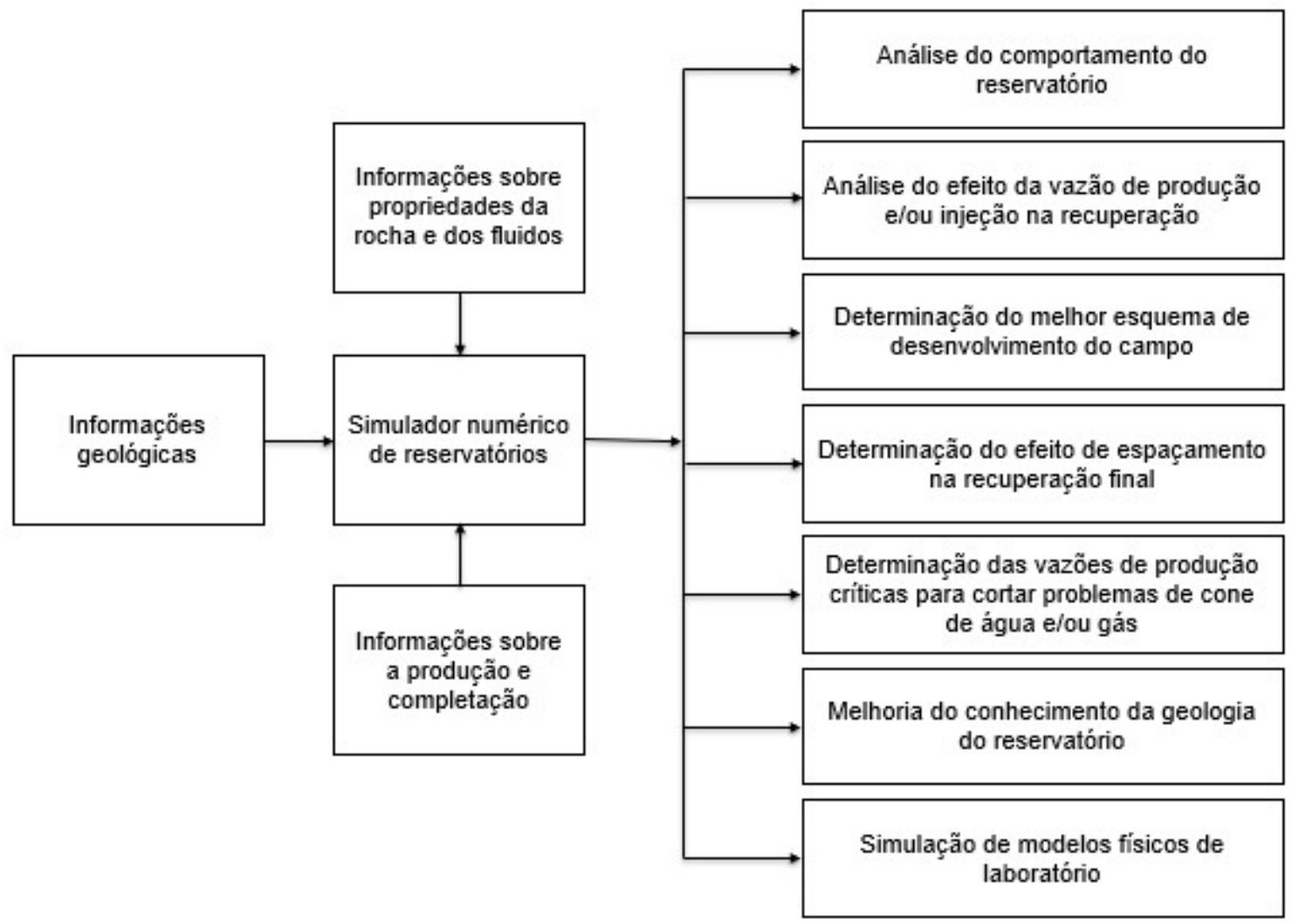

Figura 14. Aplicações de simuladores numéricos de reservatório na engenharia de petróleo (Rosa et al., 2006).

Muitos simuladores numéricos de reservatório possuem funções que permitem a simulação em reservatórios de óleo e gás de folhelho, entre eles GEM, do Computer Modelling Group (CMG), Eclipse 300, da Schlumberger, e COMET3, da Advanced Resources International Inc., apesar de apresentarem limitações (Gholinezhad et al., 2018).

Para avaliações que dizem respeito à capacidade, segurança e estratégias de injeção relacionadas ao armazenamento geológico de $\mathrm{CO}_{2}$, diversos estudos foram realizados com a utilização de simuladores numéricos de reservatórios. Entretanto, grande parte desses estudos trata da injeção de $\mathrm{CO}_{2}$ em reservatórios de aquíferos salinos e o uso de simulação numérica de reservatório para armazenamento geológico de carbono em reservatórios de gás de folhelhos é, na grande maioria dos casos, condicionado ao processo de recuperação avançada de gás.

Em Kalantari-Dahaghi (2010), é apresentado um estudo de viabilidade da aplicação de recuperação avançada de gás e armazenamento de $\mathrm{CO}_{2}$, considerando um modelo 
tridimensional gerado a partir de propriedades típicas de folhelhos, rede de fraturas naturais discreta e fraturamento hidráulico. A simulação numérica inclui refinamento local logarítmico de grid e modelo com multiporosidade, e considera variações das propriedades das fraturas e do reservatório em intervalos consistentes com valores de reservatórios de gás de folhelho. Os resultados mostraram que quase todo o volume de $\mathrm{CO}_{2}$ injetado ficou adsorvido na matriz, o que levou à conclusão de que os reservatórios de gás de folhelho podem ser bons candidatos para armazenamento de $\mathrm{CO}_{2}$.

Eshkalak et al. (2014) compararam o impacto na produção de gás de estratégias de recuperação avançada de gás e da aplicação de refraturamento, em reservatório sintético de gás de folhelho. Os resultados do GEM/CMG se mostraram favoráveis à técnica de refraturamento quando comparada à injeção contínua de $\mathrm{CO}_{2}$ e huff n' puff, como é chamada a técnica de injeção de $\mathrm{CO}_{2}$ em grandes quantidades por poucos dias, seguida de um período de armazenamento de energia e, então, da produção. Apesar de não abordar o volume de $\mathrm{CO}_{2}$ injetado e pouco tratar de armazenamento, o trabalho tem como conclusão a recomendação da combinação entre refraturamento com posterior processo de injeção de $\mathrm{CO}_{2}$, o que poderia implicar em maior potencial para armazenamento.

A eficiência da técnica huff n' puff para recuperação avançada foi analisada em Jiang et al. (2014). Mecanismos de transporte de gás, como fluxo de escorregamento e difusão de Knudsen, mecanismos de armazenamento de $\mathrm{CO}_{2}$, mecanismos de adsorção e dessorção dos gases, permeabilidade dependente da tensão e redes complexas de fraturas naturais foram considerados na simulação. Apesar da conclusão sobre seu baixo potencial para incrementar a produção de metano, huff n' puff é posta como possibilidade viável para armazenamento de carbono, devido aos grandes volumes de $\mathrm{CO}_{2}$ sequestrados em ambos os cenários com variações do tempo de alternância de injeção de $\mathrm{CO}_{2}$.

Zhan et al. (2017) empregaram simulações numéricas no GEM para investigação da viabilidade de sequestro de $\mathrm{CO}_{2}$ em reservatórios de gás de folhelho e quantificar as incertezas associadas, a partir da consideração de mecanismos de fluxo de três estágios. Concluiu-se que um reservatório de gás de folhelho é ideal para armazenamento de $\mathrm{CO}_{2}$, devido a fatores específicos desse tipo de formação e técnicas de produção, notadamente fraturamento hidráulico, adsorção e dessorção multicomponente, fluxo de escorregamento e mecanismos de difusão. 
Kim et al. (2017) examinam os efeitos geomecânicos e de transporte multicomponente para avaliação da injeção de $\mathrm{CO}_{2}$ em reservatórios de gás de folhelho, também para armazenamento e recuperação avançada de gás. O modelo apresentado, que considera adsorção multicomponente, dissolução, difusão molecular e compactação dependente de tensão, foi avaliado em simulação numérica de injeção de $\mathrm{CO}_{2}$ pelos métodos contínuo e huff n' puff, com base em dados da Formação Barnett americana. O modelo foi ainda aplicado a outras formações de folhelho, Marcellus e New Albany Shale. A análise das simulações apontou como principais fatores de influência para a eficiência da injeção de $\mathrm{CO}_{2}$ a permeabilidade das fraturas naturais, comprimento das fraturas hidráulicas, espaçamento entre poços e as constantes de Langmuir.

Outros estudos também analisaram a aplicação dos modelos numéricos desenvolvidos sobre viabilidade do armazenamento de $\mathrm{CO}_{2}$ em determinadas formações geológicas de folhelhos.

Schepers et al. (2009) descrevem a modelagem para produção na Formação Ohio, do período Devoniano, na porção oeste do Estado de Kentucky, nos Estados Unidos, com avaliação de cenários com diferentes espessuras de reservatório e estratégias de injeção de $\mathrm{CO}_{2}$ para recuperação avançada de gás. Essas estratégias consistem em injeção contínua de $\mathrm{CO}_{2}$ e em huffn' puff. O software COMET3 multifásico é utilizado no estudo, com simulação de dupla-porosidade. Dos cenários avaliados, aqueles com injeção contínua apresentaram resultados muito superiores de produção acumulada e fator de recuperação, enquanto os cenários com huff n' puff demonstraram potencial baixo, com resultados abaixo das avaliações sem injeção alguma. Além do resultado positivo da injeção contínua de $\mathrm{CO}_{2}$ para recuperação avançada de gás, a depender da espessura determinada nos cenários, a retenção do $\mathrm{CO}_{2}$ chega à metade do volume total injetado.

A formação de New Albany, de Illinois, nos Estados Unidos, foi a base para modelagem de reservatório em Liu et al. (2013), que investigou a hipótese de injeção de $\mathrm{CO}_{2}$ para armazenamento e recuperação avançada de gás. A avaliação dos folhelhos é realizada em relação à injetividade de $\mathrm{CO}_{2}$, capacidade e efetividade de armazenamento, além do impacto na produção de metano. O modelo com dupla-porosidade, duplapermeabilidade e poços horizontais com fraturamento hidráulico, incorpora também fluxo Darcyano e difusivo, adsorção e dessorção, efeitos de histerese e dissolução de $\mathrm{CO}_{2}$. $\mathrm{O}$ desempenho do processo de injeção simulada no GEM apontou que 95\% do volume 
injetado foi sequestrado efetivamente de forma instantânea, com breakthrough de $\mathrm{CO}_{2}-$ ou a chegada de $\mathrm{CO}_{2}$ ao poço produtor - após cinco anos. O principal mecanismo de armazenamento demonstrado foi por adsorção, enquanto trapas residuais e por solubilidade apresentaram proporções pouco relevantes. A análise de sensibilidade conduzida para parâmetros geológicos e de engenharia apontou maior influência de variações no volume estimulado de rocha e de COT na efetividade do armazenamento. Já a recuperação avançada de metano não impactou de forma significativa o volume total em nenhuma das estratégias de injeção utilizadas (injeção contínua e huff n' puff), não chegando a $1 \%$.

Em Liu et al. (2016), é aplicada simulação numérica de longo termo a um reservatório com características da Formação de Yanchang, da chinesa Bacia de Ordos, promissora para produção de gás e armazenamento de $\mathrm{CO}_{2}$. Com um modelo bidimensional simplificado de transporte reativo em simulador composicional, são estudados os mecanismos de trapa de longo termo em reservatórios de gás de folhelho, considerando as interações entre adsorção de gás e reações $\mathrm{CO}_{2}$-rocha-água. O estudo conclui que, para curto e médio termo, o $\mathrm{CO}_{2}$ é majoritariamente armazenado sob as fases supercrítica (livre) e adsorvida, enquanto, no longo termo, gradualmente o mecanismo de trapa mineral passa a desempenhar papel dominante, que continua a aumentar o sequestro do $\mathrm{CO}_{2}$ sob a fase dissolvida e mineral, reduzindo as fases supercrítica e adsorvida.

Em estudo voltado exclusivamente ao armazenamento de carbono, sem considerar produção de gás, Chen et al. (2015) descrevem um método analítico para estimar a capacidade de armazenamento de $\mathrm{CO}_{2}$ em reservatórios de gás de folhelho depletados, a partir do modelo de fluxo trilinear criado por Ozkan et al. (2009), mas considerando regiões externas com dupla-porosidade, um poço horizontal multifraturado e alguns elementos, como difusão de $\mathrm{CO}_{2}$ de Knudsen, adsorção de $\mathrm{CO}_{2}$ e efeito de sensibilidade à tensão. Com a validação do método, realizada com simulação no ECLIPSE 300 aplicada a um reservatório derivado da Formação New Albany, o trabalho traz resultados de análise de sensibilidade, indicando que o coeficiente de sensibilidade à tensão, o índice de adsorção e o coeficiente de difusão de Knudsen impactam no aumento da capacidade de armazenamento. 


\section{A FORMAÇÃO IRATI}

\subsection{Bacia do Paraná}

A Bacia do Paraná, localizada na porção centro-leste da América do Sul, ilustrada na Figura 15, possui cerca de $1.600 .000 \mathrm{~km}^{2}$ e é preenchida por $5.000 \mathrm{~m}$ aproximadamente de sedimentos paleozoicos, mesozoicos, lavas basálticas e, pontualmente, rochas cenozoicas (Schneider et al., 1974). Abrange o leste do Paraguai, norte da Argentina, norte do Uruguai e os estados brasileiros de São Paulo, Paraná, Santa Catarina, Rio Grande do Sul, Mato Grosso, Mato Grosso de Sul, Goiás e Minas Gerais, totalizando $1.100 .000 \mathrm{~km}^{2}$ no Brasil (Zalán et al, 1990).

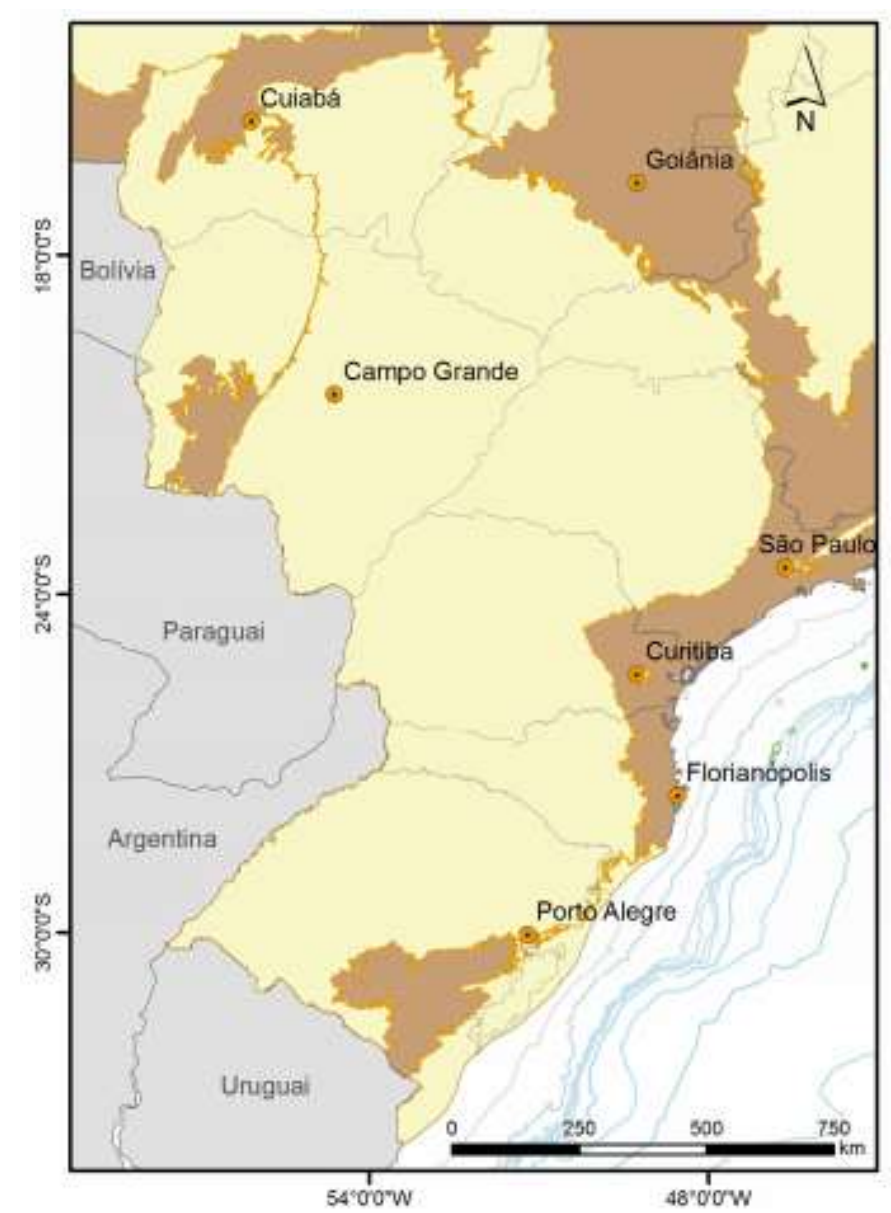

\section{Legenda}
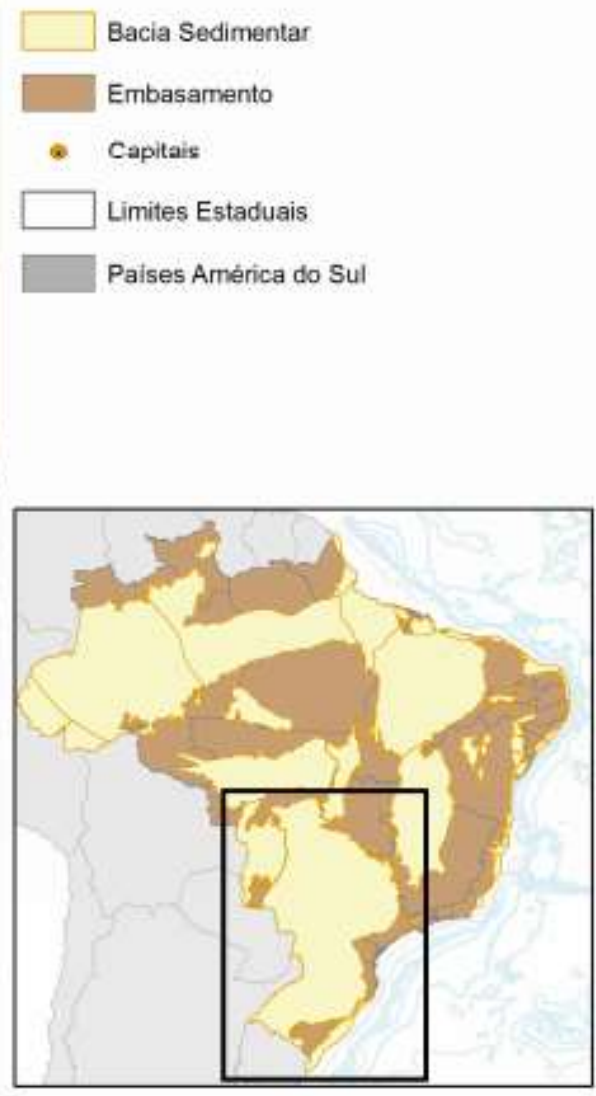

Figura 15. Localização da Bacia do Paraná (ANP, 2017). 
Caracterizada como uma bacia sedimentar intracratônica, a Bacia do Paraná pertence ao contexto geológico paleocontinental de Gondwana, com evolução relativa aos períodos Paleozoico e Mesozoico. A carta estratigráfica de Milani et al. (2007), exposta na Figura 16, traz seis grandes sequências deposicionais: ordovício-siluriana, devoniana, carbonífero-eotriássica, neotriássica, jurássico-eocretácea e neocretácea. As supersequências estratigráficas identificadas por Milani (1998) correspondem ao Rio Ivaí (ordovício-siluriana), Paraná (devoniana), Gondwana I (carbonífero-eotriássica), Gondwana II (meso a neotriássica), Gondwana III (jurássico-eocretácea) e Bauru (neocretácea). As três primeiras supersequências representam ciclos transgressivoregressivos relacionados à oscilação do nível relativo do mar característico do período Paleozoico, enquanto as demais correspondem a pacotes sedimentares continentais mesozoicos associados a intrusões ígneas.

As Figuras 17 e 18 apresentam um mapa geológico simplificado com contorno estrutural do embasamento cristalino e a sequência geológica esquemática da Bacia do Paraná, respectivamente. 


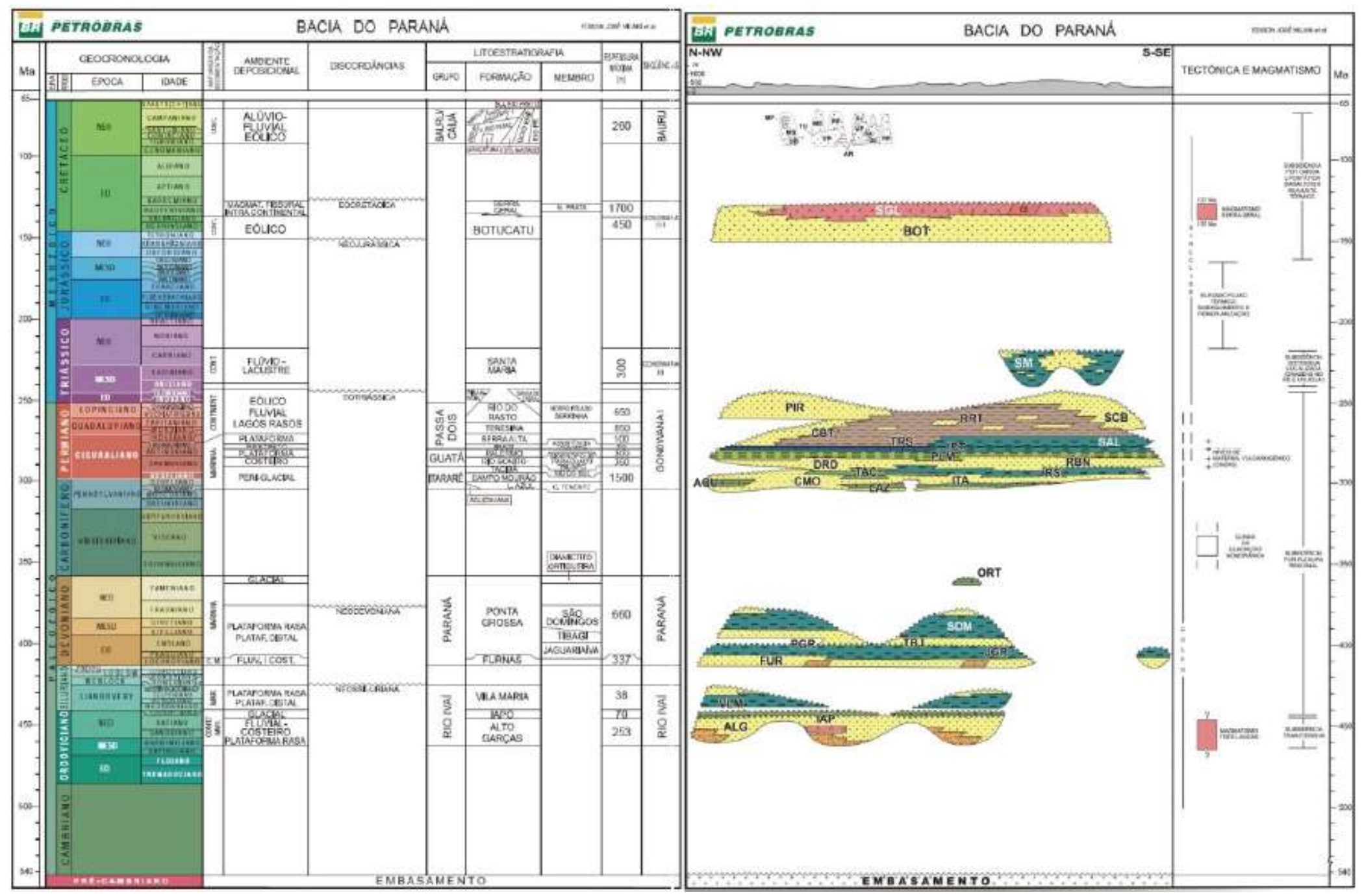

Figura 16. Carta estratigráfica da Bacia do Paraná (Milani et al., 2007). 


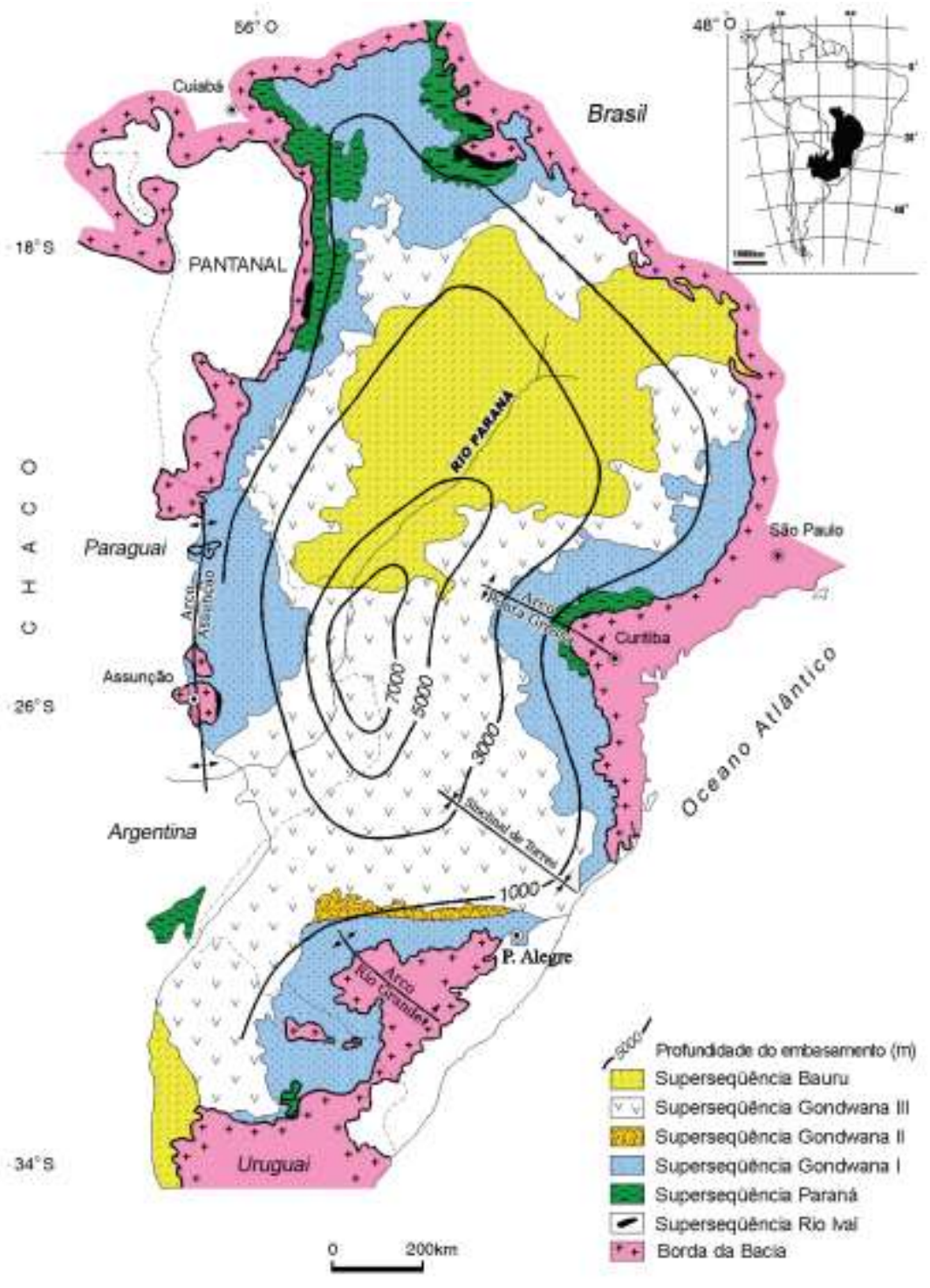

Figura 17. Mapa geológico simplificado da Bacia do Paraná (adaptado de Milani et al., 2006). 


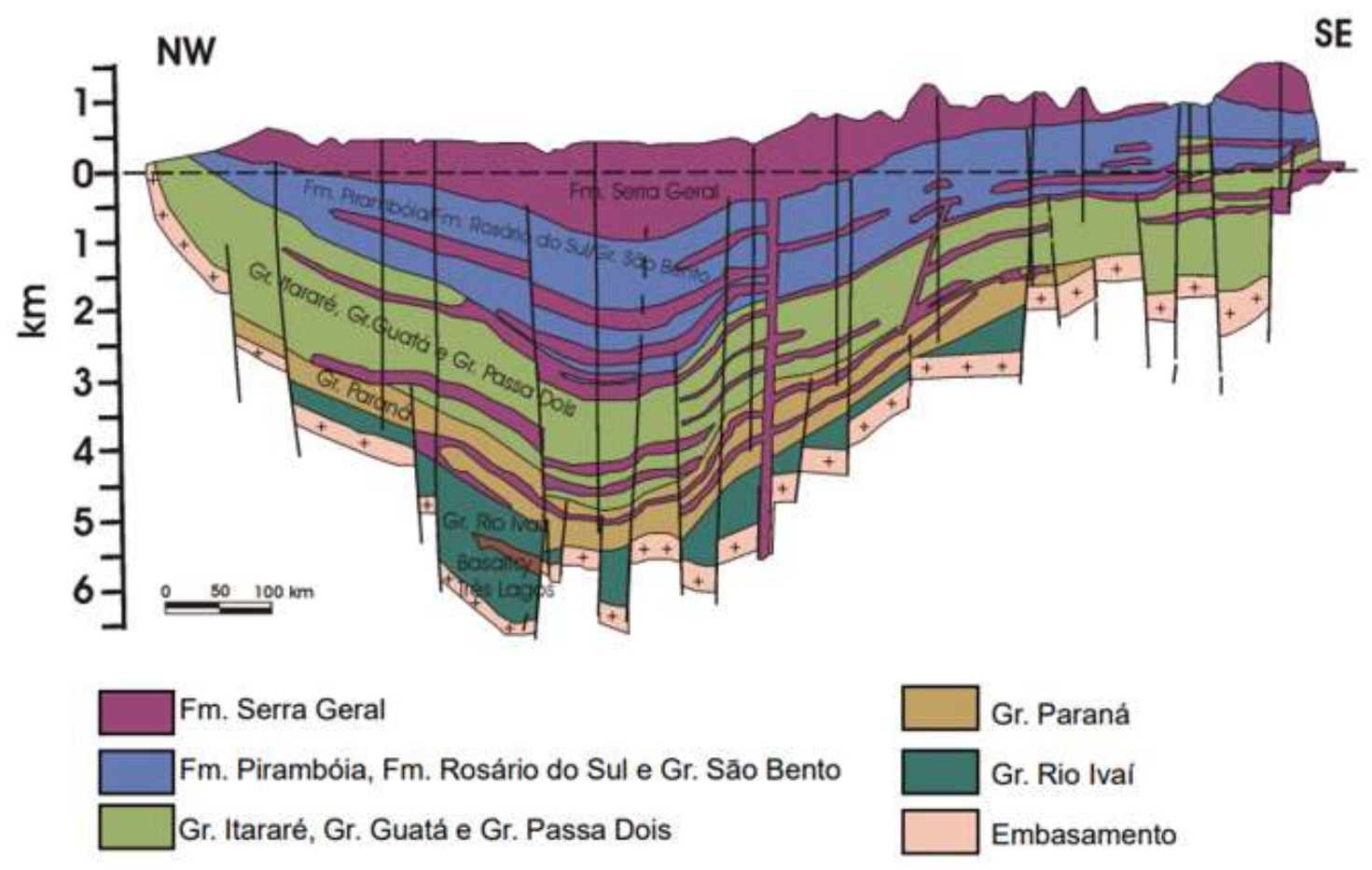

Figura 18. Seção geológica esquemática da Bacia do Paraná (Milani e Zalán, 1998).

$\mathrm{Na}$ Bacia do Paraná existem duas formações de folhelhos que atuam como rochas geradoras, os folhelhos devonianos da Fm. Ponta Grossa e os permianos da Fm. Irati, cujas maturações da matéria orgânica, migração de fluidos e trapeamento estão ligados à presença de corpos ígneos intrusivos (Artur e Soares, 2002). Estas formações constituem os dois sistemas petrolíferos comprovados da Bacia, o Ponta Grossa - Itararé e o Irati Rio Bonito/Pirambóia (ANP, 2017). Os potenciais de geração dos folhelhos em questão foram levantados por da Silva (2007), que, a partir da análise de amostras e comparações com parâmetros geoquímicos e petrofísicos, concluiu que a Fm. Irati apresenta altos teores de riqueza orgânica, com condições entre médias e excelentes para produção e conservação de matéria orgânica, enquanto a Fm. Ponta Grossa apresentou condições baixas e médias.

\subsection{Caracterização da $\mathbf{F m}$. Irati}

A Formação Irati, cujo nome significa "rio do mel" em tupi (Amaral, 1967), pertence à Supersequência Gondwana I e é subdivida entre os membros Assistência (ao topo), constituído por folhelhos e siltitos cinza escuros, e folhelhos pretos betuminosos 
associados a calcários, e Taquaral (à base), com folhelhos cinza, pouco carbonosos e não betuminosos (Hachiro, 1997).

Com espessura média de $40 \mathrm{~m}$, é composta de forma geral por acumulações de carbonatos e evaporitos ao norte da Bacia do Paraná e por folhelhos betuminosos ao sul (Milani et al., 2007). Seus folhelhos ricos em matéria orgânica compõem o sistema petrolífero Irati-Piramboia, junto aos arenitos do permiano-triássico. Sua maturidade termal é bastante variável e os episódios de geração de hidrocarbonetos são relacionados ao magmatismo da Formação Serra Geral, durante o período Cretáceo (Araújo et al., 2000), embora outros eventos de geração, durante o permo-triássico, tenham também sido considerados (Mateus et. al. 2014). As análises de da Silva (2007) apresentaram valores de COT que chegam a 21\%, com média de $2 \%$ e Lisboa (2006), até $14,3 \%$, em análise do membro Assistência. De Souza (2018) também analisou amostras da formação, cujos resultados de COT mostraram uma média de 6,35\%.

Quanto à propriedade de adsorção, Weniger et al. (2010) demonstraram a correlação positiva entre o COT dos folhelhos ricos em matéria orgânica das formações Irati e Ponta Grossa e sorção de CH4 e CO2, como pode ser concluído pela Figura 19. No estudo, são analisadas isotermas de sorção de alta pressão para os dois gases em três amostras da Fm. Irati a $45^{\circ} \mathrm{C}$, cujos registros foram realizados até $20 \mathrm{MPa}$. Os parâmetros de Langmuir resultantes dessa análise são apresentados na Tabela 1.

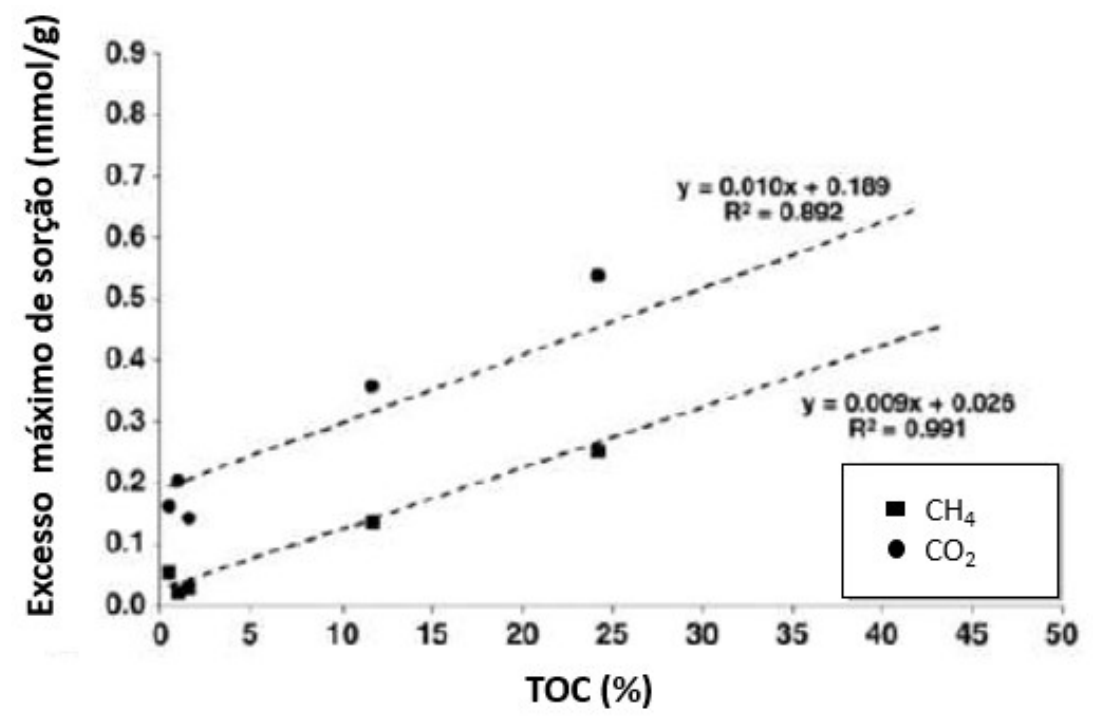

Figura 19. Relação entre excesso máximo de sorção e COT para amostras de folhelhos da Fm. Irati e Fm. Ponta Grossa, com base em testes realizados a $45^{\circ} \mathrm{C}$, entre 8 a $12 \mathrm{MPa}$ (De Souza, 2018, adaptado de Weniger et al., 2010). 
Tabela 1. Resultados de experimentos de adsorção de metano e dióxido de carbono a alta pressão em amostras da Fm. Irati (Weniger et al., 2010), medidos a $45^{\circ} \mathrm{C}$.

${ }^{\mathrm{a}} \mathrm{nL}=$ sorção de Langmuir;

${ }^{\mathrm{b}} \mathrm{PL}=$ pressão de Langmuir.

\begin{tabular}{ccccc}
\hline \multirow{2}{*}{ Amostra } & \multicolumn{2}{c}{$\mathrm{CH}_{4}$} & \multicolumn{2}{c}{$\mathrm{CO}_{2}$} \\
\cline { 2 - 5 } & $\mathrm{n}_{\mathrm{L}}{ }^{\mathrm{a}}(\mathrm{mmol} / \mathrm{g})$ & $\mathrm{P}_{\mathrm{L}}{ }^{\mathrm{b}}(\mathrm{MPa})$ & $\mathrm{n}_{\mathrm{L}}^{\mathrm{a}}(\mathrm{mmol} / \mathrm{g})$ & $\mathrm{P}_{\mathrm{L}}{ }^{\mathrm{b}}(\mathrm{MPa})$ \\
\hline 08_168 & 0,37 & 8,39 & 2,02 & 15 \\
\hline $\mathbf{0 8 \_ 1 7 0}$ & 0,25 & 14,16 & 1,25 & 13,43 \\
\hline 08_154 & 0,04 & 5,65 & 0,65 & 19,9
\end{tabular}

A partir das micrografias obtidas na análise de microscopia eletrônica de varredura (MEV) realizada por De Souza (2018), foi possível observar a presença de microvazios e de porosidades interpartículas, que contribuem para o volume total de microporos das rochas da Fm. Irati. A partir das imagens de MEV, apresentadas na Figura 20, é possível estimar a porcentagem da área ocupada pelos poros em relação à área total. Essa avaliação de porosidade aponta resultados próximos de 4\% para a Figura 20a e 8\% para a Figura $20 \mathrm{~b}$. 

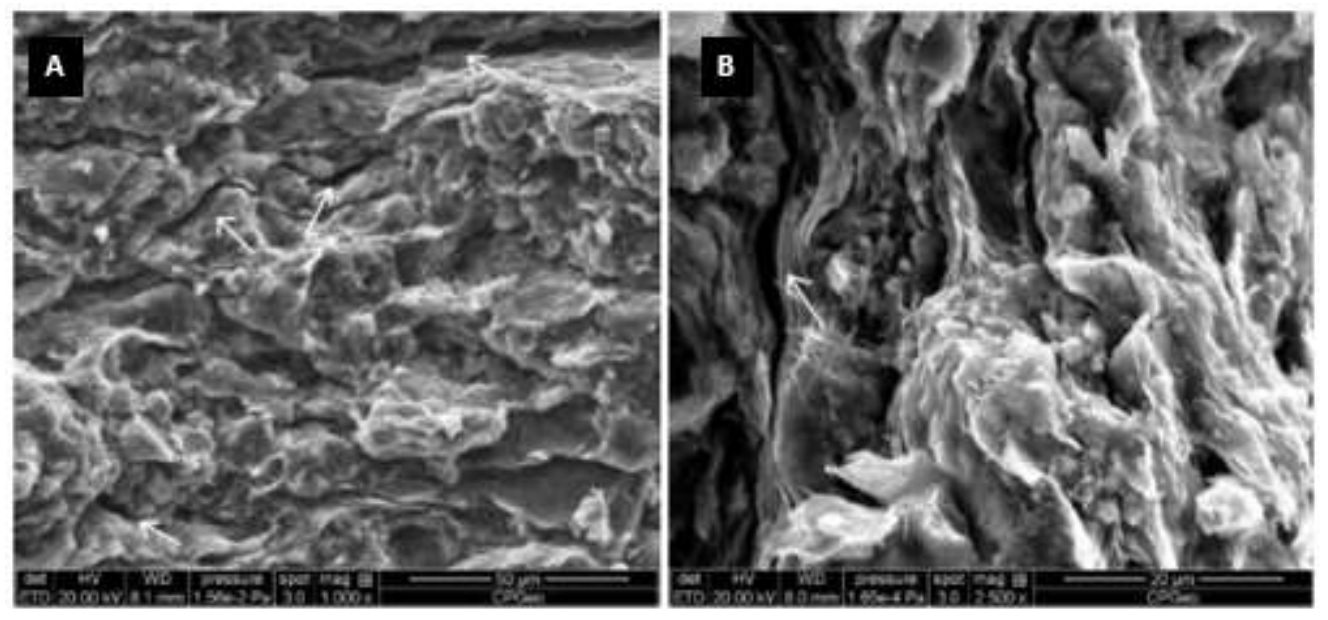

Figura 20. Imagens de microscopia eletrônica de varredura (MEV) de amostras da Fm. Irati, com presença de microvazios entre as placas de argilominerais, poros interpartículas (De Souza, 2018). 


\section{MÉTODO DE TRABALHO}

O desenvolvimento do método de trabalho para obtenção das estimativas da capacidade injeção e custos envolvidos em processo de armazenamento de $\mathrm{CO}_{2}$ na Fm. Irati considerou importantes limitações de disponibilidade de dados e definições. $\mathrm{O}$ acesso a valores da Fm. Irati é bastante restrito devido à baixa atividade de exploração e produção na Bacia do Paraná. Além disso, como tratado anteriormente, a modelagem de reservatórios de gás de folhelho ainda possui grandes lacunas de conhecimento e a aplicação do conceito de injeção de $\mathrm{CO}_{2}$ nessas formações é recente, com poucos estudos dedicados ao objetivo exclusivo de armazenamento. Dessa forma, para compreender as incertezas das características geológicas e considerar o conceito de capacidade de armazenamento, o método construído para o presente estudo pode ser considerado um ponto de partida para obtenção de valores prospectivos para projetos de armazenamento de $\mathrm{CO}_{2}$ em formações geológicas de folhelhos negros pouco exploradas ou com baixa disponibilidade de dados. Também é proposta abordagem para injeção de $\mathrm{CO}_{2} \mathrm{em}$ reservatório de gás não depletado, com base na limitação da pressão de injeção a valores abaixo da pressão de fratura da formação.

\subsection{Etapas do desenvolvimento do trabalho}

O estudo foi realizado em três etapas principais, que consideram atividades relacionadas: (i) ao conjunto de valores atribuídos ou adequados às condições de um reservatório hipotético na Fm. Irati; (ii) às possíveis variações das características assumidas nesse reservatório hipotético; e (iii) à abrangência dos custos finais diante dessas incertezas geológicas.

Para o primeiro grupo de atividades, foram identificados os principais fatores que influenciam na capacidade de armazenamento geológico de carbono, a partir de revisão da literatura. Essa identificação foi utilizada para definição das características geológicas e parâmetros de injeção de $\mathrm{CO}_{2}$ para simulação. Com isso, foram levantadas as informações disponíveis na literatura sobre a Fm. Irati, no que se refere às propriedades de rochas. Devido à relativa baixa atividade de exploração na região e à ausência de histórico de produção na Formação, fez-se necessária a seleção de dados de outra formação de folhelhos negros para complementação de dados. A Fm. Barnett dos Estados 
Unidos foi selecionada devido à sua utilização pela Agência Nacional de Petróleo, Gás Natural e Biocombustíveis (ANP) como referência para estimativa do potencial das formações brasileiras de folhelhos negros para hidrocarbonetos, além da grande disponibilidade de informações na literatura. Posteriormente, foi realizada a construção do modelo geológico base (M0) no módulo Builder, do simulador da Computer Modelling Group (CMG-2017), com a introdução dos dados selecionados para composição do reservatório, além de um poço horizontal com fraturamento hidráulico. Foi então realizada simulação numérica no módulo composicional GEM (Generalized Equation-of-State Model Compositional Reservoir Simulator), da CMG (2017) em 1000 anos, para determinação da capacidade total teórica de injeção de $\mathrm{CO}_{2}$. Para compreensão da influência das características geológicas na capacidade, executou-se uma análise de sensibilidade em função da maximização da injeção de $\mathrm{CO}_{2}$.

Devido às incertezas geológicas, já que parte das informações empregadas no modelo de base não estão disponíveis para a Formação Irati, foram utilizados dados referentes a outra formação e, então, criados modelos limites pessimista e otimista, com valores mínimos $(\mathrm{M}-)$ e máximos $(\mathrm{M}+)$ para as características adotadas da Fm. Barnett relevantes à capacidade de armazenamento de $\mathrm{CO}_{2}$, com base em levantamento de valores de outras formações de folhelhos negros no mundo. Variações para a porosidade da Fm. Irati também foram incluídas nos modelos limites. Esses modelos foram então submetidos à simulação numérica no GEM, para levantar o intervalo de resultados de potencial de capacidade teórica de injeção de $\mathrm{CO}_{2}$.

Para a etapa de estimativa de custos, os resultados das simulações numéricas de reservatório foram utilizados junto à definição da composição de custos, estabelecida com base em levantamento de estudos publicados pertinentes à proposta do trabalho. Por fim, foram calculados os custos totais por poço e o valor mínimo do preço da tonelada de $\mathrm{CO}_{2}$ para que o projeto apresente viabilidade econômica.

De maneira simplificada, as atividades realizadas foram as seguintes:

- Definição das características e valores para simulação numérica de reservatório relativos à Fm. Irati, com complementação da Fm. Barnett;

- Construção e simulação numérica de reservatório do modelo base (M0), em 1.000 anos; 
- Análise de sensibilidade das características do reservatório em função da injeção de $\mathrm{CO}_{2}$;

- Definição das características e valores para os modelos limites mínimo (M-) e máximo $(\mathrm{M}+)$;

- Construção e simulação numérica de reservatório dos modelos limites (M- e M+), em 1.000 anos;

- Definição dos custos de um projeto de poço injetor de $\mathrm{CO}_{2}$; e

- Cálculo dos custos totais por poço e custos por tonelada de $\mathrm{CO}_{2}$ injetado para períodos de 10, 20, 30, 40 e 50 anos de injeção.

\subsection{Modelo geológico base}

O modelo geológico base (M0) tridimensional foi criado no módulo Builder, da CMG, com área de $1.200 \mathrm{~m}$ x $600 \mathrm{~m}$, suficiente para incorporar com segurança o volume de influência de um poço injetor horizontal com fraturamento hidráulico, cujas definições são tratadas no item 4.3. A espessura determinada é de $40 \mathrm{~m}$, apontada por Milani et al. (2007) como valor médio para a Fm. Irati. Por se tratar de um reservatório em formação de folhelho e, portanto, com baixa permeabilidade, o espaço para armazenamento de $\mathrm{CO}_{2}$ fica restrito ao volume estimulado pelos poços e fraturamento hidráulico, possibilitando que a análise por simulação de reservatório seja realizada apenas na área de alcance do poço injetor, considerando uma região sem falhas. O reservatório é inicialmente composto apenas por $\mathrm{CH}_{4}$ e água da formação.

Geralmente, reservatórios com fraturas naturais são representados de forma simplificada por dupla-porosidade, que classifica os valores entre porosidade da matriz e das fraturas, de modo a reduzir consideravelmente o tempo de simulação. Esta simplificação foi adotada neste estudo, considerando a presença de fraturas naturais na Fm. Irati. Para porosidade da matriz, foi calculada a porcentagem aproximada da área ocupada por poros em relação à área total das imagens de MEV da Fm. Irati apresentadas em De Souza (2018). Para o modelo base, foi selecionado o valor intermediário de $6 \%$, enquanto as porosidades obtidas de $4 \%$ e $8 \%$ foram utilizadas posteriormente para os modelos limites. Estes números encontrados estão contidos no intervalo de porosidades médias de potenciais reservatórios de folhelhos negros no mundo. O levantamento das porosidades estimadas nos estudos do órgão americano Energy Information 
Administration (EIA, 2011 e 2013), que avaliou recursos recuperáveis de hidrocarbonetos de formações de folhelhos em 137 formações no mundo, apresentou valores de 1,6\% a $12 \%$. Devido à ausência de dados ou referência para cálculo de porosidade das fraturas naturais da Fm. Irati, foi adotado valor médio encontrado em folhelhos de 0,5\%, apontado em Wang e Reed (2009).

A determinação da profundidade para o modelo base foi lastreada em duas condições principais. A primeira delas diz respeito ao estado físico do $\mathrm{CO}_{2}$ a ser injetado. Para maximizar o volume a ser injetado para armazenamento, o $\mathrm{CO}_{2}$ deve estar em estado supercrítico, ou seja, a pressões e temperaturas acima de 7,38 $\mathrm{MPa}$ e $31,1^{\circ} \mathrm{C}$, assumindo maior potencial para compressão. Esse ponto é atingido a profundidades entre 800 e 850 m, como indicado na Figura 21 (van der Meer, 2005; Holloway e Savage, 1993). Também foi considerada uma margem de segurança de $1.000 \mathrm{~m}$ do Aquífero Guarani, que possui profundidade média de $320 \mathrm{~m}$, de acordo com 50 poços cadastrados no Banco de Dados Hidrogeológicos da extinta Superintendência de Desenvolvimento de Recursos Hídricos

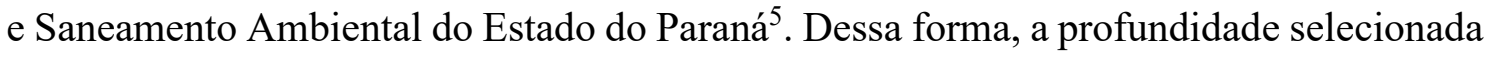
foi de $1.320 \mathrm{~m}$, satisfazendo as condições mencionadas. Apesar da Fm. Irati chegar à profundidade de $3.000 \mathrm{~m}$, optou-se por este valor com maior potencial de ocorrência, para ampliar o espaço de aplicação deste estudo.

\footnotetext{
${ }^{5}$ Instituto das Águas do Paraná. Disponível em: <http://www.aguasparana.pr.gov.br/pagina-57.html>. Acesso em: 02 out. 2019.
} 


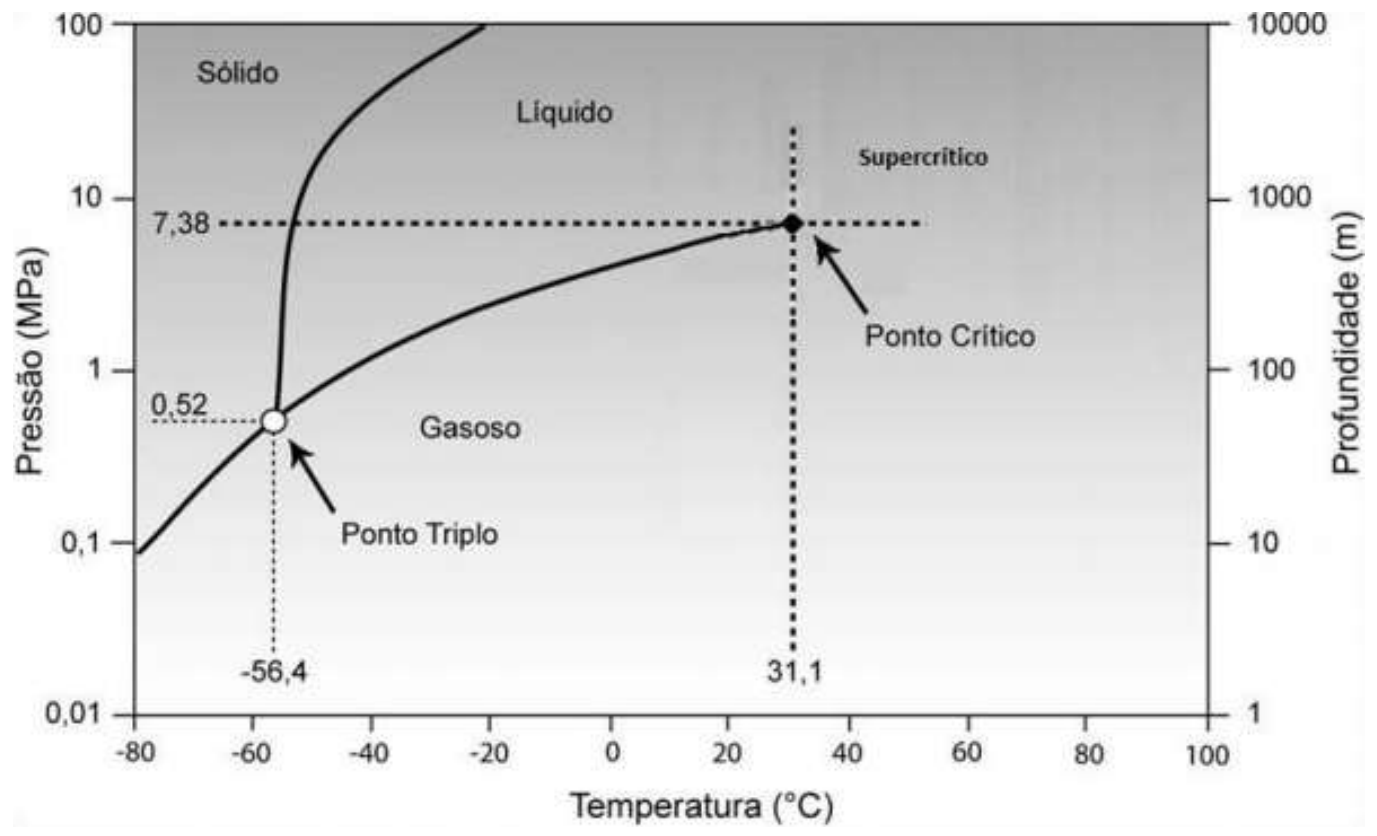

Figura 21. Diagrama de fases do $\mathrm{CO}_{2}$, com indicação do ponto crítico da fase supercrítica (Constant, 2015, adaptado de van der Meer, 2005).

Em relação à pressão do reservatório, foi assumido um gradiente de pressão hidrostática médio de 0,475 psi/ft, referente à Fm. Barnett (Vidas e Hugman, 2008). Este número não difere de valores médios gerais, já que EIA (2013) utiliza como premissa gradientes de pressão de 0,35 a $0,6 \mathrm{psi} / \mathrm{ft}$ de profundidade - posteriormente utilizados nos modelos limites. Sendo $1 \mathrm{psi} / \mathrm{ft}$ o equivalente a $22,621 \mathrm{kPa} / \mathrm{m}$, o reservatório do modelo base com $1.320 \mathrm{~m}$ de profundidade ficou com pressão de $14.183 \mathrm{kPa}$.

O estudo de Gomes (2009), trouxe resultados de recursos geotermais de até $64^{\circ} \mathrm{C}$ para profundidade de $1 \mathrm{~km}$ na Bacia do Paraná. Considerando uma abordagem conservadora, a temperatura adotada foi de $49^{\circ} \mathrm{C}$.

A permeabilidade, considerada extremamente baixa para folhelhos, foi extraída do estudo de Bhandari et al. (2015) com valores da Fm. Barnett, de 0,0000963 mD e $0,0000023 \mathrm{mD}$ para permeabilidades da matriz horizontal e vertical, respectivamente. Para a permeabilidade das fraturas naturais assumiu-se valor utilizado na simulação numérica de reservatórios em Zhu et al. (2017), com base em Heller e Zoback (2014).

Dada a ausência de referências para a saturação de água à profundidade determinada, foi definida uma saturação de gás de $55 \%$, cujo impacto das variações foi incluído nas análises posteriores. 
Os aspectos relevantes para modelagem de reservatórios de gás de folhelho observados no levantamento teórico do presente estudo - rede de fraturas naturais, adsorção e mecanismos de difusão - foram também incorporados aos modelos trabalhados para representação simplificada da Fm. Irati. As redes de fraturas naturais foram incorporadas pela utilização de modelo com dupla-porosidade, distinguindo porosidades e permeabilidades entre matriz e fratura, cujos valores já foram tratados nesta descrição do método.

Os parâmetros de Langmuir adotados foram extraídos de Weniger at al. (2010), que analisou isotermas de amostras da Fm. Irati. Para esse modelo base, foram utilizados os resultados da amostra $08 \_170$, por apresentarem valores intermediários. Convertendo os números de pressão de $\mathrm{MPa}$ para $\mathrm{kPa}^{-1}$ e mantidos os valores de quantidade de substância (mmol/g igual a gmol/kg), tem-se, para o $\mathrm{CH}_{4}$, pressão e volume de Langmuir equivalentes a $0,25 \mathrm{gmol} / \mathrm{kg}$ e $7,062 \times 10^{-5} \mathrm{kPa}^{-1}$ e, para o $\mathrm{CO}_{2}, 1,25 \mathrm{gmol} / \mathrm{kg}$ e $7,45 \times 10^{-5}$ $\mathrm{kPa}^{-1}$.

A incorporação dos mecanismos de difusão, pela dificuldade de aplicação ao software, considerou as simplificações tratadas no levantamento teórico, com agrupamento de escala, dado que a maior parte dos poros em folhelhos é inferior a $10 \mathrm{~nm}$. Com base na escala nanométrica, foi aplicado no GEM recurso para estabelecimento de fluxo não darcyano e coeficientes de difusão constantes para $\mathrm{CH}_{4} \mathrm{e} \mathrm{CO}_{2}$, desprezando os efeitos viscosos. A análise de coeficientes de difusão de $\mathrm{CH}_{4}$ e $\mathrm{CO}_{2}$ de Wang et al. (2017) mostrou variações de $1,4 \times 10^{-7}$ a $1,6 \times 10^{-6} \mathrm{~cm}^{2} / \mathrm{s}$. Outro ponto ponderado foi a diferença entre os dois valores. O coeficiente de difusão do $\mathrm{CO}_{2}$ é menor que o do $\mathrm{CH}_{4}$ sob a mesma pressão (Wang et al., 2017; Ho et al., 2018). Assim, os valores determinados foram $1,0 \times 10^{-6}$ e $0,8 \times 10^{-6}$ para $\mathrm{CH}_{4}$ e $\mathrm{CO}_{2}$, respectivamente.

Por fim, foram acrescentadas outras características importantes para análise de comportamento de reservatórios de gás de folhelho, mas que possuem poucos valores atribuídos a formações reais. Dessa forma, foram empregados números utilizados em outras simulações numéricas de reservatório em folhelhos. São eles: (i) densidade, assumida em $2.550 \mathrm{~kg} / \mathrm{m}^{3}$ por Aguilera (2016) para as Formações Barnett, Marcellus e 


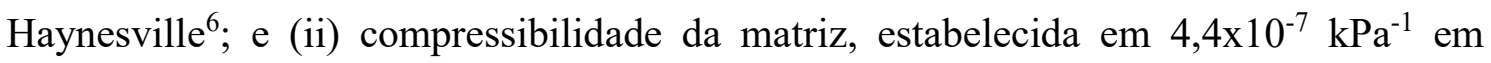
simulação para a Fm. Barnett de Yu et al. (2014).

A Tabela 2 apresenta o resumo dos dados utilizados na construção do modelo base M0.

Tabela 2. Valores utilizados para o reservatório do modelo de base M0.
Característica
Valor
Referência

Dimensões (m)

$1.200 \times 600 \times 40$

(a)

$\begin{array}{lll}\text { Porosidade da matriz (fração) } & 6 \% & \text { De Souza }(2018)^{1}\end{array}$

\begin{tabular}{ccc}
\hline $\begin{array}{c}\text { Porosidade das fraturas } \\
\text { naturais (fração) }\end{array}$ & $0,5 \%$ & Wang e Reed (2009) \\
\hline $\begin{array}{c}\text { Permeabilidade horizontal da } \\
\text { matriz (nD) }\end{array}$ & 96,3 & Bhandari et al. (2015) \\
\hline $\begin{array}{c}\text { Permeabilidade vertical da } \\
\text { matriz (nD) }\end{array}$ & 2,3 & Bhandari et al. (2015) \\
\hline $\begin{array}{c}\text { Permeabilidade das fraturas } \\
\text { naturais (mD) }\end{array}$ & 0,01 & Zhu et al (2017) e Heller e \\
Zoback (2014)
\end{tabular}

${ }^{6}$ A densidade assumida para o modelo a partir de Aguilera (2016) é próxima à densidade média da Bacia do Paraná utilizada em Gomes (2009), de $2650 \mathrm{~kg} / \mathrm{m}^{3}$. 


\begin{tabular}{|c|c|c|}
\hline $\begin{array}{l}\text { Saturação de gás inicial } \\
\text { (fração) }\end{array}$ & $55 \%$ & Aguilera (2016) \\
\hline $\begin{array}{l}\text { Volume de Langmuir } \mathrm{CH}_{4} \\
\qquad(\mathrm{gmol} / \mathrm{kg})\end{array}$ & 0,25 & Weniger et al. (2010) \\
\hline $\begin{array}{l}\text { Pressão de Langmuir } \mathrm{CH}_{4} \\
\qquad\left(\mathrm{kPa}^{-1}\right)\end{array}$ & $7,06215 \times 10^{-5}$ & Weniger et al. (2010) \\
\hline $\begin{array}{l}\text { Volume de Langmuir } \mathrm{CO}_{2} \\
\qquad(\mathrm{gmol} / \mathrm{kg})\end{array}$ & 1,25 & Weniger et al. (2010) \\
\hline $\begin{array}{l}\text { Pressão de Langmuir } \mathrm{CO}_{2} \\
\qquad\left(\mathrm{kPa}^{-1}\right)\end{array}$ & $7,45 \times 10^{-5}$ & Weniger et al. (2010) \\
\hline $\begin{array}{l}\text { Coeficiente de difusão } \mathrm{CH}_{4} \\
\qquad\left(\mathrm{~cm}^{2} / \mathrm{s}\right)\end{array}$ & $1 \times 10^{-6}$ & Wang et al. (2017) \\
\hline $\begin{array}{l}\text { Coeficiente de difusão } \mathrm{CO}_{2} \\
\qquad\left(\mathrm{~cm}^{2} / \mathrm{s}\right)\end{array}$ & $0,8 \times 10^{-6}$ & Wang et al. (2017) \\
\hline Compressibilidade $\left(\mathrm{kPa}^{-1}\right)$ & $4,4 \times 10^{-7}$ & Yu et al. (2014) \\
\hline Densidade $\left(\mathrm{kg} / \mathrm{m}^{3}\right)$ & 2.550 & Aguilera (2016) \\
\hline
\end{tabular}

${ }^{1}$ Valores da tabela calculados com base nas referências citadas;

(a) Área de $1200 \mathrm{~m}$ x $600 \mathrm{~m}$ com base nas dimensões do poço horizontal com fraturas e profundidade de $40 \mathrm{~m}$ de Milani et al. (2007);

(b) Respeito ao mínimo de $800 \mathrm{~m}$ de profundidade e à distância de aquífero;

(c) Calculado com base no gradiente de pressão de Vidas e Hugman (2008).

\subsection{Poço injetor}

Além da seleção de dados das caraterísticas geológicas do reservatório, também foram incluídas definições de parâmetros relacionados à engenharia do poço injetor. 
O comprimento do poço e densidade de estágios do fraturamento hidráulico foram baseados no exemplo de poços com completações mais recentes utilizados na Fm. Barnett, aplicado por EIA (2013) como parâmetro de estimulação de poço intensa para estimativa do fator de recuperação. Foram aproximados para o poço deste estudo 1.000 $\mathrm{m}$ de extensão horizontal (a $90^{\circ}$ ), com 11 estágios. A asa das fraturas alcança $140 \mathrm{~m}$ e a espessura interna, 0,6096 m, valor padrão do GEM. A altura das fraturas foi determinada em 10 m acima e abaixo do poço, deixando uma margem de segurança para não abranger o total de $40 \mathrm{~m}$ de espessura do reservatório.

A determinação do item potencialmente mais crítico do projeto, a pressão de fundo do poço, está relacionada à pressão de fratura da formação, que, por segurança, deve ser superior à pressão total do reservatório após o término do período de injeção de $\mathrm{CO}_{2}$. A pressão de injeção também é o principal fator que limita a vazão de injeção. Em revisão de estudos de injeção de $\mathrm{CO}_{2}$ em reservatórios de gás de folhelho depletados, $\mathrm{Du}$ e Nojabei (2019) relatam definições de restrição da vazão entre 100 e 5000 Mscf/d, o mesmo que 2.832 e $283.168 \mathrm{~m}^{3} / \mathrm{d}$. Todavia, esses estudos buscam determinar o limite da vazão em função da recuperação avançada de gás e óleo, o que tende a resultar em vazões inferiores quando em comparação à proposta de injeção apenas para armazenamento de $\mathrm{CO}_{2}$. Hoteit et al. (2019) utilizam limite de vazão entre 15 e $50.000 \mathrm{Mscf} / \mathrm{d}$ (424.753 e $1.415 .842 \mathrm{~m} / \mathrm{d}$ ) para análise de injeção de $\mathrm{CO}_{2}$ exclusivamente para armazenamento. Para injeção em reservatórios não depletados, é possível estabelecer paralelo com estudos de aquíferos salinos, já que os reservatórios de hidrocarbonetos são tradicionalmente estudados como alvo de injeção depois de depletados. De maneira geral, a vazão de injeção de $\mathrm{CO}_{2}$ para aquíferos salinos é limitada pela pressão de injeção, que respeita a pressão de fratura da formação (Szulczewski, 2009). Essa abordagem pode ser considerada conservadora, pois a propagação de fraturas pode ser benéfica para a capacidade do armazenamento, mas pode ser um bom parâmetro por priorizar a segurança do armazenamento.

Para o cálculo da pressão de fratura, devido à ausência de estudos com esse propósito na Fm. Irati, foi considerado um gradiente de fratura médio para formações de folhelhos, que varia entre 0,5 e 1,0 psi/ft (11,31 a 22,62 kPa/m) (Halliburton, 2008). Estes valores foram então considerados para os modelos limites, enquanto a média de $0,75 \mathrm{psi} / \mathrm{ft}$ $(16,97 \mathrm{kPa} / \mathrm{m})$ foi selecionada para o modelo base. Portanto, multiplicando esse gradiente pela profundidade determinada no item anterior $(1.320 \mathrm{~m})$, obtém-se uma pressão de 
fratura de 990 psi, equivalente a $22.395 \mathrm{kPa}$. Apesar da escassa abordagem de estudos científicos tratando de metodologia para determinação da pressão de injeção de $\mathrm{CO}_{2} \mathrm{em}$ reservatórios de folhelhos para estocagem de $\mathrm{CO}_{2}$, a relação entre a pressão de fratura calculada e a pressão original do reservatório possui paralelos quando comparada com as relações de Zhao et al. (2018) e Wanniarachchi et al. (2017). No primeiro, em uma análise do impacto da depletação de reservatórios de gás de folhelho na pressão de fratura, as pressões de fratura são de $10 \%$ a $80 \%$ maiores que as pressões iniciais dos reservatórios, considerando possíveis anisotropias de parâmetros geomecânicos. Já em Wanniarachchi et al. (2017), essa proporção chega a até 160\%. Assim, o valor calculado para pressão de fratura do reservatório hipotético da Fm. Irati encontra-se dentro desse intervalo, com uma relação de $60 \%$. Essa comparação e constatação de valores compatíveis com estudos em outras formações é um importante indicativo da escolha de números conservadores e adequados, já que este parâmetro - a pressão de fratura - exerce grande impacto no potencial de capacidade de armazenamento de $\mathrm{CO}_{2}$. Finalmente, considerando uma margem de segurança de $1.000 \mathrm{kPa}$, a pressão de fundo do poço resultante foi $21.395 \mathrm{kPa}$ para o modelo base.

A Tabela 3 resume os valores assumidos para o poço incluído no modelo base e as Figuras 22 e 23 apresentam imagens do modelo no Builder.

Tabela 3. Valores utilizados para o poço injetor com fraturamento hidráulico do modelo base M0.

\begin{tabular}{cc}
\hline Característica & Valor \\
\hline Comprimento do poço $(\mathrm{m})$ & 1.000 \\
Número de estágios do fraturamento hidráulico & 11 \\
Asa das fraturas $(\mathrm{m})$ & 140 \\
Espessura interna das fraturas $(\mathrm{m})$ & 0,6096 \\
Altura das fraturas $(\mathrm{m})$ & 20 \\
Pressão máxima no fundo do poço $(\mathrm{kPa})$ & 21.395
\end{tabular}




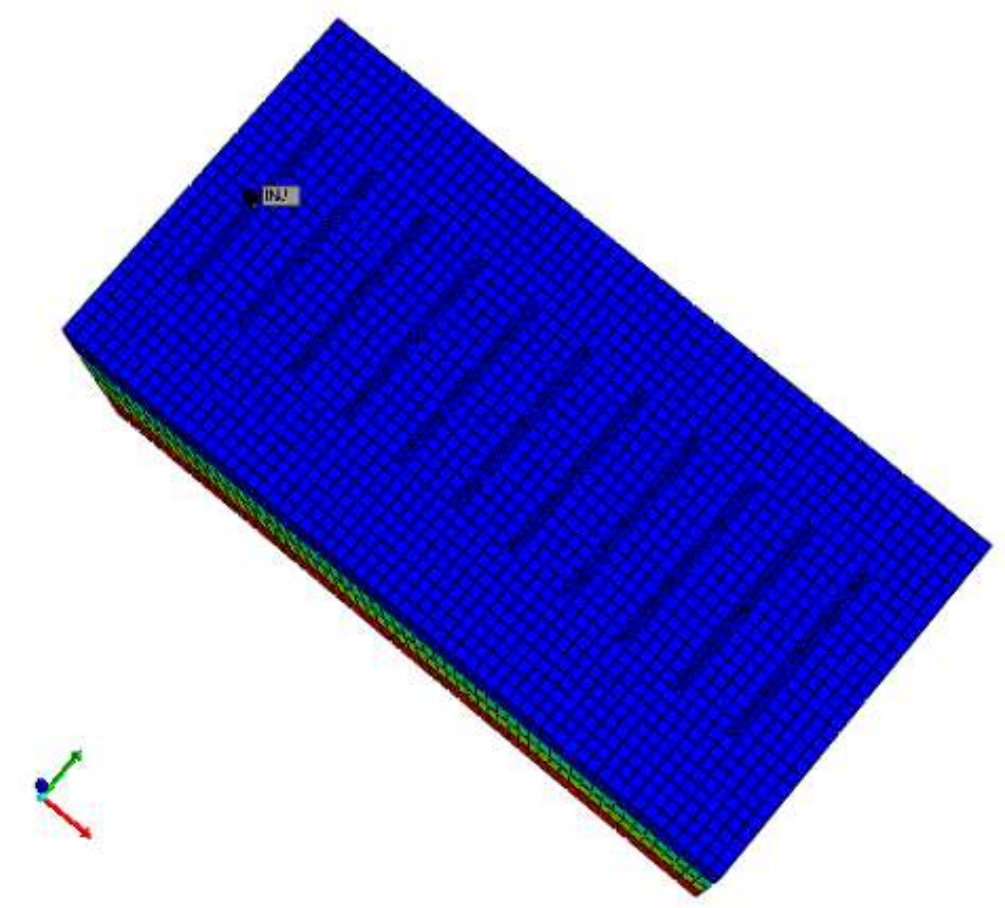

Figura 22. Imagem do modelo M0 no Builder, referente ao reservatório hipotético na Fm. Irati.

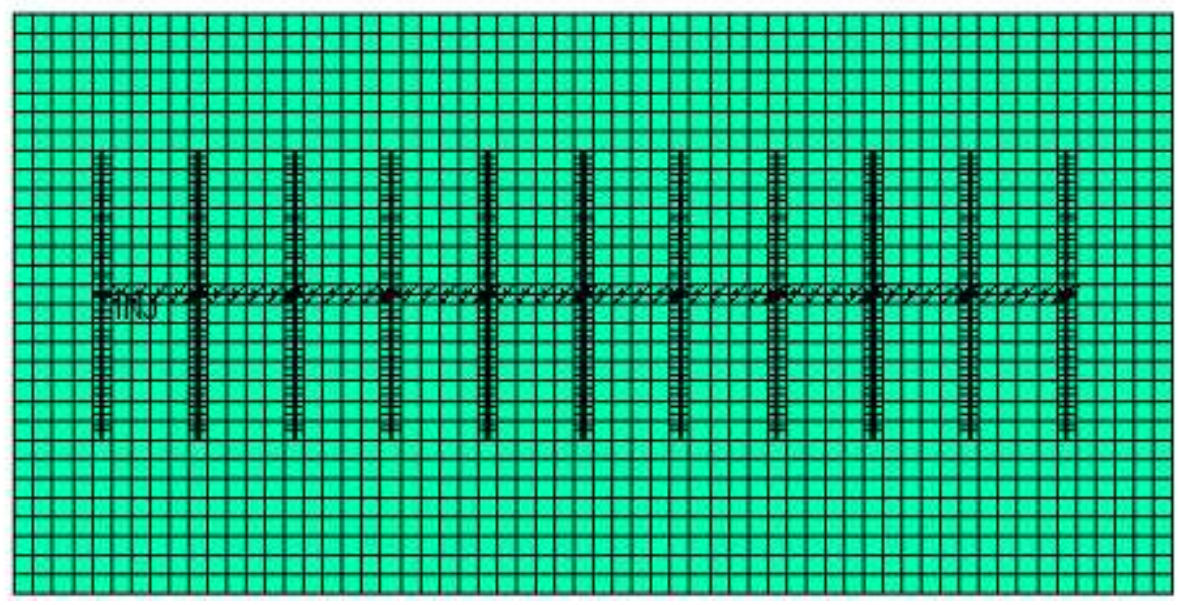

Figura 23. Vista bidimensional da camada com o poço injetor, no Builder.

\subsection{Parâmetros para análise de sensibilidade}

A influência das características geológicas do reservatório na capacidade de armazenamento de $\mathrm{CO}_{2}$ também foi examinada neste trabalho. Por se tratar de abordagem relativamente nova, há poucos estudos com este intuito aplicado a reservatórios de 
folhelhos. É possível estabelecer paralelos com importantes fatores considerados na avaliação de acumulações de hidrocarbonetos em reservatórios convencionais, como porosidade, permeabilidade e pressão. Entretanto, por se tratar de reservatórios não convencionais, consideramos também a estimulação de volume por fraturamento hidráulico e propriedades geoquímicas, notadamente a capacidade de adsorção de $\mathrm{CO}_{2}$ na matéria orgânica.

Para contribuir com o conhecimento do comportamento de reservatórios não convencionais como receptores de $\mathrm{CO}_{2}$ para armazenamento, foi realizada uma análise de sensibilidade das características geológicas em função da maximização do volume de injeção de $\mathrm{CO}_{2}$. Foram variadas espessura, porosidade, permeabilidade, pressão, temperatura, saturação de gás inicial e coeficiente de difusão do $\mathrm{CO}_{2}$, compressibilidade e densidade, em 20\% para mais e para menos, durante 10 anos de injeção. As variações de pressão foram acompanhadas proporcionalmente pelas variações na pressão de fundo de poço, $60 \%$ maiores. A Tabela 4 apresenta os valores assumidos para as características determinadas.

Tabela 4. Parâmetros assumidos para análise de sensibilidade das características geológicas do reservatório não convencional (M0), em função da injeção de $\mathrm{CO}_{2}$.

\begin{tabular}{cccc}
\hline Variável & $\mathbf{- 2 0 \%}$ & Base & $\mathbf{2 0 \%}$ \\
\hline Espessura $(\mathrm{m})$ & 30 & 40 & 50 \\
\hline Porosidade (fração) & $4,8 \%$ & $6,0 \%$ & $7,2 \%$ \\
\hline Permeabilidade $(\mathrm{mD})$ & $7,70 \times 10^{-5}$ & $9,63 \times 10^{-5}$ & $1,16 \times 10^{-4}$ \\
\hline Pressão $(\mathrm{kPa})$ & 11346,4 & 14183,0 & 17019,6 \\
\hline Temperatura $\left({ }^{\circ} \mathrm{C}\right)$ & 39,2 & 49 & 58,8 \\
\hline Saturação de gás $(\mathrm{fração})$ & $44 \%$ & $55 \%$ & $66 \%$ \\
\hline Coeficiente de difusão $\mathrm{CO}_{2}\left(\mathrm{~cm}^{2} / \mathrm{s}\right)$ & $6,4 \times 10^{-7}$ & $8,0 \times 10^{-7}$ & $9,6 \times 10^{-7}$ \\
\hline Compressibilidade $\left(\mathrm{kPa}^{-1}\right)$ & $3,52 \times 10^{-7}$ & $4,40 \times 10^{-7}$ & $5,28 \times 10^{-7}$ \\
\hline Densidade $\left(\mathrm{kg} / \mathrm{m}^{3}\right)$ & 2040 & 2550 & 3060 \\
\hline
\end{tabular}




\subsection{Modelos geológicos limites}

Devido à necessidade de recorrer em muitos dos valores do reservatório aos dados da Fm. Barnett, que ocorre na Bacia de Fort Worth no Texas (Pollastro et. al. 2007), similar geologicamente à Formação Irati, este trabalho buscou incorporar na avaliação do potencial de armazenamento de $\mathrm{CO}_{2}$ na Fm. Irati a imprecisão quanto às características geológicas com a criação de modelos limites, que consideram valores mínimos (M-) e máximos $(\mathrm{M}+)$ para outras formações de reservatórios de folhelhos negros em todo o mundo. Para essa análise do potencial intervalo de capacidade de armazenamento de $\mathrm{CO}_{2}$ para a Fm. Irati, foram variadas, a partir do modelo base (M0), as seguintes características:

- Porosidade, de acordo com os valores estimados para a Fm. Irati, de 4\% a 8\%;

- Permeabilidade, com base na variação máxima assumida em EIA (2013), de 0,00001 a $0,001 \mathrm{mD}$;

- Pressão, com variações de gradientes de pressão assumidos em EIA (2013) para subpressão de 0,35 psi/ft e sobrepressão de 0,6 psi/ft, aplicados à profundidade de $1.320 \mathrm{~m}$;

- Saturação inicial de gás, que, devido à dificuldade de encontrar valores para saturação de água na literatura, foram utilizados como base os valores calculados em Aguilera (2016) para as formações de Barnett, Marcellus e Haneysville, que variam de $35 \%$ a $45 \%$, aproximadamente. Com margem de segurança, as variações foram fixadas de $30 \%$ a $50 \%$;

- Parâmetros de Langmuir, extraídos de Weniger et al. (2010) para Fm. Irati, com as amostras 08_168 e 08_154. O modelo pessimista ficou com volume de 0,04 gmol $/ \mathrm{kg}$ e pressão de $1,77 \times 10^{-4} \mathrm{kPa}^{-1}$ para $\mathrm{CH}_{4}$ e $0,65 \mathrm{gmol} / \mathrm{kg}$ e $5,03 \times 10^{-5} \mathrm{kPa}^{-1}$. O otimista, com $0,37 \mathrm{gmol} / \mathrm{kg}$ e $1,19 \times 10^{-4} \mathrm{kPa}^{-1}$ para $\mathrm{CH}_{4}$ e $2,02 \mathrm{gmol} / \mathrm{kg} \mathrm{e}$ $6,67 \times 10^{-5} \mathrm{kPa}^{-1}$ para $\mathrm{CO}_{2}$; e

- Pressão de fundo do poço, seguindo o mesmo raciocínio estabelecido para M0, com os gradientes de fratura variando de 0,5 a 1,0 psi/ft (Halliburton, 2008).

A Tabela 5 apresenta os valores trabalhados na construção dos modelos limites. 
Tabela 5. Definição dos valores mínimos e máximos das características geológicas para composição dos cenários limites $\mathrm{M}-\mathrm{e} \mathrm{M}+$.

\begin{tabular}{|c|c|c|c|c|}
\hline Variável & M- & Base & $\mathbf{M}+$ & Referência \\
\hline Porosidade (fração) & $4 \%$ & $6 \%$ & $8 \%$ & De Souza $(2018)^{1}$ \\
\hline Permeabilidade (mD) & 0,00001 & 0,0000963 & 0,001 & EIA (2013) \\
\hline Pressão $(\mathrm{kPa})$ & 10.451 & 14.183 & 17.916 & (a) \\
\hline Saturação de gás (fração) & $50 \%$ & $55 \%$ & $70 \%$ & Aguilera (2016) \\
\hline $\begin{array}{l}\text { Volume de Langmuir } \mathrm{CH}_{4} \\
\qquad(\mathrm{gmol} / \mathrm{kg})\end{array}$ & 0,04 & 0,25 & 0,37 & $\begin{array}{l}\text { Weniger et al. } \\
\qquad(2010)\end{array}$ \\
\hline Pressão de Langmuir $\mathrm{CH}_{4}\left(\mathrm{kPa}^{-1}\right)$ & $1,77 \times 10^{-4}$ & $7,062 \times 10^{-5}$ & $1,19 \times 10^{-4}$ & $\begin{array}{l}\text { Weniger et al. } \\
\qquad(2010)\end{array}$ \\
\hline $\begin{array}{l}\text { Volume de Langmuir } \mathrm{CO}_{2} \\
\qquad(\mathrm{gmol} / \mathrm{kg})\end{array}$ & 0,65 & 1,25 & 2,02 & $\begin{array}{l}\text { Weniger et al. } \\
\qquad(2010)\end{array}$ \\
\hline Pressão de Langmuir $\mathrm{CO}_{2}\left(\mathrm{kPa}^{-1}\right)$ & $5,03 \times 10^{-5}$ & $7,45 \times 10^{-5}$ & $6,67 \times 10^{-5}$ & $\begin{array}{l}\text { Weniger et al. } \\
\qquad(2010)\end{array}$ \\
\hline Pressão no fundo do poço $(\mathrm{kPa})$ & 13.930 & 21.395 & 28.860 & (b) \\
\hline
\end{tabular}

alculado com base na referência da tabela.

(a) Calculado com base nos gradientes de pressão de EIA, (2013);

(b) Calculado com base na relação entre pressão de fratura e pressão da formação.

\subsection{Composição de custos}

Considerando a inexistência de poços terrestres com fraturamento hidráulico e de regulações relativas às atividades de CCS no Brasil, a análise da literatura de avaliação econômica de armazenamento de carbono foi realizada com parâmetros aplicados em outros países. Dessa forma, optou-se pela utilização dos valores estabelecidos em Bielicki et al. (2018), publicação recente do International Journal of Greenhouse Gas Control, que trata especificamente de injeção de $\mathrm{CO}_{2}$ para armazenamento - sem considerar recuperação avançada de hidrocarbonetos -, em reservatórios de folhelhos negros, 
comparando também com aquíferos salinos. Os custos são determinados pela seguinte composição:

- Fixos de hub: avaliações iniciais e equipamentos de superfície;

- Fixos de operação e manutenção (O\&M) de hub: custos gerais e administrativos (G\&A) e pesquisas anuais;

- Fixos de poço: custos iniciais de avaliação da integridade do poço, custos do equipamento da cabeça de poço e cuidados pós-injeção;

- Fixos de O\&M de poço: equipamentos de monitoramento, custos G\&A, inspeção de revestimento e testes de integridade mecânica para vazão e pressão; e

- Variáveis de poço: monitoramento e cuidados pós-injeção no local, transporte de $\mathrm{CO}_{2}$ do hub para o poço e injeção.

Por se tratar de análise econômica para armazenamento de carbono em poços de formações geológicas dos Estados Unidos, os custos fixos de poço consideram a reutilização de poços anteriormente produtores para injeção do $\mathrm{CO}_{2}$. Assim, tais custos apresentariam maior discrepância em relação à aplicação no Brasil, já que não existem poços produtores para reaproveitamento na Fm. Irati. Para estimar o custo de construção de um poço novo foi assumido um valor 50\% maior que o custo de um poço reaproveitado.

Os custos em dólares atribuídos ao projeto de injeção constam abaixo, na Tabela 6.

Tabela 6. Custos atribuídos ao projeto de poço injetor (adaptado de Bielicki et al., 2018).

\begin{tabular}{cc} 
Custos & Valor \\
\hline $\begin{array}{c}\text { Fixos de hub (mil dólares) } \\
\text { Fixos de operação e manutenção de hub (mil } \\
\text { dólano) }\end{array}$ & 400 \\
Fixos de poço (mil dólares) & 400 \\
\hline
\end{tabular}


Fixos de operação e manutenção de poço (mil

dólares/ano)

Variáveis de poço (dólares/ $\mathrm{tCO}_{2}$ )
500

0,5

Por fim, a análise de custos foi estabelecida para períodos de 10, 20, 30, 40 e 50 de injeção de $\mathrm{CO}_{2}$, cujos resultados são extraídos dos resultados das simulações de reservatórios dos modelos M-, M0 e M+, e considera a dedução dos custos de capital (CAPEX) relativos a custos fixos de hub e de poço anterior ao primeiro ano de injeção. Os resultados foram então agrupados por vazão de injeção anual, em tonelada de $\mathrm{CO}_{2}$ injetado por ano, e então aplicados os custos operacionais fixos (anuais) e variáveis (por tonelada de $\mathrm{CO}_{2}$ ). Como o objetivo da análise é fornecer uma base para compreensão da ordem de grandeza dos custos envolvidos para comparação com valores atualmente praticados de precificação de $\mathrm{CO}_{2}$, não foram considerados fatores econômicos como inflação e taxa de desconto e depreciação dos bens. A soma dos custos anuais para cada modelo resultou nos custos totais para os períodos determinados e os custos de injeção por tonelada de $\mathrm{CO}_{2}$ são resultado da divisão desses custos totais pelo total injetado, respeitando os períodos de injeção. 


\section{RESULTADOS E DISCUSSÃO}

Os resultados obtidos a partir das simulações de reservatório dos modelos propostos são apresentados a seguir para a estimativa da capacidade de injeção de $\mathrm{CO}_{2}$ por poço e análise de sensibilidade das características geológicas. No item posterior, são apontadas as estimativas de custos, com os cálculos econômicos para projetos de 10 a 50 anos de injeção.

\subsection{Estimativa da capacidade de injeção de $\mathrm{CO}_{2}$ por poço}

A simulação numérica de reservatórios de um período de mil anos do modelo base M0 apontou um potencial teórico de capacidade para injeção de aproximadamente 783 mil de toneladas de $\mathrm{CO}_{2}$, como identificado na Figura 24.

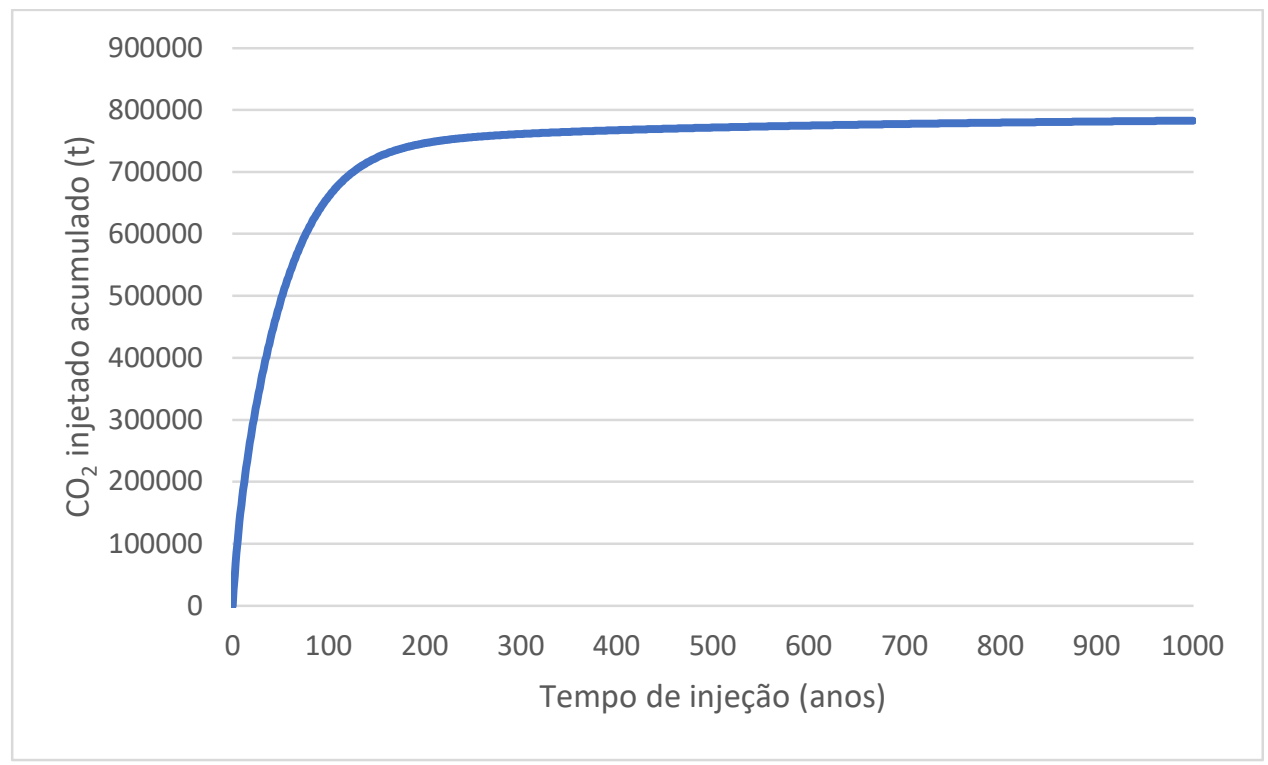

Figura 24. Total de $\mathrm{CO}_{2}$ injetado no modelo base $\mathrm{M} 0$, em 1.000 anos.

O total de $\mathrm{CO}_{2}$ injetado anualmente tem início com cerca de 25 mil toneladas, com um declínio de $47 \%$ nos primeiros 10 anos. A partir de vinte anos, o declínio fica em torno de $17 \%$ a cada dez anos, com variações menos estáveis após 260 anos de injeção. No $136^{\circ}$ ano, a injeção de $\mathrm{CO}_{2}$ já fica abaixo de mil toneladas por ano e abaixo de 100 toneladas no $278^{\circ}$ ano de injeção. 
Esses resultados demonstram que o tempo de injeção para atingir a capacidade total de armazenamento de $\mathrm{CO}_{2}$ do reservatório hipotético excede o período de um projeto comercial, dado que parece improvável um projeto com mais de 136 anos de planejamento. Portanto, na análise de custos, são utilizados valores para projetos com períodos mais razoáveis, mas que não encerram o potencial teórico total avaliado.

As Figuras 25 e 26 apresentam a injeção de $\mathrm{CO}_{2}$ anual e a taxa de declínio a cada dez anos do modelo base (M0), respectivamente.

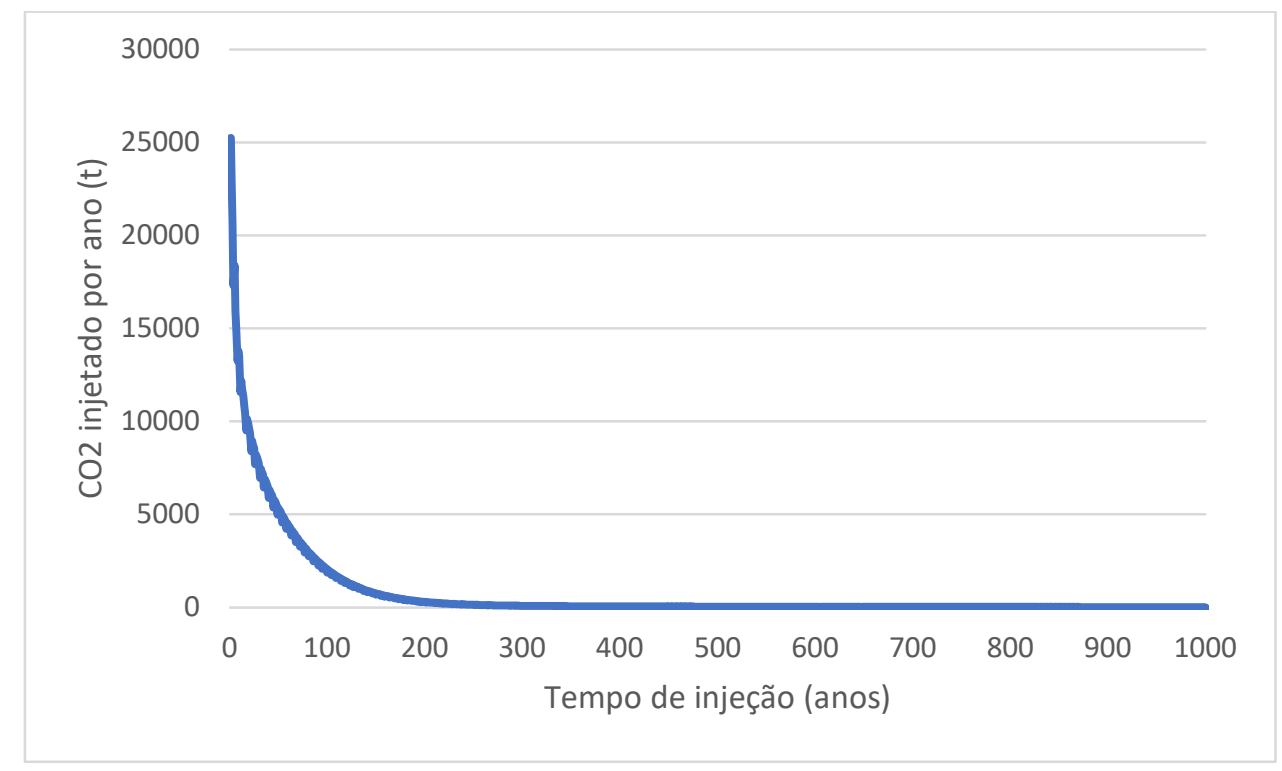

Figura 25. Injeção de $\mathrm{CO}_{2}$ anual, no modelo base (M0). 


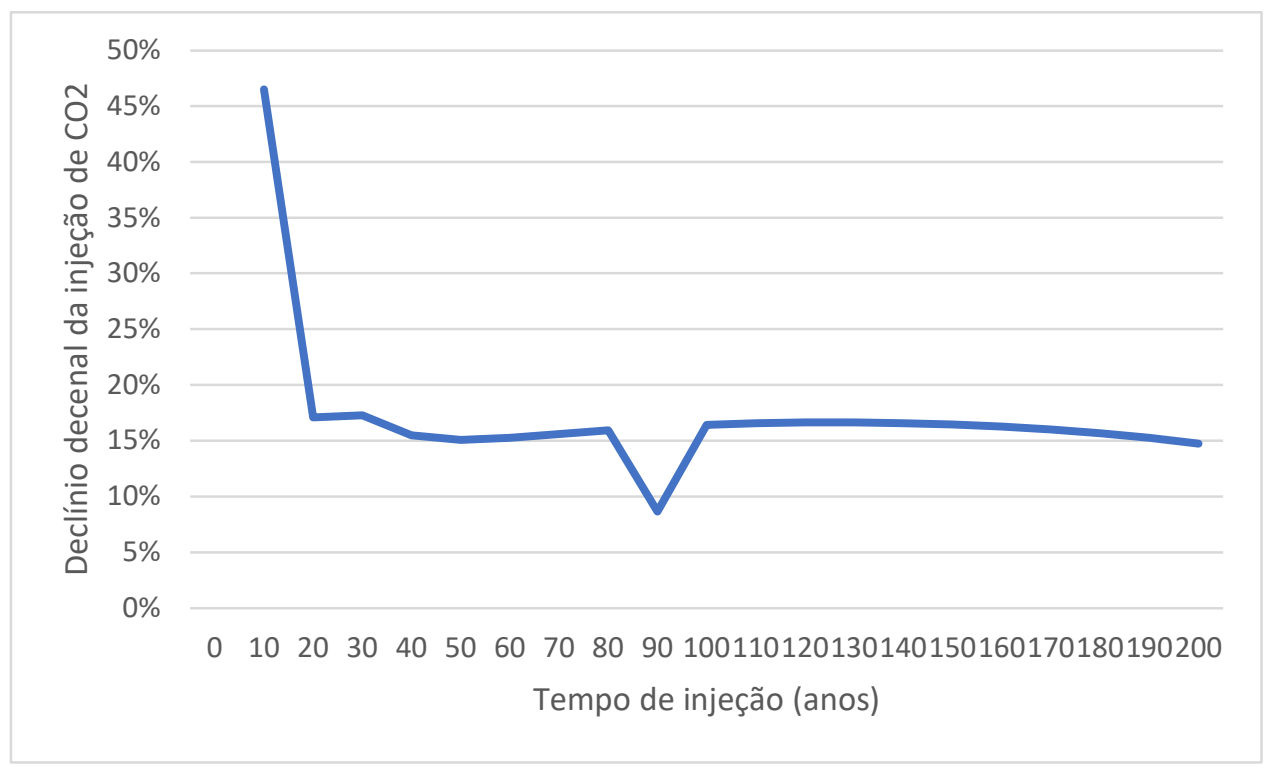

Figura 26. Declínio da injeção de $\mathrm{CO}_{2}$ a cada dez anos, no modelo base (M0).

A vazão de injeção ficou dentro dos limites estabelecidos em outros estudos de injeção de $\mathrm{CO}_{2}$ em reservatórios de gás e óleo de folhelho, revisados em Du e Nojabei (2019), atingindo um pico de $35.000 \mathrm{~m}^{3} / \mathrm{d}$ no primeiro ano. O comportamento da vazão é apresentado nas Figuras 27 e 28, para tempos de injeção de 1000 e 20 anos, respectivamente.

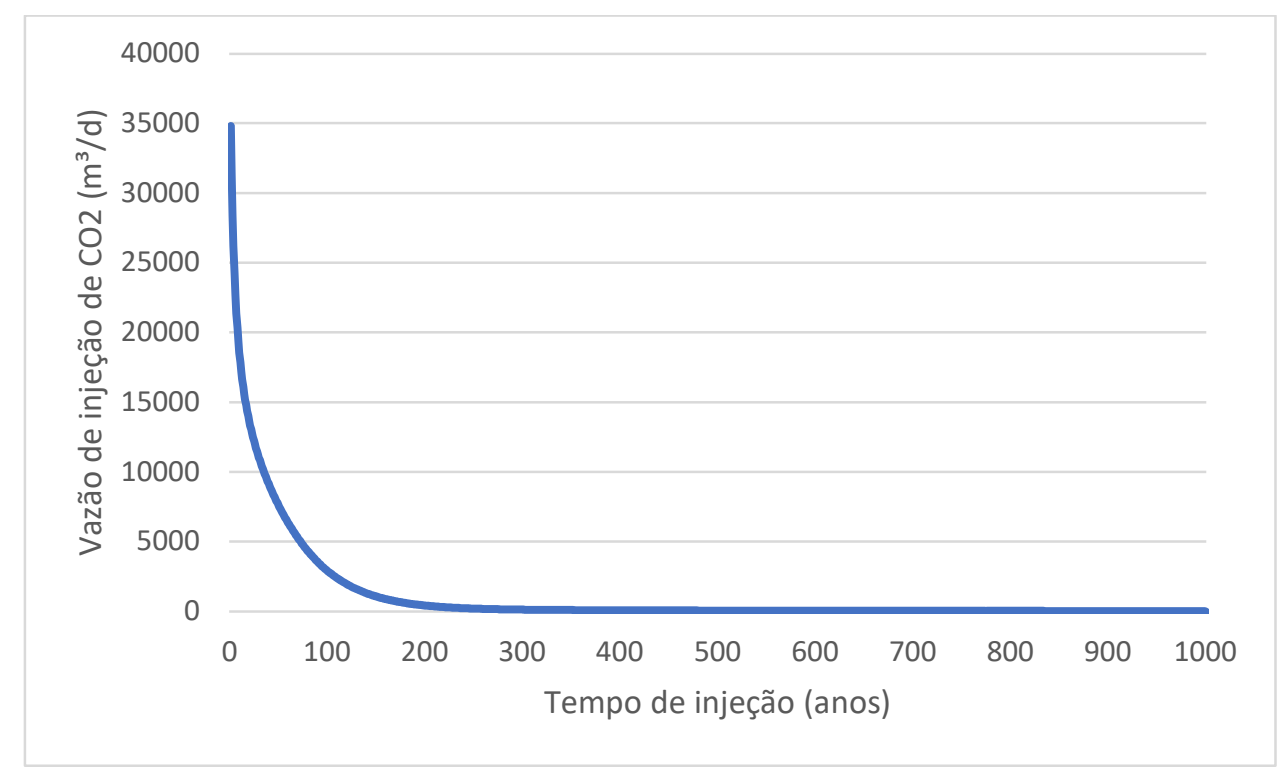

Figura 27. Vazão de injeção de $\mathrm{CO}_{2}$, em 1000 anos. 


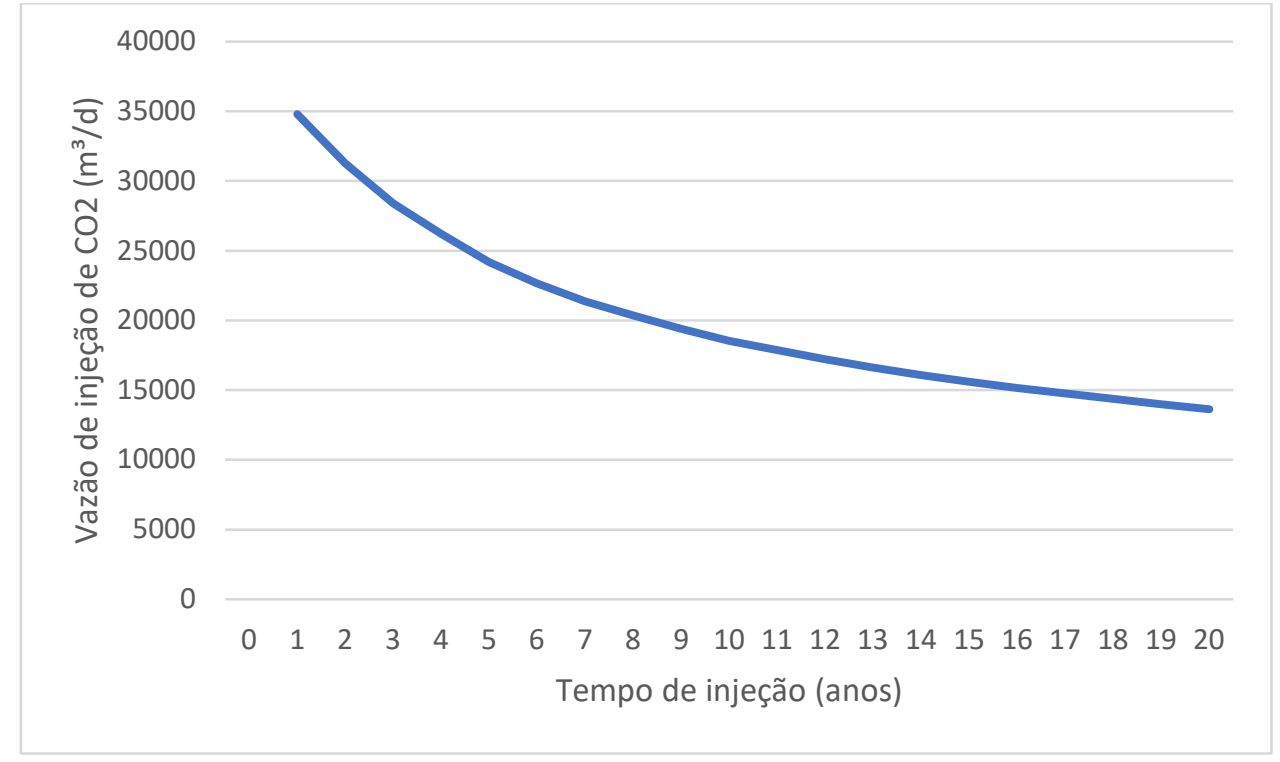

Figura 28. Detalhe da vazão de injeção de $\mathrm{CO}_{2}$ nos primeiros 20 anos.

A Figura 29 mostra a evolução da proporção de $\mathrm{CO}_{2}$ na fase gasosa nas quatro camadas do reservatório, cada uma com $10 \mathrm{~m}$. Na camada superior, identificada como “camada 1" na ilustração, observamos que, ao fim do período de injeção, a fração de $\mathrm{CO}_{2}$ fica mantida quase uniformemente entre $20 \%$ e $30 \%$, com exceção de pequenas porções relativas à parte superior da passagem do poço injetor e fraturas hidráulicas, nas quais a fração pode chegar a $60 \%$ da fase gasosa. $\mathrm{Na}$ "camada 2 ", onde se encontra o poço, observam-se as mesmas porcentagens, mas com as regiões em torno do poço alcançando mais blocos. A terceira camada (de cima para baixo) apresenta proporções quase que homogêneas de $20 \%$ a $30 \%$ de $\mathrm{CO}_{2}$. Já a última camada traz um padrão bastante diferenciado da distribuição de $\mathrm{CO}_{2}$ em relação ao total da fase gasosa. A região em torno do poço e fraturas hidráulicas com maior fração de $\mathrm{CO}_{2}$ ocupa praticamente toda a área, com valores em torno de $30 \%$ a $70 \%$, deixando apenas as extremidades com porcentagens de 0 a $20 \%$. Esse comportamento pode ser justificado pela maior saturação de água em relação às demais camadas superiores e, portanto, pela presença de baixíssimas quantidades de $\mathrm{CH}_{4}$. Considerando a baixa compressibilidade da água, o $\mathrm{CO}_{2}$ injetado que atingiu a quarta camada ficou totalmente armazenado sob a fase adsorvida. 


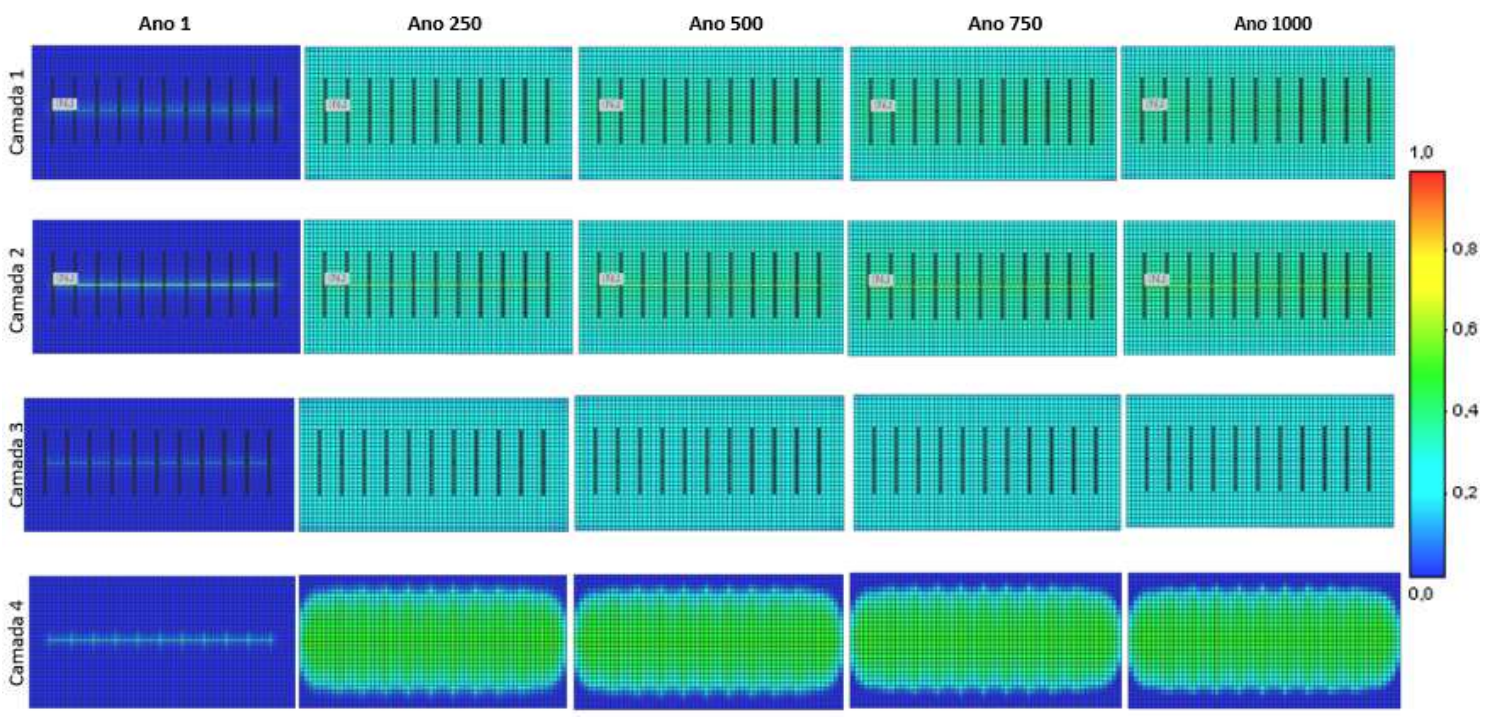

Figura 29. Vista em planta das quatro camadas do reservatório, identificando a evolução da fração de $\mathrm{CO}_{2}$ na fase gasosa do reservatório, até o fím do período de injeção de $\mathrm{CO}_{2}$, em anos selecionados. As frações são identificadas por cores de acordo com a legenda ao lado, de 0 em azul a 1,0 (equivalente a 100\%) em vermelho.

Ao término do período de injeção, a fase de adsorção de $\mathrm{CO}_{2}$ em relação ao total armazenado variou entre $70 \%$ e $80 \%$ nas duas camadas superiores e $80 \%$ até $100 \%$ nas inferiores, como ilustrado na Figura 30. A Figura 31 mostra a evolução da adsorção de $\mathrm{CO}_{2}$ em gmole $/ \mathrm{m}^{3}$ na camada do poço injetor até o ano 136 , no qual a vazão de injeção ficou inferior a mil toneladas de $\mathrm{CO}_{2}$ por ano. 
Camada 1

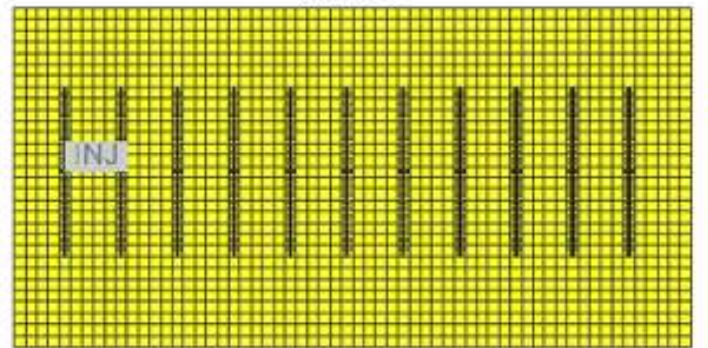

Camada 3

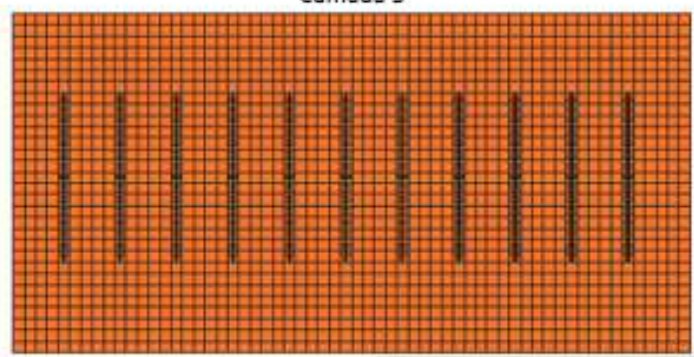

Camada 2

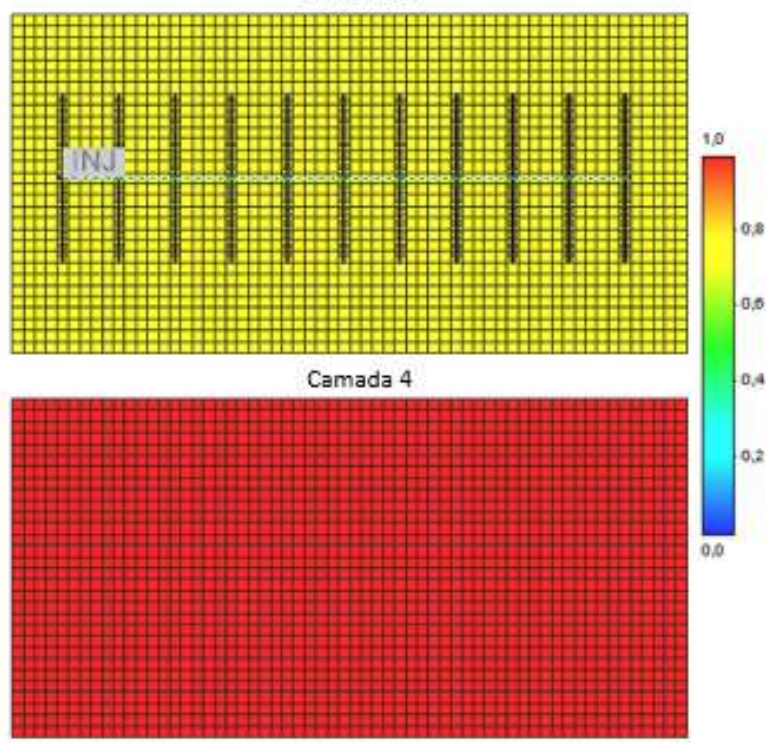

Figura 30. Vista em planta das quatro camadas do reservatório ao fim do período de injeção, identificando as proporções do armazenamento de $\mathrm{CO}_{2}$ na fase em adsorção em relação ao total de $\mathrm{CO}_{2}$ armazenado.

Ano 1

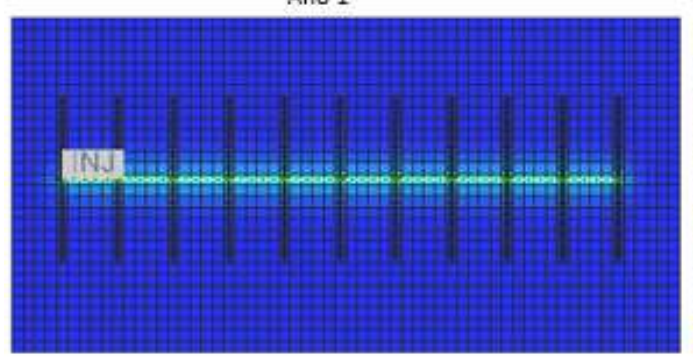

Ano 90

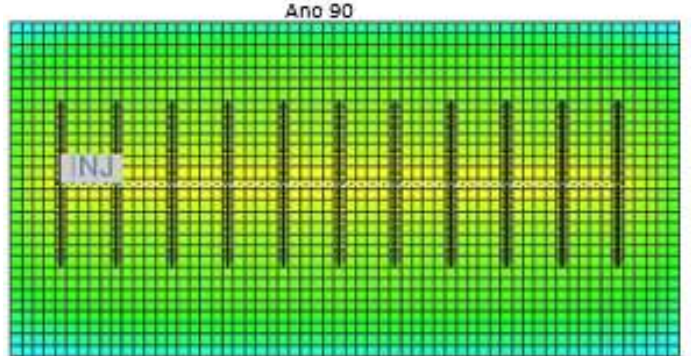

Ano 45

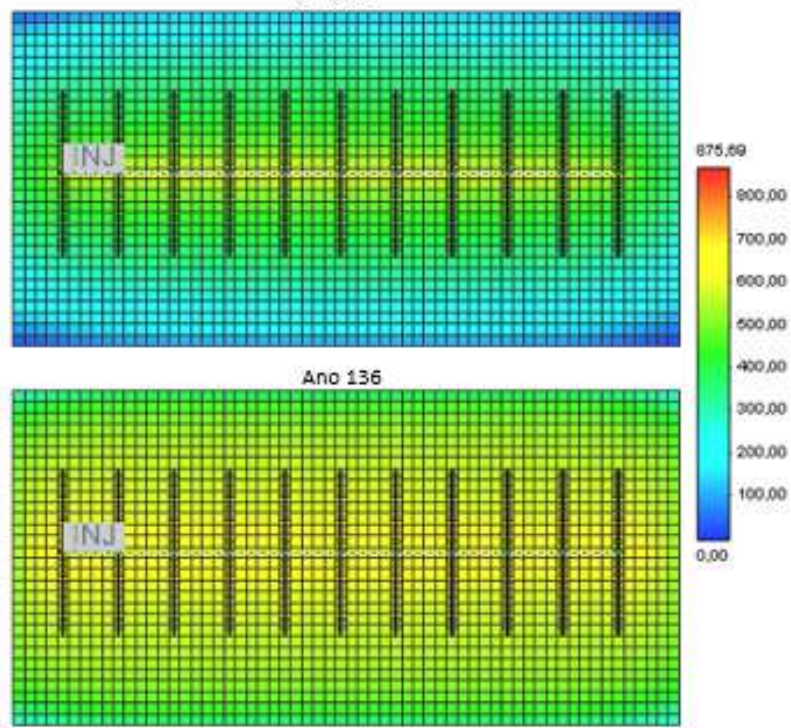

Figura 31. Vista em planta da camada 2, na qual está localizado o poço injetor, identificando as concentrações de $\mathrm{CO}_{2}$ por volume, em gmole $/ \mathrm{m}^{3}$, em anos selecionados, até o $136^{\circ}$ ano.

A efetividade total do armazenamento de $\mathrm{CO}_{2}$ na fase em adsorção apresentou valores de $40 \%$ a 77\%, como observado na Figura 32. Ao final do período de simulação, aproximadamente $13,68 \times 10^{9}$ gmole de $\mathrm{CO}_{2}$ foram adsorvidas e $0,92 \times 10^{9}$ gmole de $\mathrm{CH}_{4}$ 
sofreram processo de dessorção, cuja evolução é apresentada na Figura 33. Entretanto, não é possível estabelecer uma relação de deslocamento de $\mathrm{CO}_{2} / \mathrm{CH}_{4}$, pois não se sabe se o potencial máximo de adsorção foi atingido pelo $\mathrm{CH}_{4}$ antes do início da injeção de $\mathrm{CO}_{2}$.

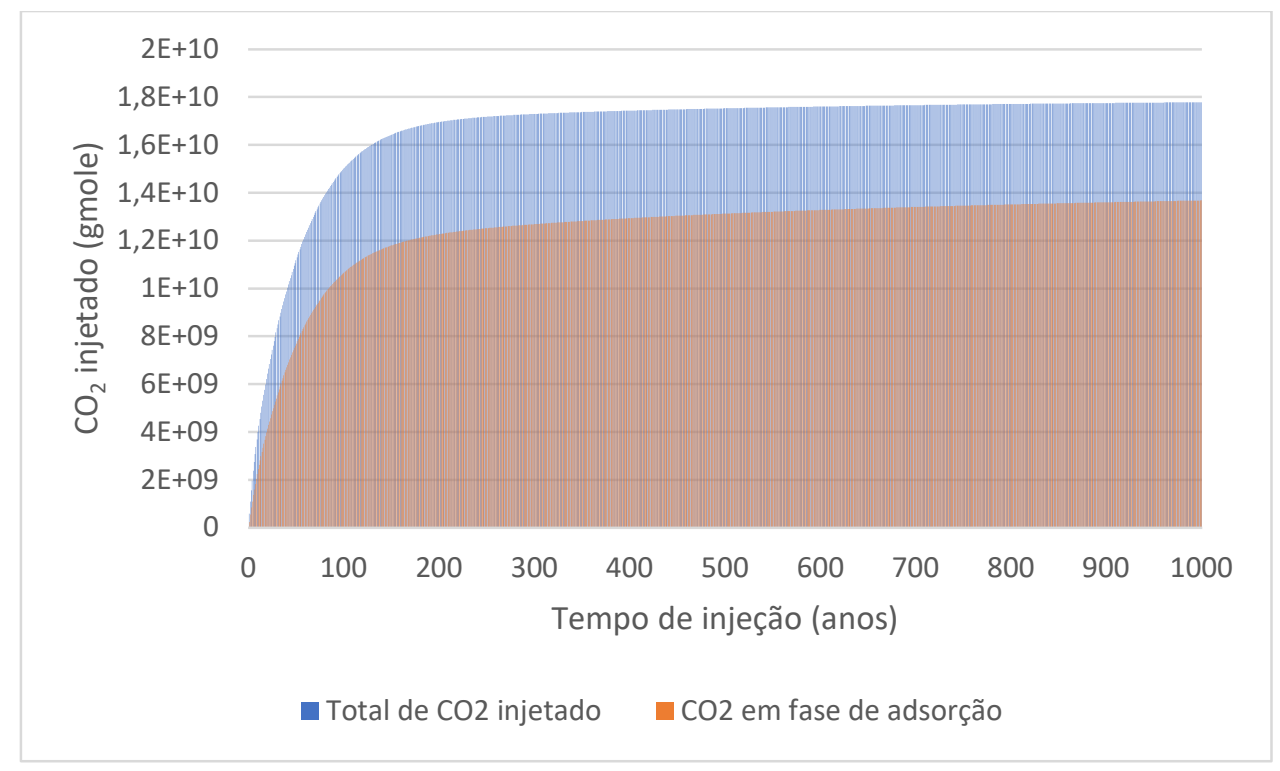

Figura 32. Evolução da fase em adsorção do $\mathrm{CO}_{2}$ em relação do total injetado, em M0.

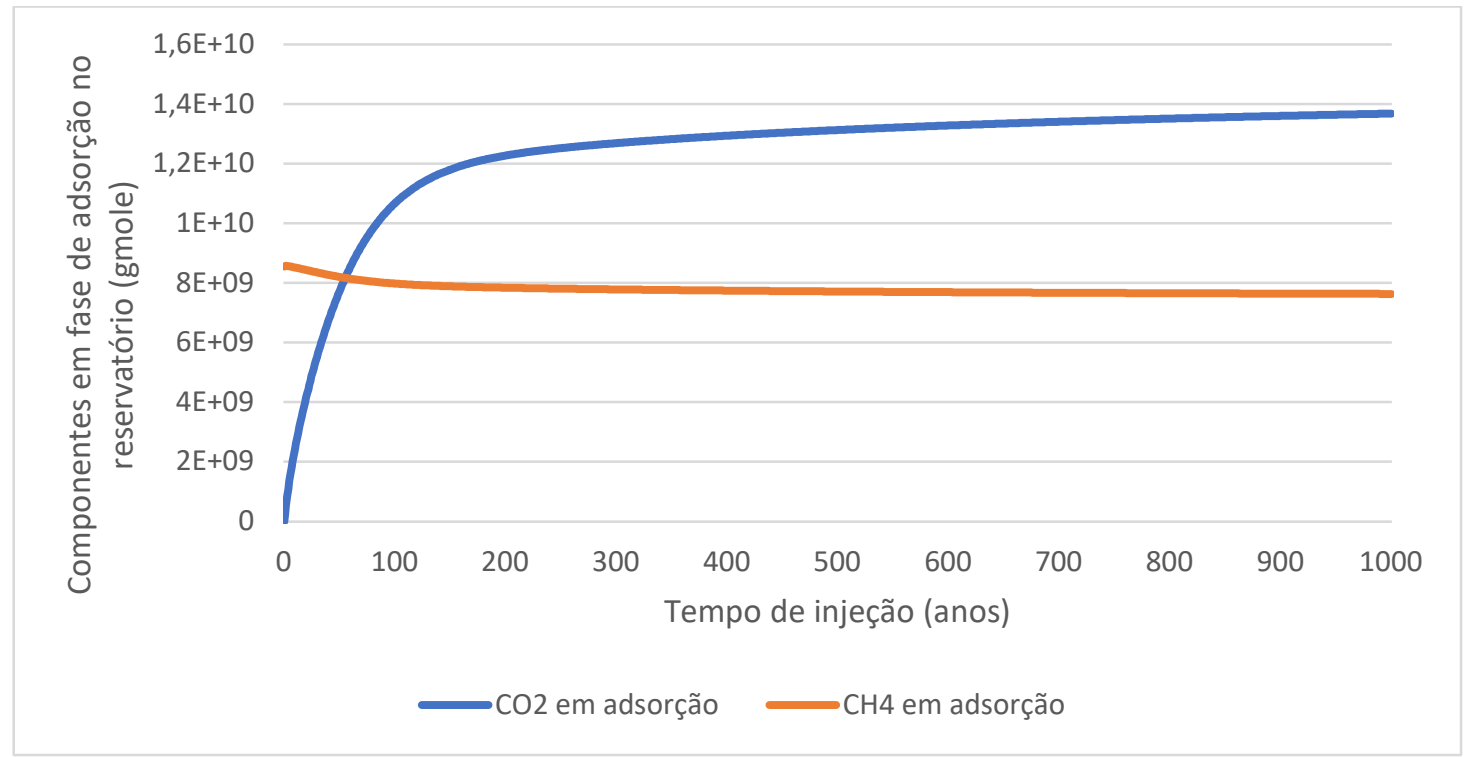

Figura 33. Evolução da fase em adsorção do $\mathrm{CO}_{2}$ em relação ao $\mathrm{CH}_{4}$ em adsorção no reservatório, em M0. 
A análise de sensibilidade das propriedades do reservatório em relação à capacidade de injeção de $\mathrm{CO}_{2}$ apontou maior influência da pressão, espessura, saturação de gás, densidade, porosidade e permeabilidade, por ordem de amplitude dos resultados. Já a temperatura, compressibilidade e coeficiente de difusão do $\mathrm{CO}_{2}$ apresentaram pouca influência, como mostra a Figura 34. A variação da pressão do reservatório teve resultados mais expressivos por ser acompanhada da variação da pressão de injeção. Considerando que pressão e espessura (impacto no volume do reservatório) são os fatores de maior influência esperados, esta análise de sensibilidade enfatiza importante diferença do impacto das características geológicas entre reservatórios convencionais e não convencionais: nestes últimos, porosidade e permeabilidade são pouco relevantes para a capacidade de armazenamento de $\mathrm{CO}_{2}$, devido aos seus baixos valores. Ressalta-se a influência da saturação de gás no potencial de injeção, que indica que reservatórios saturados de gás possuem maior capacidade de armazenamento de carbono que reservatórios saturados de água. Pode ser um indicativo de que reservatórios de gás apresentem maior potencial para armazenamento de $\mathrm{CO}_{2}$ que reservatórios de aquíferos, porém são necessários estudos comparativos para validação.

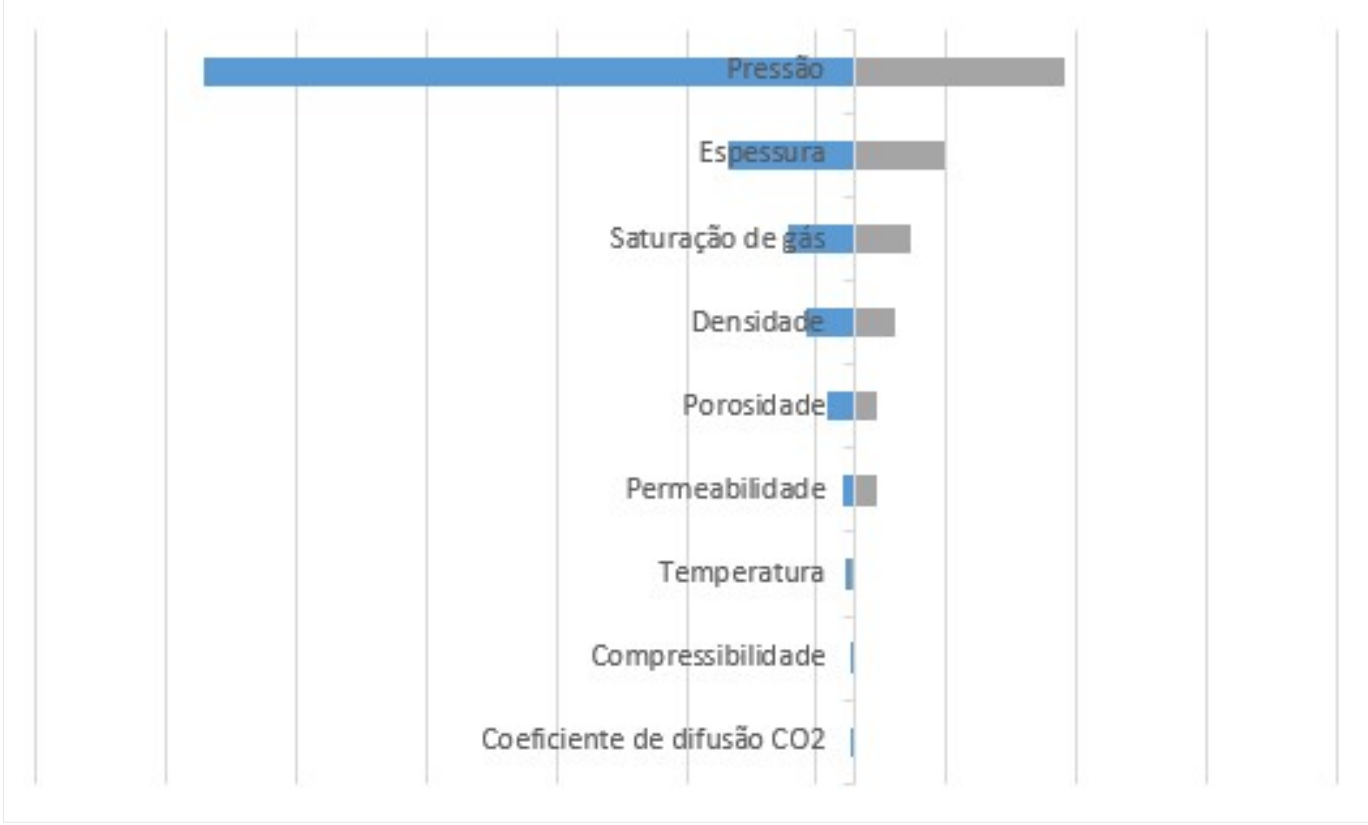

Figura 34. Análise de sensibilidade das propriedades do reservatório em relação à injeção de $\mathrm{CO}_{2}$. Foram considerados os seguintes parâmetros: pressão, espessura, saturação de gás, densidade, porosidade, permeabilidade, temperatura, compressibilidade e coeficiente de difusão do $\mathrm{CO}_{2}$. 
A segurança do armazenamento não foi prejudicada, já que a pressão final do reservatório ficou abaixo da pressão de fratura. Apenas no ano 760 o reservatório atingiu o valor equivalente à pressão final com o total de $\mathrm{CO}_{2}$ injetado, $21.507 \mathrm{kPa}$, como identificado na Figura 35. A Figura 36 mostra a evolução da pressão na camada do poço injetor até o fim do ano 136, no qual a vazão de injeção fica abaixo de mil toneladas de $\mathrm{CO}_{2}$ por ano.

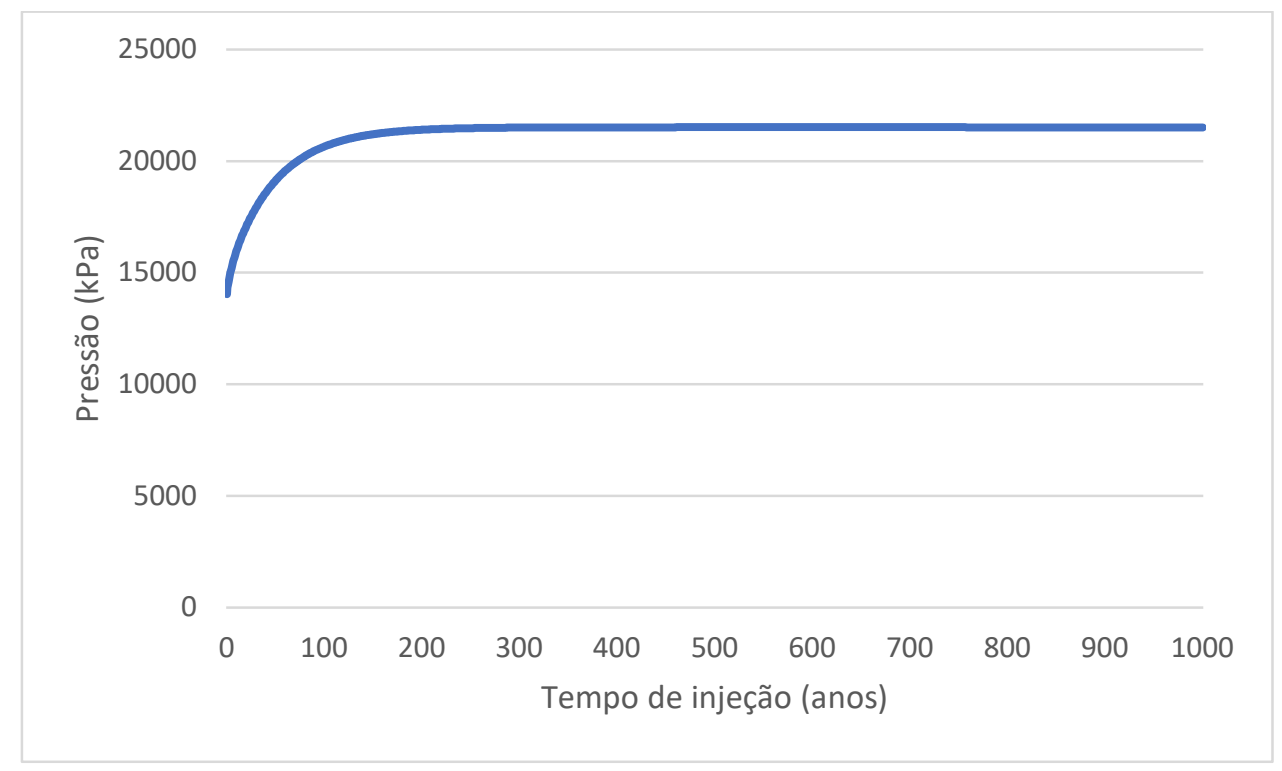

Figura 35. Evolução da pressão ao logo do tempo de injeção, com valor máximo de $21.507 \mathrm{kPa}$ atingido no ano 760 , em M0. 


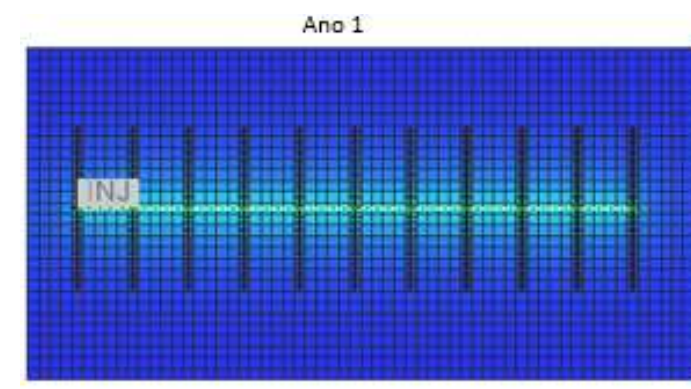

Ano 90

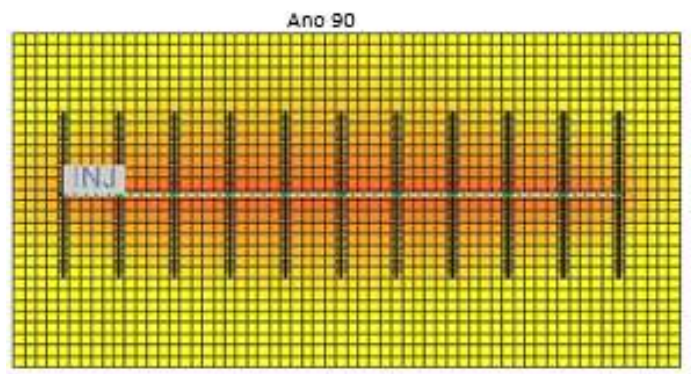

Ano 45

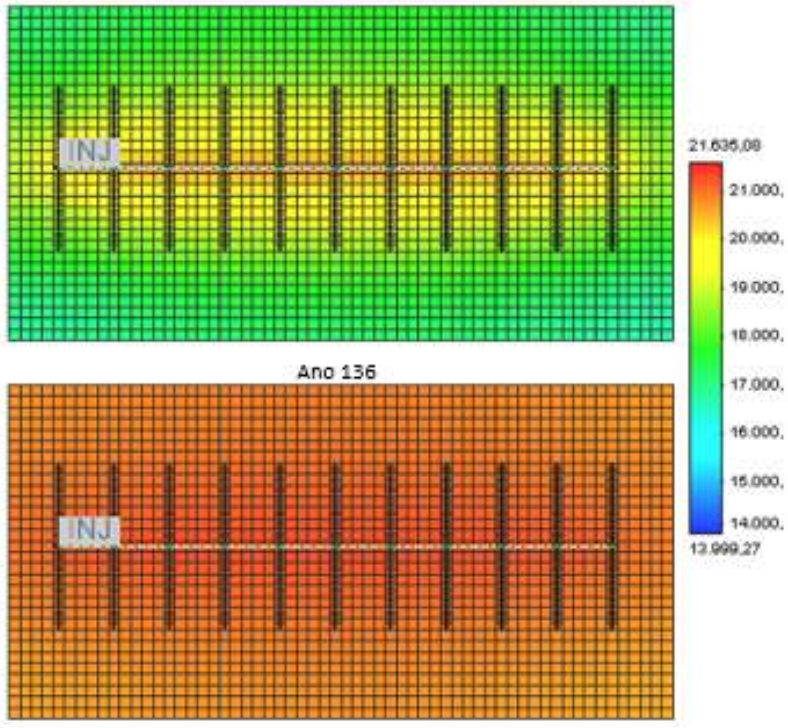

Figura 36. Vistas em planta da camada com poço injetor de $\mathrm{CO}_{2}$, mostrando a evolução da pressão $(\mathrm{em} \mathrm{kPa})$ em anos selecionados.

Com relação aos resultados das simulações dos modelos limites $\mathrm{M}-\mathrm{e} \mathrm{M}+$, a capacidade de armazenamento ficou entre 166 e 1193 mil toneladas de $\mathrm{CO}_{2}$, que demonstram a amplitude do impacto das variações das características geológicas no resultado quando considerado um tempo de injeção praticamente irrestrito. Os resultados para capacidade de armazenamento constam na Figura 37 abaixo. 


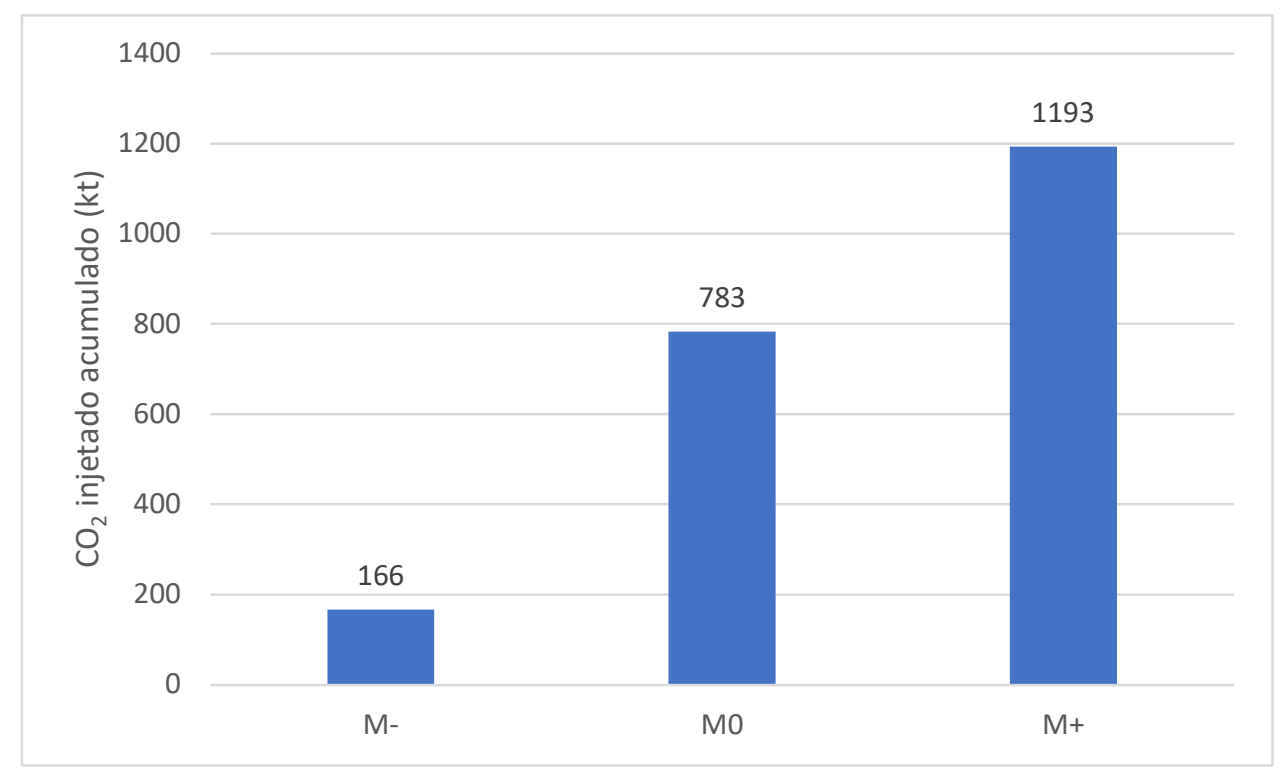

Figura 37. Comparativo do $\mathrm{CO}_{2}$ armazenado nos modelos limites (M- e $\mathrm{M}+$ ) e base (M0), em 1000 anos.

Quanto ao armazenamento de $\mathrm{CO}_{2}$ na fase em adsorção, as porcentagens finais ficaram 56\% em M- e 69\% em M+, conforme ilustrado na Figura 38.

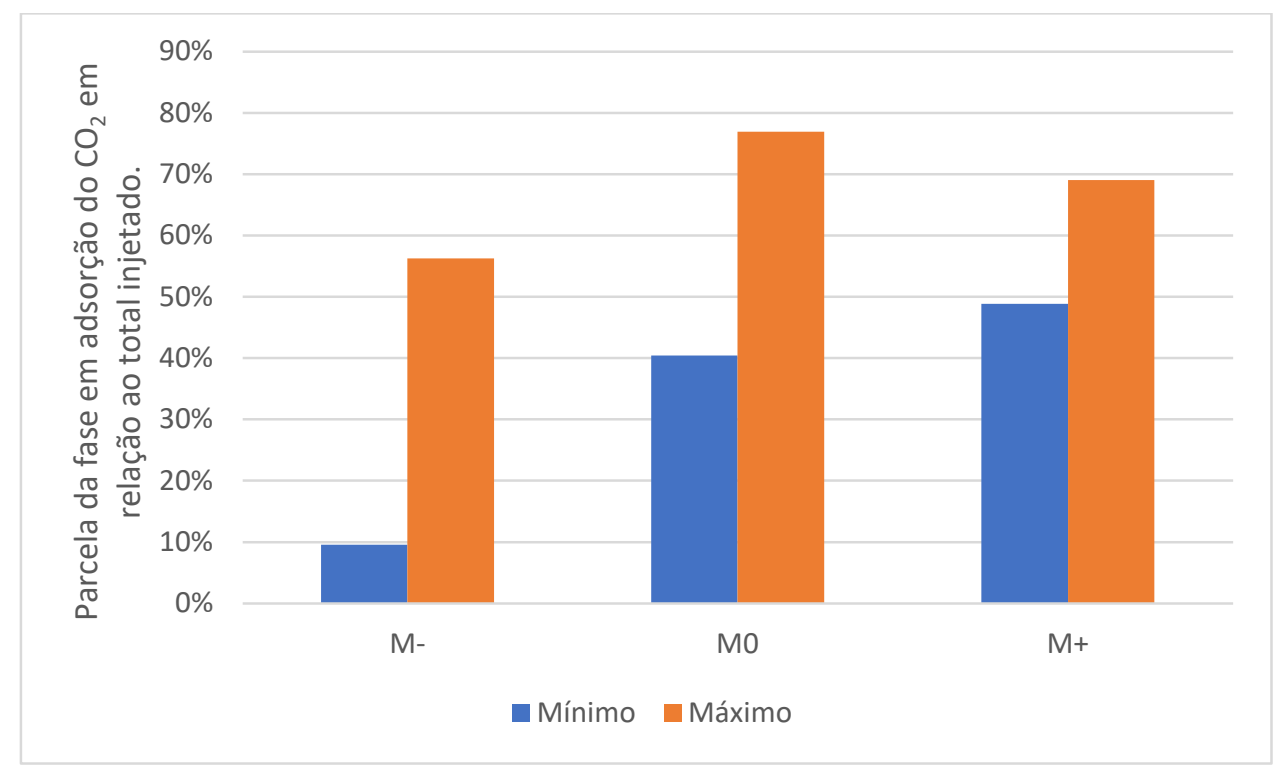

Figura 38. Comparativo da efetividade do armazenamento de $\mathrm{CO}_{2}$ na fase adsorvida em relação ao total injetado, nos modelos limites (M- e M+) e base (M0), em 1000 anos. 
Os intervalos de capacidade entre os cenários pessimista e otimista demonstram a grande influência da variação das propriedades do reservatório, notadamente a pressão e a saturação de gás, dado que a espessura e a densidade não foram alteradas em relação ao modelo base. Por isso, fica clara a relevância da obtenção de dados refinados para construção do modelo geológico, reduzindo as incertezas. Para uma avaliação do potencial da Fm. Irati como um todo, são necessários outros estudos que forneçam a área total em que possam ser realizadas as atividades de injeção de $\mathrm{CO}_{2}$, considerando o espaçamento entre poços adequado. Como a espessura utilizada no modelo é a média de toda a formação, a área determinada seria multiplicada pelos resultados deste trabalho, fornecendo uma estimativa para toda a extensão da Fm. Irati.

A comparação desse potencial com outras formações de folhelho é limitada pelas diferenças de abordagens da literatura até o momento. De maneira geral, a injeção de $\mathrm{CO}_{2}$ em reservatórios de gás de folhelho é estudada para reservatórios em que já foram alvo de produção e quase sempre associada à recuperação avançada de gás. Se por um lado a capacidade de armazenamento tende a ser menor em reservatórios não depletados, por outro, o objetivo de recuperação avançada de gás tende a minimizar a injeção de $\mathrm{CO}_{2}$.

Apesar das incertezas nos parâmetros utilizados, o presente trabalho apresenta estimativas para o potencial de capacidade de armazenamento de $\mathrm{CO}_{2}$ na Fm. Irati sem considerar a produção de óleo/gás, embasado na possibilidade de injeção de $\mathrm{CO}_{2}$ até uma pressão de segurança inferior à pressão de fratura do reservatório. A partir desse conceito, levanta-se a possibilidade de armazenar carbono em reservatórios de gás de folhelho sem a necessidade de produção local de recursos fósseis.

\subsection{Estimativa dos custos}

Para as estimativas dos custos de projeto de um poço, os resultados das simulações foram restringidos a até 50 anos de injeção de $\mathrm{CO}_{2}$, avaliados em períodos de 10, 20, 30, 40 e 50 anos. Nestes recortes, o total de $\mathrm{CO}_{2}$ injetado ficou entre 175,83 e 491,88 mil toneladas, conforme apresentado na Figura 39 para o modelo base M0. 


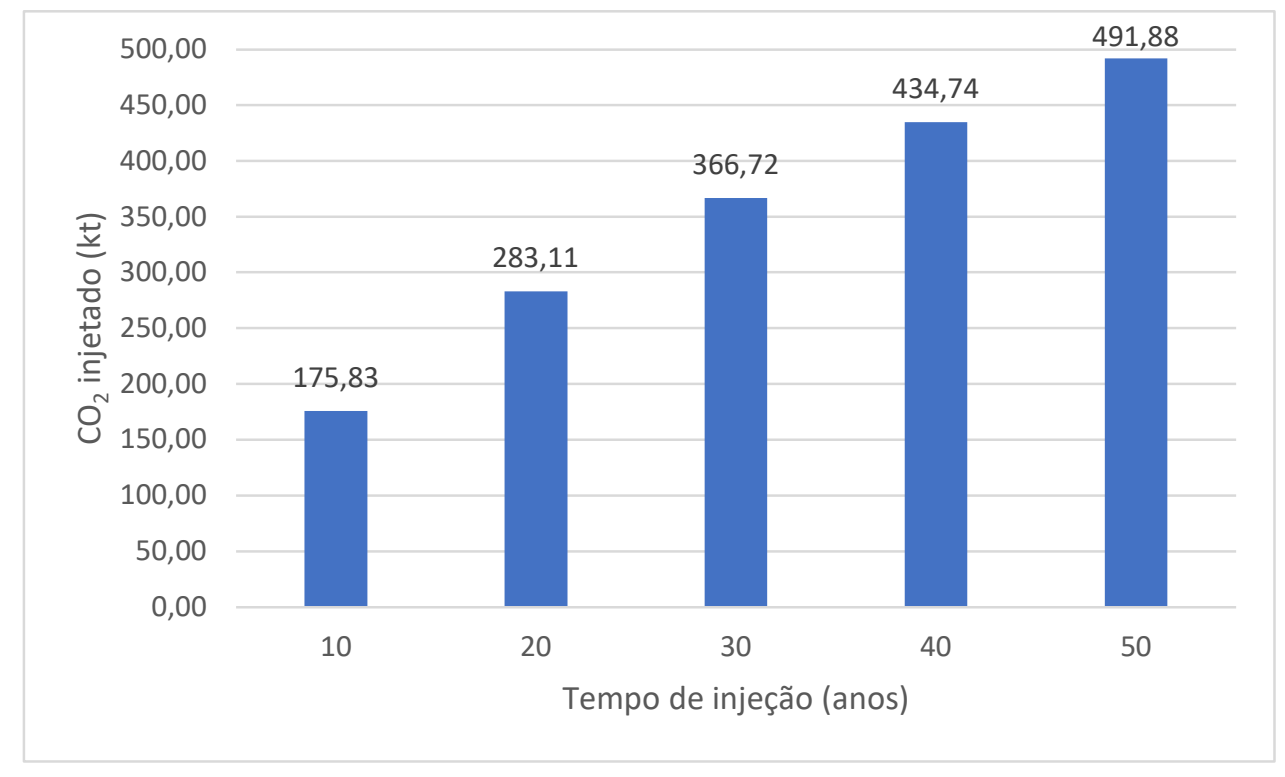

Figura 39. Total de $\mathrm{CO}_{2}$ injetado por tempo de projeto, em M0.

Seguindo as premissas de custos tratadas anteriormente, o modelo base M0 apresentou custos de 22,69 a 58,85 milhões de dólares por poço, em 10 e 50 anos, respectivamente, como exposto na Figura 40. Devido à baixa representação dos custos de poço variáveis nos custos totais, o crescimento dos custos por poço segue um padrão próximo ao linear, aumentando em cerca de 9 milhões de dólares a cada dez anos.

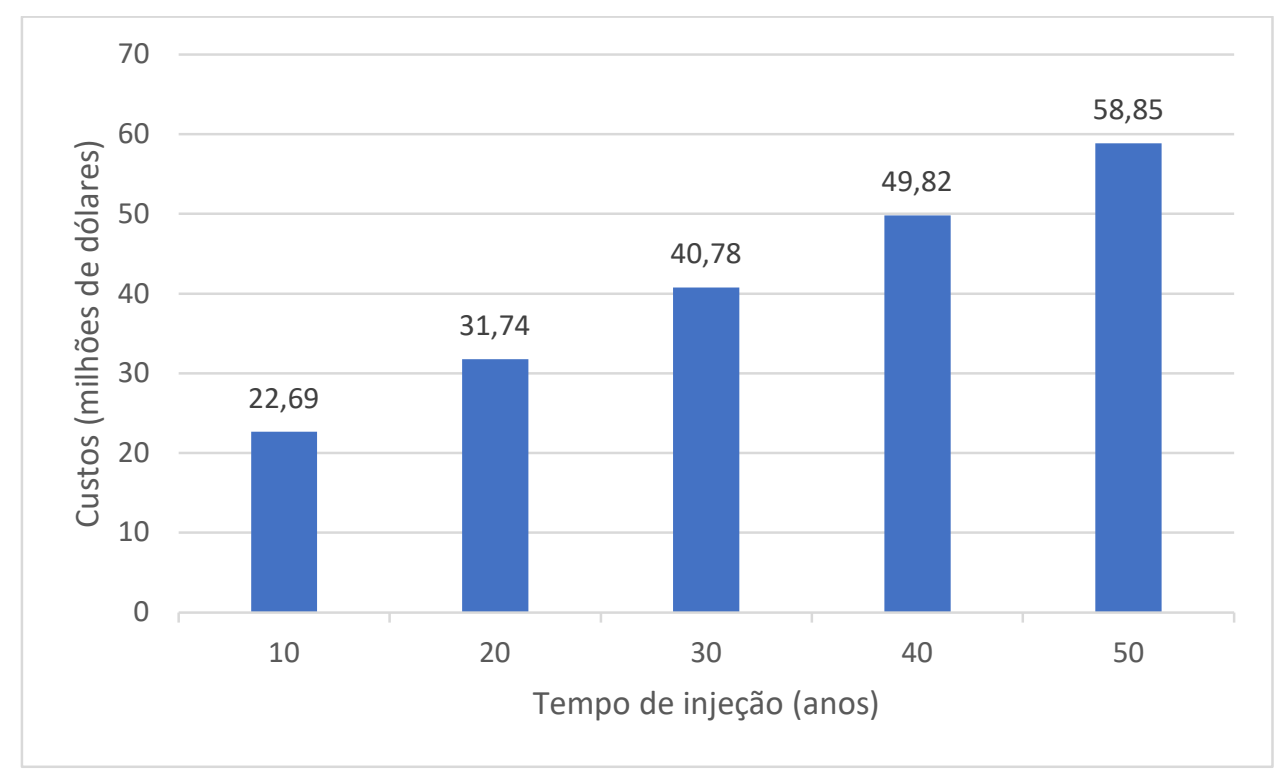

Figura 40. Custos totais por poço por tempo de injeção de $\mathrm{CO}_{2}$, em $\mathrm{M} 0$. 
Como parâmetro para comparação para determinação do break-even do preço do $\mathrm{CO}_{2}$ para viabilidade econômica do projeto, foi calculado o custo por tonelada de $\mathrm{CO}_{2}$ injetado para os mesmos períodos de injeção. Novamente, os relativos baixos custos variáveis resultam em uma redução desse parâmetro de acordo com o aumento da quantidade de $\mathrm{CO}_{2}$ injetado, quando excluído o CAPEX anterior ao início do projeto. As Figuras 41 e 42 representam essa relação entre custos de injeção por quantidade de $\mathrm{CO}_{2}$ e os valores finais para até 50 anos de injeção, respectivamente. Em M0, um projeto de 10 anos chega a ter custo de 129,04 dólares por tonelada e em 50 anos, 119,64. Entretanto, os períodos de 20 e 30 apresentam os menores valores, inferiores a 113 dólares, por possuírem o maior incremento de injeção de $\mathrm{CO}_{2}$ em relação aos demais períodos. Esse comportamento pode ser observado na Figura 43, que compara a variação do incremento da injeção de $\mathrm{CO}_{2}$ à variação do aumento ou redução do custo por tonelada de $\mathrm{CO}_{2}$ injetado a cada 10 anos.

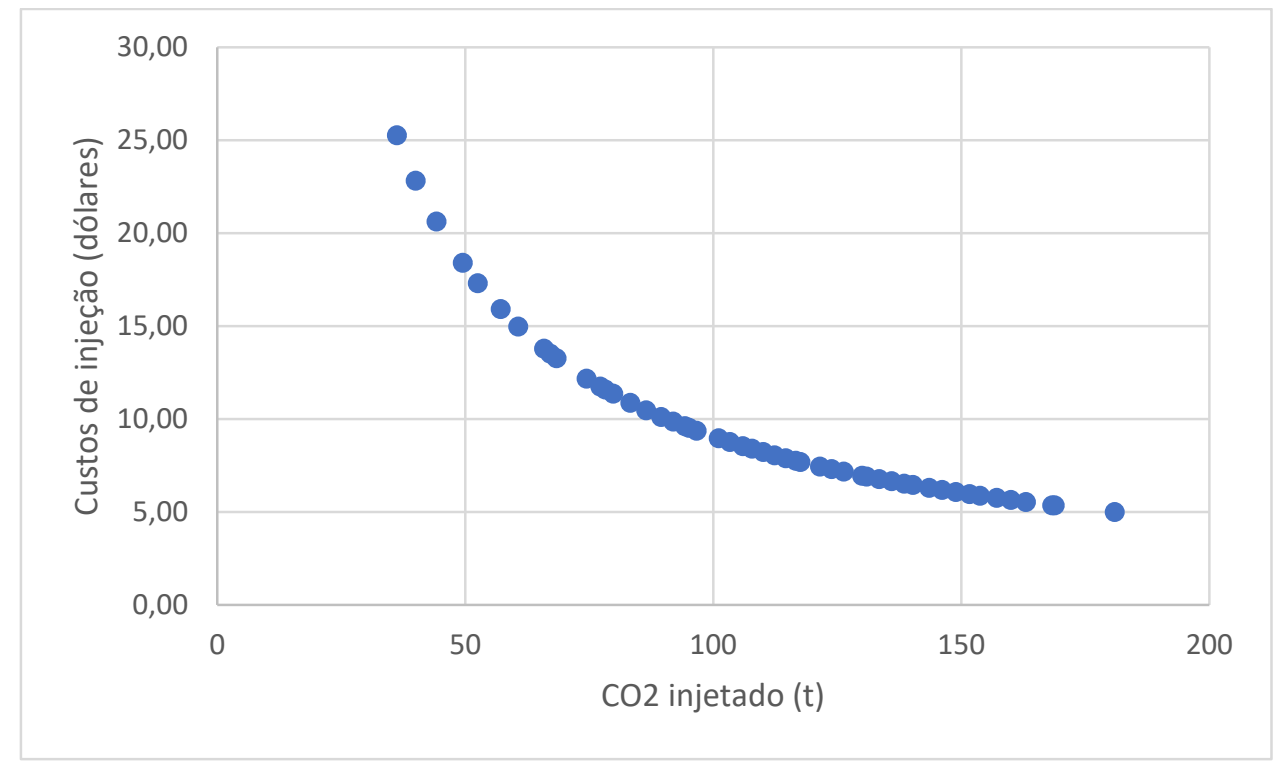

Figura 41. Relação entre custos de injeção por quantidade de $\mathrm{CO}_{2}$ injetado, em M0. 


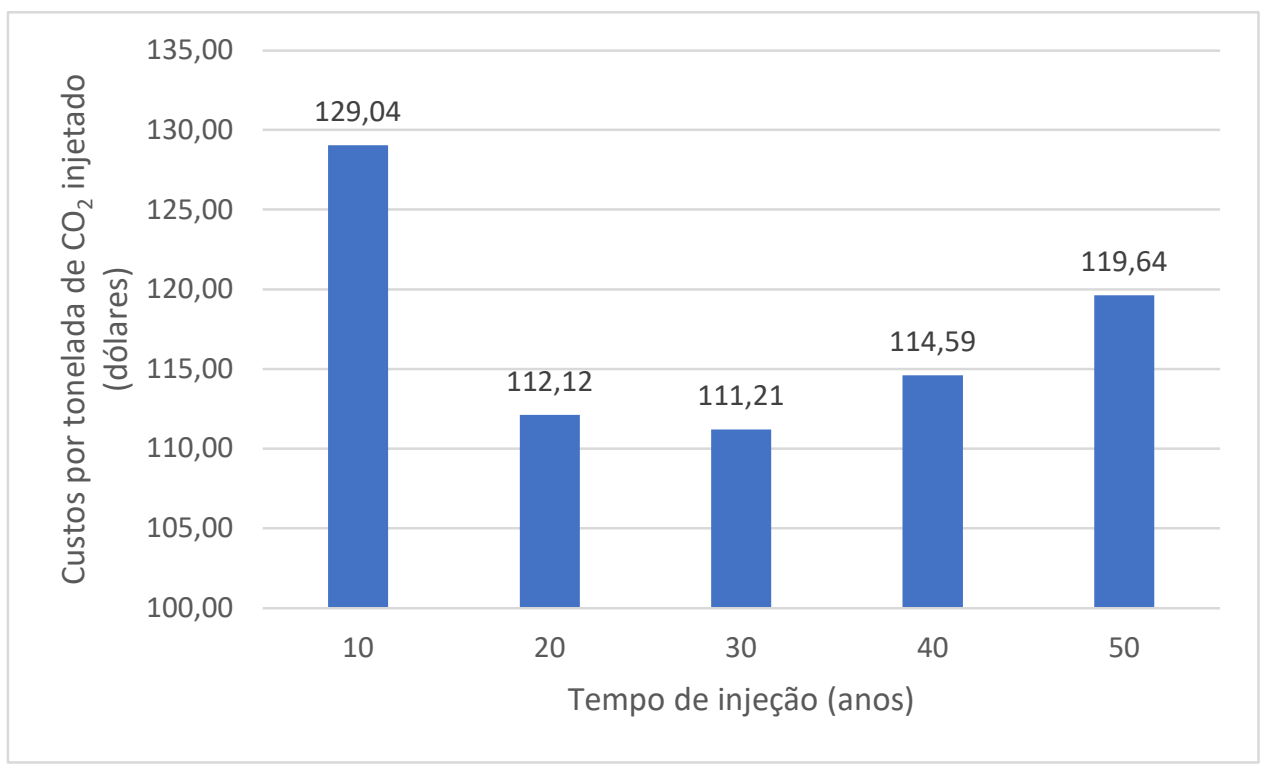

Figura 42. Custos por tonelada de $\mathrm{CO}_{2}$ injetado, em M0.

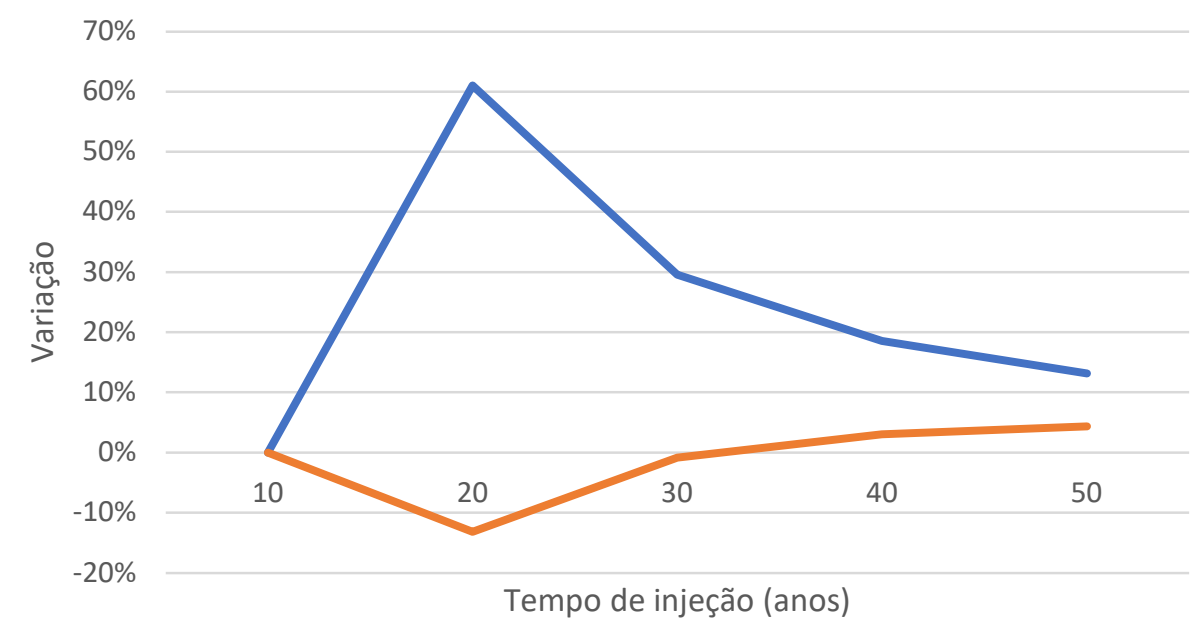

Incremento da injeção de CO2

Aumento/redução do custo por tonelada

Figura 43. Relação da variação do incremento da injeção de $\mathrm{CO}_{2}$ e o aumento ou redução do custo por tonelada de $\mathrm{CO}_{2}$ injetado, a cada 10 anos.

Quando considerados os modelos limites (M- e M+), que representam os valores máximos e mínimos para as características com maiores incertezas do reservatório, a injeção total de $\mathrm{CO}_{2}$ ficou entre 133 e 783 mil toneladas (Figura 44). Como esperado, os custos totais dos projetos são muito próximos aos do modelo base M0, já que os custos variáveis de poço são pouco representativos. Dessa forma, os custos por poço continuam 
entre cerca de 22 e 59 milhões de dólares, para 10 e 50 anos de injeção, respectivamente, como apresentado na Figura 45.

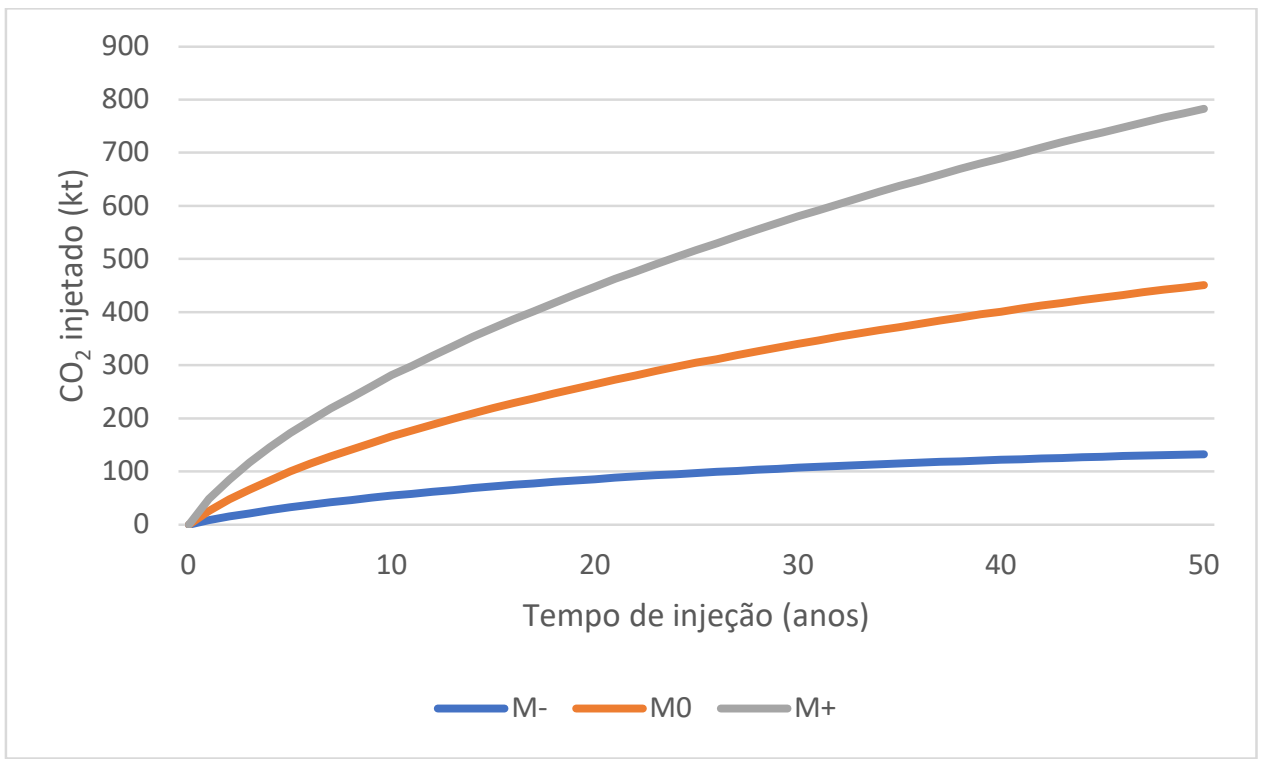

Figura 44. Evolução do $\mathrm{CO}_{2}$ injetado em 50 anos, nos modelos $\mathrm{M}-, \mathrm{M} 0$ e M+.

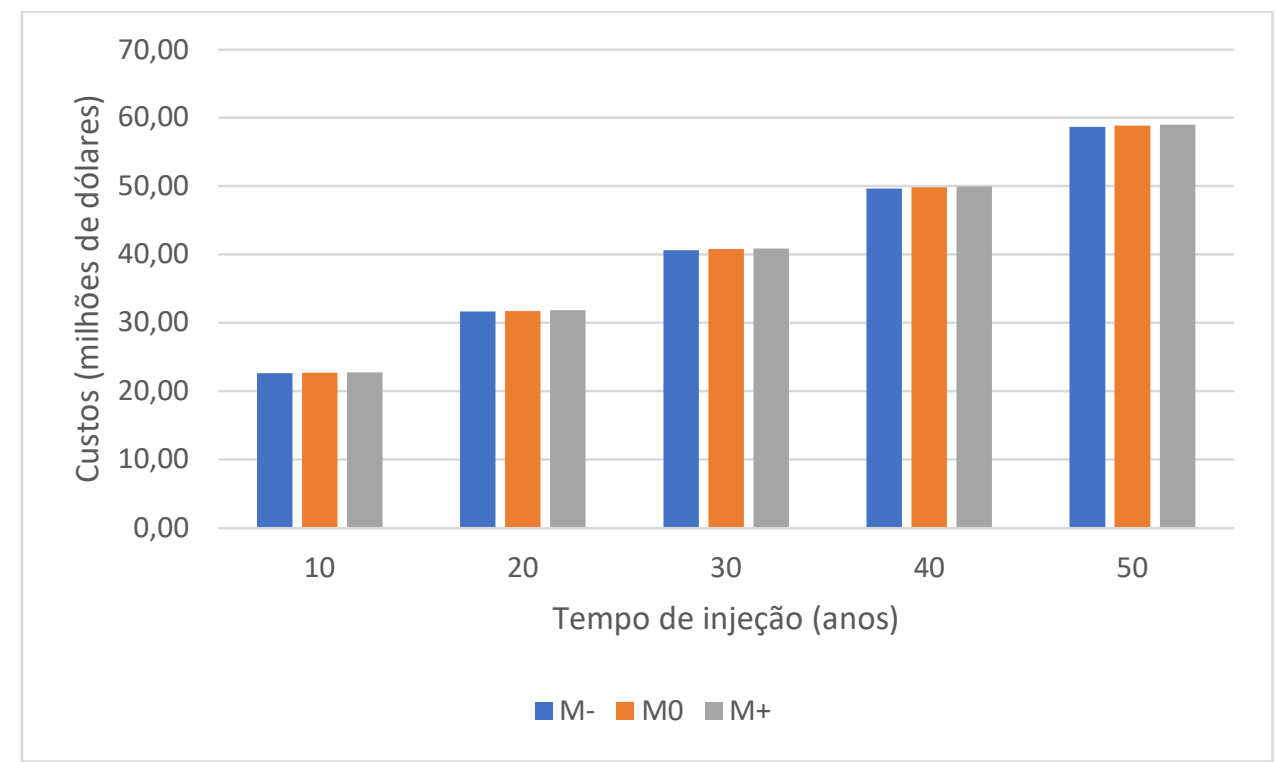

Figura 45. Comparativo de custos totais por tempo de projeto em M-, M0 e M+. 
Entretanto, como observado nos resultados das simulações de reservatório, as variações das características geológicas provocaram grandes diferenças no total de $\mathrm{CO}_{2}$ injetado. Assim, o custo por tonelada de $\mathrm{CO}_{2}$ injetado para $\mathrm{M}-\mathrm{e} \mathrm{M}+$ obteve valores consideravelmente distantes de M0, apesar da tendência continuar similar. O projeto com período de injeção de 30 anos manteve os valores mais baixos em M+ e M0, com 72 e 111 dólares, respectivamente. Para M-, o período de projeto com valor mais baixo foi de 20 anos, com custo de 371 dólares por tonelada. Em M+ e M0, os maiores custos foram para 10 anos de injeção, com 83 e 129 dólares por tonelada cada, enquanto em M-, o maior valor foi em 50 anos de projeto, custando 441 dólares por tonelada. A comparação das variações de custos por tonelada de $\mathrm{CO}_{2}$ injetado por tempo de projeto nos três modelos pode ser analisada na Figura 46.

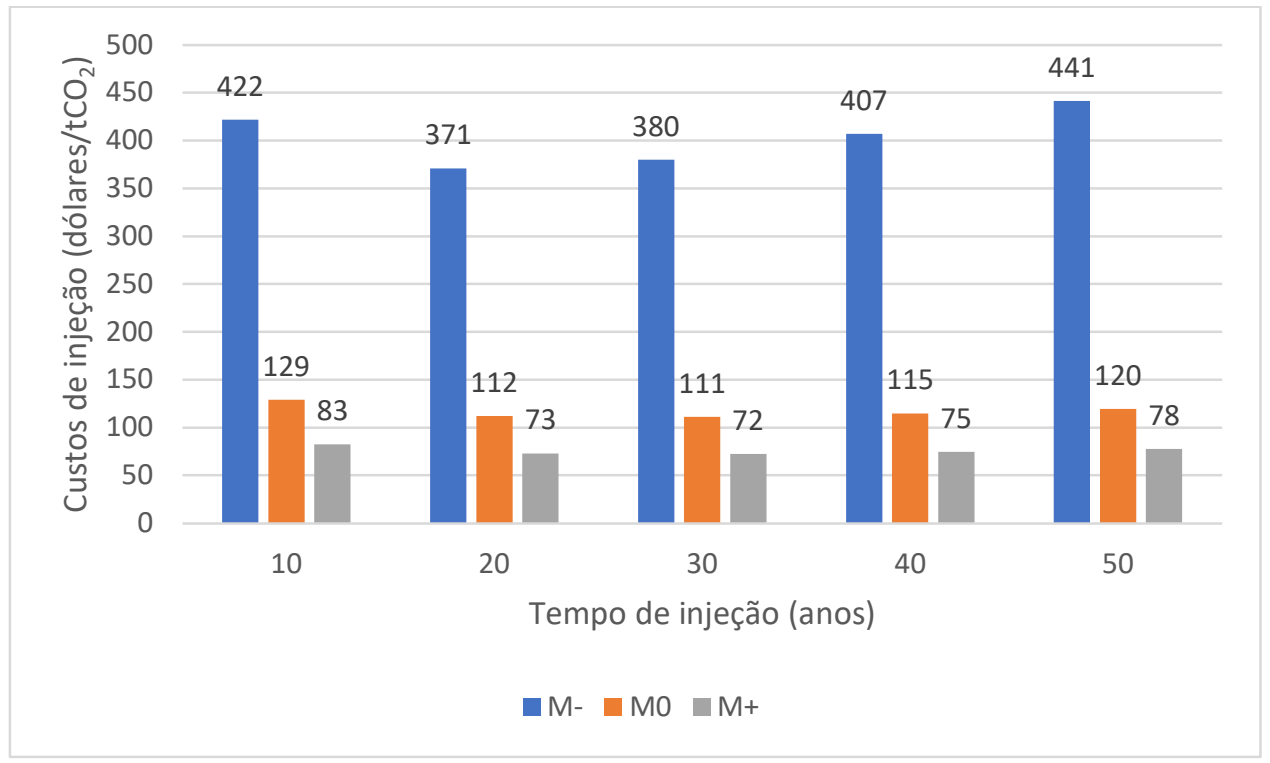

Figura 46. Comparação das variações de custos por tonelada de $\mathrm{CO}_{2}$ injetado por tempo de projeto em $\mathrm{M}-, \mathrm{M} 0$ e $\mathrm{M}+$.

A partir desses resultados, observa-se que os fatores decisivos dos custos de um projeto de poço injetor de $\mathrm{CO}_{2}$ são a construção e condicionamento de um poço novo e, em menor escala, o período do projeto. Devido à inexistência de produção em reservatório de gás ou óleo de folhelho no Brasil, os custos de poços determinados neste trabalho podem diferir dos custos reais que seriam praticados no país. A própria determinação da composição de custos para injeção de $\mathrm{CO}_{2}$ em reservatórios de gás de folhelho, mesmo em regiões em que já existe produção, é tratada de formas muito divergentes, dado que ainda não existem projetos comerciais dessa natureza. As lacunas ou incertezas de 
regulação para atividades de CCS também contribuem para a dificuldade de avaliação de custos, como por exemplo a atribuição de responsabilidade, o tempo e as exigências de monitoramento do $\mathrm{CO}_{2}$ injetado. As abordagens metodológicas diferem na abrangência do processo de injeção (consideração de custos de captura e de monitoramento), dos valores de cada componente, de parâmetros econômicos, do aproveitamento de infraestrutura existente, do aprofundamento das características dos reservatórios, entre outros (Bielicki et al., 2018; Davidson et al., 2014; Jiang et al., 2019; Kwak e Kim, 2017; Pei et al., 2015; Tayari et al., 2015; Wei et al., 2015; Welkenhuysen, 2018). Os custos na literatura para esse tipo de projeto chegam a variar de cerca de 20 a mais de 180 dólares por tonelada de $\mathrm{CO}_{2}$ injetado.

Contudo, os resultados obtidos neste trabalho fornecem uma base para discussão da criação de mecanismos de precificação de carbono no Brasil, apresentando estimativas do preço mínimo do $\mathrm{CO}_{2}$ para viabilização econômica de um projeto de armazenamento de $\mathrm{CO}_{2}$ na Fm. Irati. Os valores desses mecanismos chegam a até 127 dólares por tonelada de $\mathrm{CO}_{2}$ equivalente, valor este praticado somente na Suécia, enquanto o intervalo mínimo para cumprimento da meta de temperatura do Acordo de Paris foi estabelecido entre $40 \mathrm{e}$ 80 dólares por tonelada (Banco Mundial, 2019). Dessa forma, os resultados de M0 e M+ apresentados neste trabalho estão dentro de preços praticados em outros países, porém ressalta-se que a maior parte dos mecanismos de precificação utilizam preços abaixo de 60 dólares por tonelada de $\mathrm{CO}_{2}$ equivalente.

Portanto, considerando os resultados do trabalho e os aspectos acima tratados sobre a composição de custos e mecanismos de precificação de carbono, pode-se concluir que a viabilidade econômica de um projeto de armazenamento de $\mathrm{CO}_{2}$ na $\mathrm{Fm}$. Irati depende principalmente dos custos de construção e condicionamento de um poço injetor de $\mathrm{CO}_{2}$, do período e capacidade de injeção e da implementação de mecanismos de precificação de carbono. Devido aos resultados relativamente altos dos custos, seria necessária uma combinação no Brasil da criação de taxas ou licenças para $\mathrm{CO}_{2} \mathrm{com}$ políticas públicas de incentivo à redução de emissões de gases de efeito estufa, como subsídios. 


\section{CONCLUSÕES E CONSIDERAÇÕES FINAIS}

Os processos de Captura e Armazenamento de Carbono constituem relevante ferramenta para o cumprimento das metas do Acordo de Paris. Diversos contextos geológicos são frequentemente estudados para confinamento do $\mathrm{CO}_{2}$ no subsolo, notadamente aquíferos salinos profundos e reservatórios convencionais de petróleo depletados. Porém novas fronteiras de armazenamento geológico ganharam atenção nos últimos anos.

Os reservatórios de gás de folhelho apresentam grande potencial para redução das emissões dos gases de efeito estufa. $\mathrm{O}$ aumento drástico da produção desses recursos não convencionais, que levou o emblema de "revolução do shale", possibilitou a inclusão dessas formações geológicas no conjunto de opções para armazenamento de carbono.

Somadas às propriedades comuns aos reservatórios de óleo e gás que oportunizam o sequestro de $\mathrm{CO}_{2}$, como porosidade, permeabilidade, pressão, temperatura e trapeamento, os reservatórios de gás de folhelho possuem características específicas que podem favorecer as atividades de CCS. Além de permitir o aprisionamento de fluidos dentro da própria formação, atuando como reservatório e rocha selante, os folhelhos ricos em matéria orgânica possuem grande capacidade de adsorção de $\mathrm{CO}_{2}$, o que aumenta a estabilidade e a capacidade do armazenamento. A preferência de adsorção pelo $\mathrm{CO}_{2} \mathrm{em}$ relação ao $\mathrm{CH}_{4}$ também possibilita ganhos econômicos com recuperação avançada de gás natural.

Considerando a alternativa de armazenamento geológico de carbono em reservatórios de gás de folhelho e a localização estratégica da Bacia do Paraná, próxima às regiões com maiores emissões de fontes estacionárias do Brasil, o presente trabalho propôs estimar a capacidade de injeção de $\mathrm{CO}_{2}$ na Fm. Irati e potenciais custos associados.

Devido à ausência de produção de hidrocarbonetos na Fm. Irati, a falta de dados geológicos e petrofísicos de qualidade demandou a criação de cenários pessimista e otimista, que abrangem as incertezas com base em comparações de parâmetros com outras formações de folhelhos no mundo.

O estudo da capacidade de armazenamento de carbono foi realizado com simulações numéricas de reservatórios no software GEM/CMG, incorporando ao modelo geológico 
características essenciais à modelagem de reservatórios de gás de folhelho, como rede de fraturas naturais, difusividade de gás, adsorção e fraturamento hidráulico. A injeção de $\mathrm{CO}_{2}$ foi limitada a uma pressão inferior à pressão de fratura assumida da formação, com período de mil anos, permitindo atingir a capacidade total teórica do reservatório. $\mathrm{O}$ projeto foi restrito a um poço injetor em volume de reservatório representativo da extensão do poço com fraturamento hidráulico, abrangendo uma área de $1.200 \mathrm{~m}$ por 600 m, com espessura de $40 \mathrm{~m}$ - espessura média da Fm. Irati.

Os resultados das simulações apresentaram capacidade de 783 mil toneladas de $\mathrm{CO}_{2}$, podendo oscilar entre 166 e 1.193 mil toneladas quando considerados os cenários pessimista e otimista das propriedades dos reservatórios, e $77 \%$ do $\mathrm{CO}_{2}$ injetado ficou armazenado na fase adsorvida ao fim do período de injeção. A análise de sensibilidade apontou a pressão e a espessura do reservatório como fatores de maior influência na capacidade total, seguidos, em menor proporção, pela saturação de gás e densidade da formação. Essa conclusão destaca uma das principais diferenças entre armazenamento de $\mathrm{CO}_{2}$ em reservatórios convencionais e não convencionais: nestes últimos, a porosidade e a permeabilidade relevantes são produzidas artificialmente por meio de fraturamento hidráulico. A aplicação dessa avaliação de potencial de poço individual pode ser estendida de forma simplificada para áreas de superfície com possibilidade de receber um projeto dessa natureza, quando houver profundidade e espessuras próximas às utilizadas nesse estudo.

Os custos totais do projeto foram calculados para períodos de injeção entre 10 e 50 anos. No modelo base, a injeção de $\mathrm{CO}_{2}$ chegou a cerca de 492 mil toneladas, custando 59 milhões de dólares. Para os modelos pessimista e otimista, os resultados da injeção apresentaram grande variação, ficando entre 133 e 783 mil toneladas, mas os custos totais não variaram. A permanência dos custos, com baixíssimas variações quando considerada a escala dos valores do projeto, justifica-se pela predominância dos custos fixos, especialmente os relativos à construção e condicionamento do poço. Entretanto, as variações da quantidade de $\mathrm{CO}_{2}$ injetado têm, como esperado, grande impacto quando considerados os custos de injeção por tonelada de $\mathrm{CO}_{2}$. Esses custos servem de parâmetro para avaliação da viabilidade econômica do projeto em um contexto com mecanismo de precificação de carbono ou políticas de incentivo à redução de emissões de gases de efeito estufa. Em um comparativo com preços praticados em outros países, os cenários base e otimista do projeto apresentaram custos entre 72 e 129 dólares por tonelada de $\mathrm{CO}_{2}$, que 
ficam abaixo ou muito próximos do valor máximo de taxas existentes, mas ainda acima dos preços da maioria das iniciativas em vigência no mundo. Portanto, a viabilidade econômica do projeto se mostrou principalmente dependente dos custos de construção e condicionamento do poço, do período e capacidade de injeção de $\mathrm{CO}_{2}$ e da existência de mecanismos de precificação de carbono combinados com políticas públicas, como subsídios.

Por fim, o trabalho trouxe como contribuições estimativas da capacidade e custos para injeção de $\mathrm{CO}_{2}$ na Fm. Irati, valores de break-even de preços de $\mathrm{CO}_{2}$ para discussão de mecanismos de precificação de carbono no Brasil que viabilizem atividades de CCS, compreensão dos fatores de influência para capacidade de armazenamento de carbono em reservatórios de gás de folhelho e alternativa de abordagem para injeção de $\mathrm{CO}_{2} \mathrm{em}$ reservatórios não convencionais sem produção local prévia de recursos fósseis. Sugerese para trabalhos futuros a inclusão de dados mais refinados da Fm. Irati, caso sejam disponibilizados, e a incorporação de outras complexidades ao modelo do reservatório, como parâmetros geomecânicos, heterogeneidades e composição mineralógica. 


\section{Referências bibliográficas}

Aguilera, R. Shale gas reservoirs: Theoretical, practical and research issues. Petroleum Research, 1(1), 10-26. 2016. https://doi.org/10.1016/s2096-2495(17)30027-3.

Akkutlu, I. Y., Fathi, E. Multiscale Gas Transport in Shales with Local Kerogen Heterogeneities. Society of Petroleum Engineers. doi:10.2118/146422-PA. 2012.

Amaral, S. E. Contribuição ao conhecimento geológico, petrográfico e sedimentológico da Formação Irati no Estado de São Paulo. Fac. Fil., Ciên. Letras, USP. Tese, $136 \mathrm{pp}$.

Ambrose, R. J., Hartman, R. C., Diaz Campos, M., Akkutlu, I. Y., Sondergeld, C. New Pore-scale Considerations for Shale Gas in Place Calculations. Society of Petroleum Engineers. 2010. doi:10.2118/131772-MS.

Andersen, Odd. Simplified models for numerical simulation of geological $\mathrm{CO}_{2}$ storage. University of Bergen. 2017. ISBN 978-82-308-3127-4.

Andrews, I. J. The carboniferous Bowland Shale gas study: geology and resources estimation. British Geological Survey for Department of Energy and Climate Change, Londres, Reino Unido, 2013.

ANP - Agência Nacional do Petróleo, Gás Natural e Biocombustíveis. Bacia do Espírito Santo: Sumário Geológico e Setores em Oferta. 13a Rodada: Licitações de Petróleo e Gás, 18. Rodrigo Morelatto Superintendência de Definição de Blocos - SDB. 2017.

Araújo, L.M., Trigüis, J.A., Cerqueira, J.R., Freitas, L.C.S. The atypical Permian petroleum system of the Paraná Basin, Brazil. AAPG Mem. 73, 377-402. 2000.

Artur, P. C., Soares, P. C. Paleoestruturas e Petróleo na Bacia do Paraná. Revista Brasileira de Geociências, v. 32, n.4, p. 433-448, 2002.

Banco Mundial. Directory of Programs Supported by Trust Funds Directory of Programs. Junho, 2017. Disponível em: $<$ http://documents.worldbank.org $>$. Acesso em: 20 out. 2019.

Banco Mundial. State and Trends of Carbon Pricing 2019. State and Trends of Carbon Pricing 2019. 2019. https://doi.org/10.1596/978-1-4648-1435-8. 
Barenblatt, G. I., Zheltov, Iu. P., Kochina, I. N., 1960. Basic Concepts in the Theory of Seepage of Homogeneous Liquids in Fissured Rocks [Strata]. Journal of Applied Mathematics and Mechanics, vol. 24, n. 5, pp. 1286-1303.

Bhandari, A. R., Flemings, P. B., Polito, P. J., Cronin, M. B., Bryant, S. L. Anisotropy and Stress Dependence of Permeability in the Barnett Shale. Transport in Porous Media, 108(2), 393-411. 2015. https://doi.org/10.1007/s11242-015-0482-0.

Bielicki, J. M., Langenfeld, J. K., Tao, Z., Middleton, R. S., Menefee, A. H., Clarens, A. F. The geospatial and economic viability of $\mathrm{CO} 2$ storage in hydrocarbon depleted fractured shale formations. International Journal of Greenhouse Gas Control, 75(May), 8-23. 2018. https://doi.org/10.1016/j.ijggc.2018.05.015.

Chen, Z., Liao, X., Zhao, X., Lv, S., Dou, X., Guo, X., Li, L., Zang, J. Development of a Trilinear Flow Model for Carbon Sequestration in Depleted Shale. Society of Petroleum Engineers. Outubro, 2015. doi:10.2118/176153-MS.

Cipolla, C. L., Lolon, E. P., Erdle, J. C., Rubin, B. Reservoir modeling in shale-gas reservoirs. SPE Reservoir Evaluation and Engineering, 13(4), 638-653. 2010. https://doi.org/10.2118/125530-PA.

Constant, M. J. Desenvolvimento de sistema de teste laboratorial e metodologia para cromatografia gasosa acoplada a dessorvedor térmico e uso do octafluoropropano como traçador gasoso para CO2. 90 p. Dissertação de Mestrado. Faculdade de Engenharia da Pontifícia Universidade Católica do Rio Grande do Sul. Porto Alegre, 2015.

Curtis, J. B. Fractured shale-gas systems. AAPG Bulletin 85 (11): 1921-1938. 2002.

Davidson, C. L., Dahowski, R. T., Dooley, J. J., McGrail, B. P. Modelling the deployment of $\mathrm{CO}_{2}$ storage in U.S. Gas-bearing shales. Energy Procedia, 63, 7272-7279. 2014. https://doi.org/10.1016/j.egypro.2014.11.763.

Da Silva, C. G. A. Caracterização geoquímica orgânica das rochas geradoras de petróleo das Formações Irati e Ponta Grossa da Bacia do Paraná. Dissertação de Mestrado. Instituto de Química, Universidade Federal do Rio Grande do Sul. Porto Alegre, dezembro de 2007. 
De Souza, J. D. Efeitos da composição mineralógica no potencial de Adsorção de gases $\left(\mathrm{CO}_{2} / \mathrm{CH}_{4}\right)$ de folhelhos da Formação Irati: Implicações para caracterização de reservatórios Geológicos para armazenamento de $\mathrm{CO}_{2}$. Monografia. Instituto de Geociências, Universidade de São Paulo. 2018.

Du, F., Nojabaei, B. A review of gas injection in shale reservoirs: Enhanced Oil/Gas recovery approaches and greenhouse gas control. Energies, 12(12). 2019. https://doi.org/10.3390/en12122355.

EIA - United States Energy Information Administration. Review of Emerging Resources: U.S. Shale Gas and Shale Oil Plays. U.S. Energy Information Administration, July, $105 \quad$ pp. $2011 . \quad$ Disponível em: $<$ https://www.eia.gov/analysis/studies/usshalegas/pdf/usshaleplays.pdf $>$. Acesso em: 03 out. 2019.

EIA - United States Energy Information Administration. Shale Oil and Shale Gas Resources: An Assessment of 137 Shale Formations in 41 Countries Outside the US. June. 2013. Disponível em:

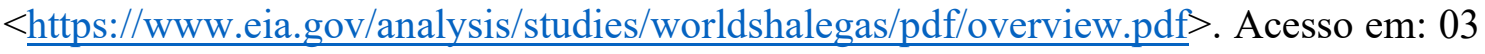
out. 2019.

Eshkalak, M. O., Al-Shalabi, E. W., Sanaei, A., Aybar, U., Sepehrnoori, K. Enhanced gas recovery by $\mathrm{CO}_{2}$ sequestration versus re-fracturing treatment in unconventional shale gas reservoirs. Society of Petroleum Engineers - 30th Abu Dhabi International Petroleum Exhibition and Conference, ADIPEC 2014: Challenges and Opportunities for the Next 30 Years, 6, 4107-4124. 2014. https://doi.org/10.2118/172083-ms.

Gandossi, L. An overview of hydraulic fracturing and other formation stimulation technologies for shale gas production. JRC Technical Reports. 2013. https://doi.org/10.2790/99937.

GCCSI - Global CCS Institute. Geological Storage of $\mathbf{C O}_{2}$ : Safe, Permanent, and Abundant. Fact Sheet. 2018. Disponível em: $<$ https://www.globalccsinstitute.com/wpcontent/uploads/2018/12/Global-CCS-Institute-Fact-Sheet_Geological-Storage-ofCO2.pdf $>$. Acesso em 30 nov. 2019. 
Gholinezhad, J., Fianu, J. S., Galal Hassan, M. Challenges in Modelling and Simulation of Shale Gas Reservoirs. SpringerBriefs in Petroleum Geoscience \& Engineering. Springer International Publishing. 2018. ISBN 9783319707686. doi: $\underline{10.1007 / 978-3-}$ 319-70769-3.

Godec, M., Koperna, G., Petrusak, R., Oudinot, A. Enhanced gas recovery and CO2 storage in gas shales: A summary review of its status and potential. Energy Procedia, 63, 5849-5857. 2014. https://doi.org/10.1016/j.egypro.2014.11.618.

Gomes, A. J. de L. Avaliação de recursos geotermais da Bacia do Paraná. Revista Brasileira de Geofísica, 28(4), 745-745, 2010. https://doi.org/10.1590/s0102261x2010000400018.

Hachiro, J. O subgrupo Irati (Neopermiano) da Bacia do Paraná. Universidade de São Paulo, 1997.

Halliburton. Halliburton Hydraulic Fracturing: Over 60 Years of Successful Performance Focused on the Environment. 2008. Disponível em: $<\underline{\text { https://www.halliburton.com/content/dam/ps/public/pe/contents/Data Sheets/web/H/H }}$ 06640.pdf>. Acesso em 13 out. 2019.

Haskett, W. J., Brown, P. J. Evaluation of unconventional resource plays. Society of Petroleum Engineers. 2005. doi: 10.2118/96879-MS.

Heller, R., Zoback, M. Adsorption of methane and carbon dioxide on gas shale and pure mineral samples. Journal of Unconventional Oil and Gas Resources, 8(C), 14-24. 2014. https://doi.org/10.1016/j.juogr.2014.06.001.

Holditch, S. A. Tight gas sands. JPT, Journal of Petroleum Technology, 58(6), 86-94. 2006. https://doi.org/10.2118/103356-MS.

Holloway, S., Survey, B. G. Sam HoUoway and David Savage. Geothermal Energy, 34(9), 925-932. 1993.

Hoteit, H.. Fahs, M., Soltanian, M. R. Assessment of $\mathrm{CO}_{2}$ injectivity during sequestration in depleted gas reservoirs. Geosciences (Switzerland), 9(5), 1-19. 2019. https://doi.org/10.3390/geosciences9050199. 
Houzé, O., Viturat, D., Fjaere, O. S. Dynamic data analysis: the theory and practice of Pressure Transient Analysis, Rate Transient Analysis, Formation Testing, Production Logging and the use of Permanent Downhole Gauges. V5.20.02. KAPA. 2018. Disponível em: <https:/www.kappaeng.com/documents/flip/dda520/files/assets/basichtml/page-1.html > . Acesso em: 02 dez. 2019.

Huang, T., Tao, Z., Li, E., Lyu, Q., Guo, X. Effect of permeability anisotropy on the production of multi-scale shale gas reservoirs. Energies, 10(10). 2017. https://doi.org/10.3390/en10101549.

IEA - International Energy Agency. Carbon Capture and Storage: The solution for deep emissions reductions. IEA, 1-12. 2015. Retrieved from https://www.iea.org/publications/freepublications/publication/CarbonCaptureandStorag eThesolutionfordeepemissionsreductions.pdf.

IEA - International Energy Agency. $\mathbf{C O}_{2}$ emissions from fuel combustion. IEA, 1-92. 2019. https://doi.org/10.1670/96-03N.

IEA - International Energy Agency. The geology of natural gas resources. 14 fev. 2011.

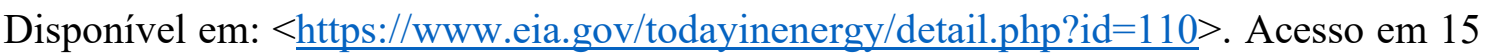
out. 2019.

IEA - International Energy Agency. World Energy Outlook 2017, IEA, Paris, 2017a. https://www.iea.org/reports/world-energy-outlook-2017.

IEA - International Energy Agency. Energy Technology Perspectives 2017: Catalysing Energy Technology Transformations. 2017b. https://doi.org/10.1787/energy tech-2017en.

IEAGHG - International Energy Agency Greenhouse Gas R\&D Programme. Potential Implications on Gas Production from shales and coals for geological storage of $\mathrm{CO}_{2}$. Report: 2013/10. IEAGHG, Cheltenham, United Kingdom, 2013. Disponível em:

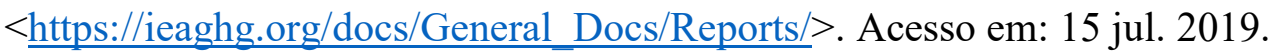

IPCC - Intergovernmental Panel on Climate Change. IPCC Special Report on Carbon Dioxide Capture and Storage. Prepared by Working Group III of the Intergovernmental Panel on Climate Change [Metz, B., O. Davidson, H. C. de Coninck, M. Loos, and L. A. 
Meyer (eds.)]. Cambridge University Press, Cambridge, United Kingdom and NewYork, NY, USA, 442 pp. 2005.

Javadpour, F., Fisher, D., Unsworth, M. Nanoscale gas flow in shale gas sediments. Journal of Canadian Petroleum Technology, 46(10), 55-61. 2007. https://doi.org/10.2118/07-10-06.

Jenkins, C. D., Boyer, C. M. Coalbed- and shale-gas reservoirs. JPT, Journal of Petroleum Technology, 60(2), 92-99. 2008. https://doi.org/10.2118/103514-JPT.

Jiang, J., Rui, Z., Hazlett, R., Lu, J. An integrated technical-economic model for evaluating $\mathrm{CO}_{2}$ enhanced oil recovery development. Applied Energy, 247(March), 190211. 2019. https://doi.org/10.1016/j.apenergy.2019.04.025.

Jiang, J., Shao, Y., Younis, R. M. Development of a Multi-Continuum Multi-Component Model for Enhanced Gas Recovery and $\mathrm{CO}_{2}$ Storage in Fractured Shale Gas Reservoirs. Society of Petroleum Engineers. 2014. doi:10.2118/169114-MS.

Kalkreuth, W., Holz, M., Levandowski, J., Kern, M., Casagrande, J., Weniger, P., Krooss, B. The coalbed methane $(\mathrm{CBM})$ potential and $\mathrm{CO}_{2}$ storage capacity of the santa Terezinha coalfield, Paraná Basin, Brazil-3D modelling, and coal and carbonaceous shale characteristics and related desorption and adsorption capacities in samples from exploration Borehole CBM001-ST-RS. Energy Exploration \& Exploitation, 31(4), 485-527. 2013. https://doi.org/10.1260/0144-5987.31.4.485.

Kang, S. M., Fathi, E., Ambrose, R. J., Akkutlu, I. Y., Sigal, R. F. Carbon Dioxide Storage Capacity of Organic-Rich Shales. Society of Petroleum Engineers. 2011. doi:10.2118/134583-PA.

Kalantari-Dahaghi, A. Numerical simulation and modeling of enhanced gas recovery and $\mathrm{CO}_{2}$ sequestration in shale gas reservoirs: A feasibility study. Society of Petroleum Engineers - SPE International Conference on CO2 Capture, Storage, and Utilization 2010, 533-550. 2010. https://doi.org/10.2118/139701-ms.

Kazemi, K., Merrill, L.S. Jr., Porterfield, K.P. and Zeman, P.R., Numerical Simulation of Water-Oil Flow in Naturally Fractured Reservoirs. SPE Journal, Vol. 16, pp. 317-326. Dezembro, 1976. 
Kearns, J., Teletzke, G., Palmer, J., Thomann, H., Kheshgi, H., Chen, Y. H. H., Paltsev, S., Herzog, H. Developing a Consistent Database for Regional Geologic $\mathrm{CO}_{2}$ Storage Capacity Worldwide. Energy Procedia, 114(617), 4697-4709. 2017. https://doi.org/10.1016/j.egypro.2017.03.1603.

Kim, T. H., Cho, J., Lee, K. S. Evaluation of $\mathrm{CO}_{2}$ injection in shale gas reservoirs with multi-component transport and geomechanical effects. Applied Energy, 190, 11951206. 2017. https://doi.org/10.1016/j.apenergy.2017.01.047.

Kundert, D. P., Mullen, M. Proper Evaluation of Shale Gas Reservoirs Leads to a More Effective Hydraulic-Fracture Stimulation. Society of Petroleum Engineers. doi:10.2118/123586-MS.

Kwak, D., Kim, J. International Journal of Greenhouse Gas Control Techno-economic evaluation of $\mathrm{CO}_{2}$ enhanced oil recovery (EOR) with the optimization of $\mathrm{CO}_{2}$ supply. International Journal of Greenhouse Gas Control, 58, 169-184. 2017. https://doi.org/10.1016/j.ijggc.2017.01.002.

Langmuir, I. The Constitution and Fundamental Properties of Solids and Liquids. Part I. Solids. Journal of the American Chemical Society, 38, 2221-2295. 1916. http://dx.doi.org/10.1021/ja02268a002.

Lisboa, A.C. Caracterização geoquímica dos folhelhos neopermianos da Formação Irati - Borda Leste da Bacia do Paraná. Dissertação (Mestrado). Rio de Janeiro: Universidade Federal do Rio de Janeiro, 2006.

Liu, D., Li, Y., Agarwal, R. K. Numerical simulation of long-term storage of $\mathrm{CO} 2$ in Yanchang shale reservoir of the Ordos basin in China. Chemical Geology, 440, 288-305. 2016. https://doi.org/10.1016/j.chemgeo.2016.08.002.

Liu, F., Ellett, K., Xiao, Y., Rupp, J. A. Assessing the feasibility of $\mathrm{CO}_{2}$ storage in the New Albany Shale (Devonian-Mississippian) with potential enhanced gas recovery using reservoir simulation. International Journal of Greenhouse Gas Control, 17, 111-126. 2013. https://doi.org/10.1016/j.ijggc.2013.04.018.

Louks R. G., Reed, R. M., Ruppel, S. C., Jarvie, D. M. Morphology, Genesis, and Distribution of Nanometer-Scale Pores in Siliceous Mudstones of the Mississippian 
Barnett Shale. Journal of Sedimentary Research; 79 (12): 848-861. 2009. doi: https://doi.org/10.2110/jsr.2009.092.

Ma, Y.Z., Sobernheim, D., Garzon, J.R. Chapter 19 - Glossary for Unconventional Oil and Gas Resource Evaluation and Development. Unconventional Oil and Gas Resources Handbook, Gulf Professional Publishing, 2016, Pages 513-526, ISBN 9780128022382. https://doi.org/10.1016/B978-0-12-802238-2.00019-5.

Magoon, L. B.; Beaumont, E. A. Petroleum systems. Chapter 3. in Exploring for Oil and Gas Traps, Edward A. Beaumont and Norman H. Foster, eds., Treatise of Petroleum Geology, Handbook of Petroleum Geology, 1999. https://doi.org/10.1306/TrHbk624.

Martini, A.M., Walter, L.M., Budai, J.M., Ku, T.C.W., Kaiser, C.J., Schoell, M. Genetic and temporal relations between formation waters and biogenic methane - upper Devonian Antrim Shale, Michigan basin, USA. Geochem. Cosmochim. 1998. Acta 62 (10), 16991720.

Martini, A.M., Walter, L.M., Ku, T.C., Budai, J.M., McIntosh, J.C., Schoell, M.. Microbial production and modification of gases in sedimentary basins: a geochemical case study from a Devonian shale gas play, Michigan basin. AAPG Bull. 87, 1355e1375. 2003.

Mateus, A., Riccomini, C., Ferreira, E. J. E. C. B., Tassinari, C. C. G. Permian-Triassic maturation and multistage migration of hydrocarbons in the Assistência Formation (Irati Subgroup), Paraná Basin, Brazil: implications for the exploration model. Braz. J. Geol. [online], vol.44, n.3, pp. 355-360. 2014. http://dx.doi.org/10.5327/Z2317$\underline{4889201400030002 .}$

Milani, E. J., França A. B., Medeiros R. A. Rochas geradoras e rochas-reservatório da Bacia do Paraná, faixa oriental de afloramentos, Estado do Paraná. Boletim de Geociências da Petrobras v.15, n.1, p. 135-162, 2006.

Milani, E. J.; Melo, J. H. G.; Souza, P. A.; Fernandes, L. A.; França, A. B. Bacia do Paraná. Boletim de Geociências da Petrobras, Rio de Janeiro, v. 15, n.2, p. 265-287. 2007. 
Milani, E. J., Zalán P. V. The Geology of Paleozoic Cratonic Basins and Mesozoic Interior Rifts of Brazil - AAPG Int. Conf. \& Exhibition - Rio de Janeiro, Brazil - Short Course Coord. Carminatti, M. 1998.

Nordbotten, J. M., Celia, M. A. Geological Storage of $\mathrm{CO}_{2}$ : Modeling Approaches for Large-Scale Simulation. John Wiley \& Sons Inc., 2012.

Nuttal, B. C., Drahovzal, J. A., Eble, C. F., Bustin, R. M. Analysis of devonian black shale in Kentucky for potential carbon dioxide sequestration and enhanced natural gas production. Kentucky Geological Survey, University of Kentucky, Lexington, Kentucky, 2005.

Organização das Nações Unidas (ONU). Framework Convention on Climate Change. Adoption of the Paris Agreement, 21st Conference of the Parties, Paris: United Nations, 2015.

Ozkan, E., Brown, M. L., Raghavan, R. S., Kazemi, H. Comparison of Fractured Horizontal-Well Performance in Conventional and Unconventional Reservoirs. Society of Petroleum Engineers. 2009. doi:10.2118/121290-MS.

Pei, P., Ling, K., He, J., Liu, Z. Shale gas reservoir treatment by a $\mathrm{CO}_{2}$-based technology. Journal of Natural Gas Science and Engineering, 26, 1595-1606. 2015. https://doi.org/10.1016/j.jngse.2015.03.026.

Pollastro, R. M., D. M. Jarvie, R. J. Hill, and C. W. Adams. Geologic framework of the Mississippian Barnett Shale, Barnett - Paleozoic total petroleum system, Bend arch - Fort Worth Basin, Texas: AAPG Bulletin, v. 91, no. 4, p. 405 - 436. 2007. https://doi.org/10.1306/10300606008.

Rani, S., Padmanabhan, E., Prusty, B. K. Review of gas adsorption in shales for enhanced methane recovery and $\mathrm{CO}_{2}$ storage. Journal of Petroleum Science and Engineering, 175, 634-643. 2019. https://doi.org/10.1016/j.petrol.2018.12.081.

Rockett, G. C. Associação de fontes emissoras e reservatórios potenciais para armazenamento geológico de $\mathrm{CO}_{2}$ na Bacia de Campos, Brasil. 41 f. Dissertação (Mestrado em Engenharia e Tecnologia de Materiais) - Pontifícia Universidade Católica do Rio Grande do Sul, Porto Alegre, 2010. 
Rosa, A., Carvalho, R., Xavier, D. Engenharia de Reservatórios de Petróleo. 1 ed. Rio de Janeiro, Interciência, 2006.

Saini, D. Engineering Aspects of Geologic $\mathrm{CO}_{2}$ Storage: Synergy between Enhanced Oil Recovery and Storage. SpringerBriefs in Petroleum Geoscience \& Engineering. Springer International Publishing, 2017. ISBN 9783319560731. doi: 10.1007/978-3-319-560748.

Schepers, K. C., Nuttall, B., Oudinot, A. Y., Gonzalez, R. Reservoir modeling and simulation of the devonian gas shale of eastern Kentucky for enhanced gas recovery and $\mathrm{CO}_{2}$ storage. SPE International Conference on CO2 Capture, Storage, and Utilization 2009, 154-173. 2009. https://doi.org/10.2118/126620-ms.

Schneider, R.L.; Muhlmann, H.; Tommasi, E.; Medeiros, R.A.; Daemon, R.F. Nogueira, A. A. Revisão Estratigráfica da Bacia do Paraná. In: Congresso Brasileiro de Geologia, 28, Porto Alegre, 1974. Anais. Porto Alegre- RS, SBG, vol.1, p. 41- 66.

Schoell, M. Genetic Characterization of Natural Gases. American Association of $\begin{array}{lllll}\text { Petroleum Geologists } & \text { Bulletin, } & \text { 67(12), } & \text { 2225-2238. }\end{array}$ https://doi.org/10.1306/ad46094a-16f7-11d7-8645000102c1865d.

Selley, R. C. UK shale gas: The story so far. Marine and Petroleum Geology, 31(1), 100109. 2012. https://doi.org/10.1016/j.marpetgeo.2011.08.017.

Sondergeld, C. H., Ambrose, R. J., Rai, C. S., Moncrieff, J. Micro-Structural Studies of Gas Shales. Society of Petroleum Engineers. 2010. doi:10.2118/131771-MS.

Sun, H., Yao, J., Gao, S., Fan, D., Wang, C., Sun, Z. Numerical study of $\mathrm{CO}_{2}$ enhanced natural gas recovery and sequestration in shale gas reservoirs. International Journal of $\begin{array}{lllll}\text { Greenhouse } & \text { Gas } & \text { Control, } & 19, & 406-419 .\end{array}$ https://doi.org/10.1016/j.ijggc.2013.09.011.

Szulczewski, M. L. Storage Capacity and Injection Rate Estimates for $\mathrm{CO}_{2}$ Sequestration in Deep Saline Aquifers in the Conterminous United States. Dissertação de Mestrado. Department of Civil and Environmental Engineering. Massachusetts Institute of Technology. Estados Unidos, 2009. 
Tayari, F., Blumsack, S., Dilmore, R., Mohaghegh, S. D. Techno-economic assessment of industrial $\mathrm{CO} 2$ storage in depleted shale gas reservoirs. Journal of Unconventional Oil and Gas Resources, 11, 82-94. 2015. https://doi.org/10.1016/j.juogr.2015.05.001.

van der Meer, B. Carbon dioxide storage in natural gas reservoirs. Oil and Gas Science and Technology, 60(3), 527-536. 2005. https://doi.org/10.2516/ogst:2005035.

Vidas, H., Hugman, B. Availability, Economics, and Production Potential of North American Unconventional Natural Gas Supplies. Fairfax, Va.: The INGAA Foundation, Novembro, 2008.

Wang, F. P., Reed, R. M. Pore Networks and Fluid Flow in Gas Shales. Society of Petroleum Engineers. 2009. doi:10.2118/124253-MS.

Wang, Z., Li, Y., Liu, H., Zeng, F., Guo, P., Jiang, W. Study on the adsorption, diffusion and permeation selectivity of shale gas in organics. Energies, 10(1), 1-15. 2017. https://doi.org/10.3390/en10010142.

Wanniarachchi, W. A. M., Gamage, R. P., Perera, M. S. A., Rathnaweera, T. D., Gao, M., Padmanabhan, E. Investigation of depth and injection pressure effects on breakdown pressure and fracture permeability of shale reservoirs: An experimental study. Applied Sciences (Switzerland), 7(7). 2017. https://doi.org/10.3390/app7070664.

Warren, J. E., Root, P. J. The Behavior of Naturally Fractured Reservoirs. SPE Journal of Petroleum Technology, vol. 3, n. 3, pp. 245-255. 1963.

Wei, N., Li, X., Dahowski, R. T., Davidson, C. L., Liu, S., Zha, Y. Economic evaluation on CO2-EOR of onshore oil fields in China. International Journal of Greenhouse Gas Control, 37, 170-181. 2015. https://doi.org/10.1016/j.ijggc.2015.01.014.

Welkenhuysen, K., Meyvis, B., Swennen, R., Piessens, K. Economic threshold of $\mathrm{CO}_{2}$ EOR and $\mathrm{CO}_{2}$ storage in the North Sea: A case study of the Claymore, Scott and Buzzard oil fields. International Journal of Greenhouse Gas Control, 78(April), 271-285. 2018. https://doi.org/10.1016/j.ijggc.2018.08.013.

Weniger, P., Kalkreuth, W., Busch, A., Kross, B. M. High-pressure methane and carbon dioxide sorption on coal and shale samples from the Paraná Basin, Brazil. International Journal of Coal Geology 84,190-205, 2010. 
William-Kovacs, J. New methods for shale gas prospect analysis. ProQuest Dissertations \& Theses 287. 2012.

Wu, Y. S., Li, J., Ding, D. Y., Wang, C., Di, Y. A generalized framework model for the simulation of gas production in unconventional gas reservoirs. SPE Journal, 19(5), 845857. 2014. https://doi.org/10.2118/163609-PA.

Yang, R., Huang, Z., Yu, W., Li, G., Ren, W., Zuo, L., Tan, X., Sepehnoori, K., Tian, S., Sheng, M. A comprehensive model for real gas transport in shale formations with complex non-planar fracture networks. Scientific Reports, 6(October), 1-13. 2016. https://doi.org/10.1038/srep36673.

Yergin, D. The quest: energy, security, and the remaking of de modern world. Penguin Group, 2011.

Yu, W., Al-Shalabi, E. W., Sepehrnoori, K. A Sensitivity Study of Potential CO 2 Injection for Enhanced Gas Recovery in Barnett Shale Reservoirs. SPE Unconventional Resources Conference - USA, 2014. https://doi.org/10.2118/169012-MS.

Zalán, P. V.; Wolf, S.; Conceição, C. J.; Marques, A.; Astolfi, M. A. M.; Vieira, I. S.; Appi, C. T.; Zanotto, O. A. Bacia do Paraná. In: RAJA GABAGLIA, G. P. \& MILANI, E. J. Origem e Evolução de Bacias Sedimentares. Rio de Janeiro, Gávea, p. 135 - 168. 1990.

Zhan, J., Yuan, Q., Fogwill, A., Cai, H., Hejazi, H., Chen, Z., Cheng, S. A Systematic Reservoir Simulation Study on Assessing the Feasibility of $\mathrm{CO}_{2}$ Sequestration in Shale Gas Reservoir with Potential Enhanced Gas Recovery. Carbon Management Technology Conference. 2017. 10.7122/484390-MS.

Zhao, K., Yuan, J., Feng, Y., Yan, C. A novel evaluation on fracture pressure in depleted shale gas reservoir. Energy Science and Engineering, 6(3), 201-216. 2018. https://doi.org/10.1002/ese3.198.

Zhu, L., Liao, X., Chen, Z., Cheng, X. Performance evaluation for carbon sequestration in shale gas reservoir systems. Carbon Management Technology Conference, CMTC 2017: Global CCUS Innovation Nexus, 1, 183-197. 2017. https://doi.org/10.7122/485740-ms. 